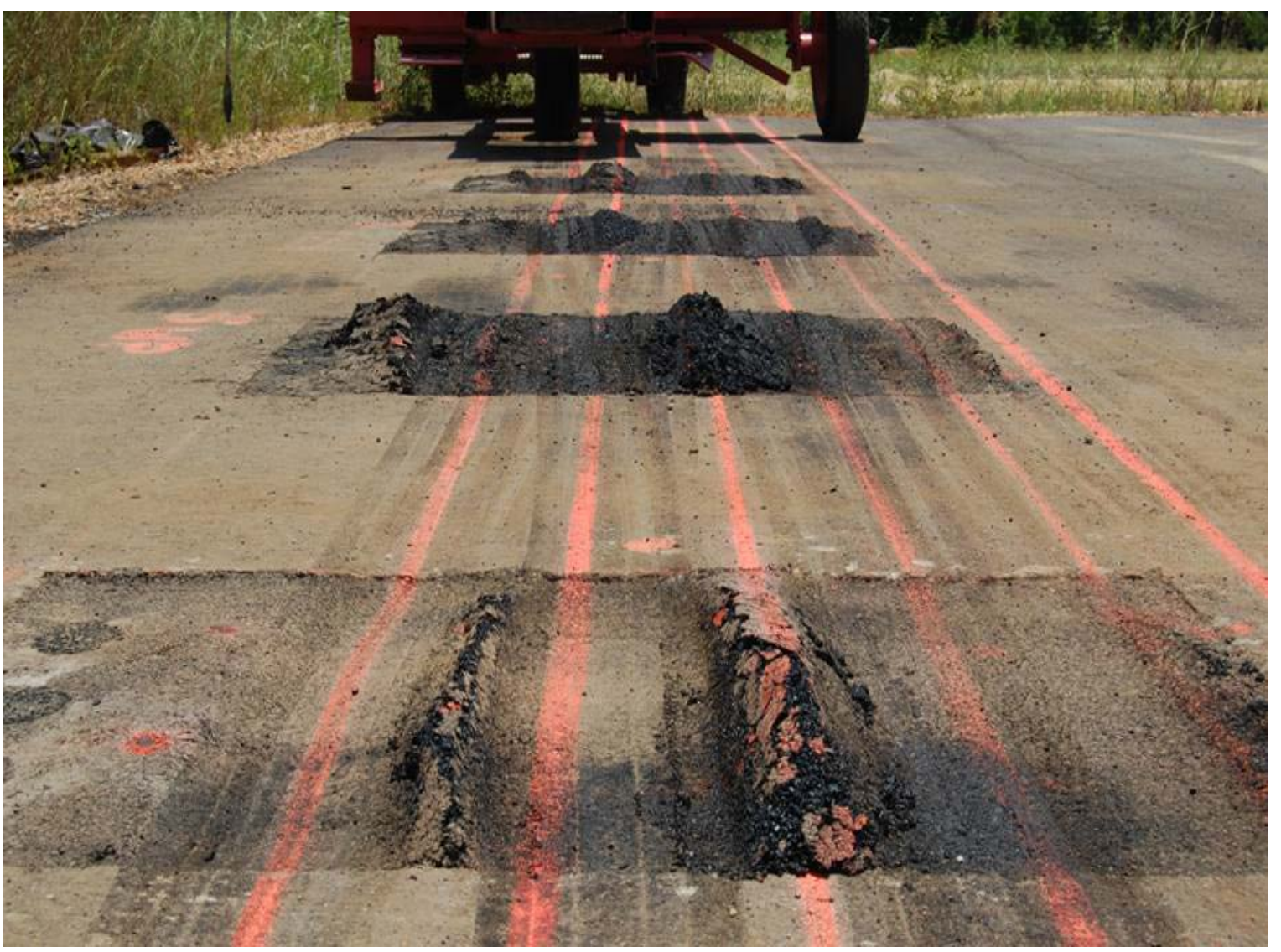




\section{Certification Tests on Cold Patch Asphalt Repair Materials for Use in Airfield Pavements}

Mariely Mejías-Santiago, Franciso del Valle Roldán, and Lucy P. Priddy

Geotechnical and Structures Laboratory

U.S. Army Engineer Research and Development Center

3909 Halls Ferry Road

Vicksburg, MS 39180-6199

Final report

Approved for public release; distribution is unlimited.

Prepared for Headquarters, Air Force Civil Engineer Support Agency

139 Barnes Avenue, Suite 1

Tyndall AFB, FL 32403-5319 


\begin{abstract}
The U.S. Army Engineer Research and Development Center (ERDC) conducted laboratory and field tests on several commercial-offthe-shelf cold patch asphalt repair products to determine their suitability for airfield pavement repairs. Testing included a suite of material property tests that were compared with results from full-scale field tests. Laboratory tests included determination of maximum theoretical specific gravities, compaction density, durability, workability, static creep, and dynamic creep. The field evaluation consisted of four repairs that were trafficked $24 \mathrm{hr}$ after compaction under controlled traffic conditions to determine the ability of the repairs to support the gross load of an F-15E aircraft. Both the laboratory and full-scale traffic tests were conducted at the ERDC in Vicksburg, MS, from May to J uly 2009. Laboratory tests were evaluated to determine their suitability for a testing protocol to certify the use of cold patch materials for airfield asphalt pavement repairs.
\end{abstract}

DISCLAIMER: The contents of this report are not to be used for advertising, publication, or promotional purposes. Citation of trade names does not constitute an official endorsement or approval of the use of such commercial products. All product names and trademarks cited are the property of their respective owners. The findings of this report are not to be construed as an official Department of the Army position unless so designated by other authorized documents. 


\section{Contents}

Figures and Tables.......................................................................................................................

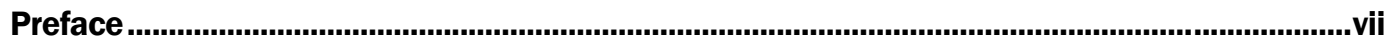

Unit Conversion Factors...........................................................................................................................viii

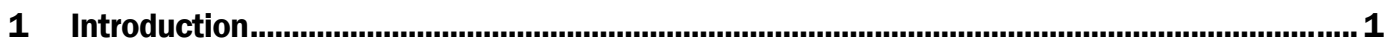

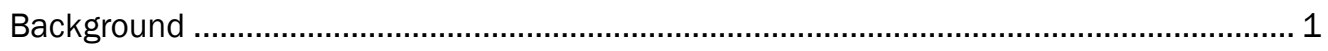

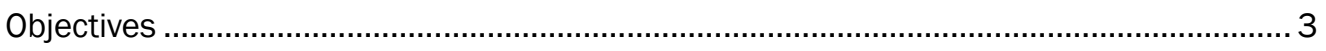

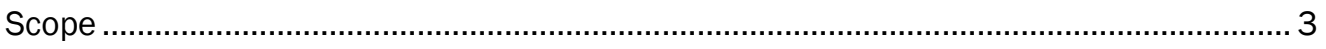

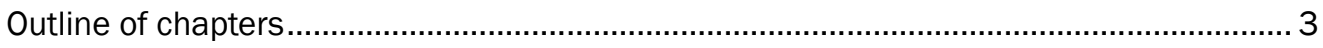

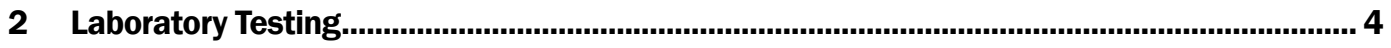

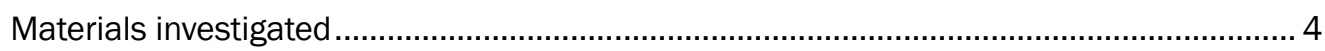

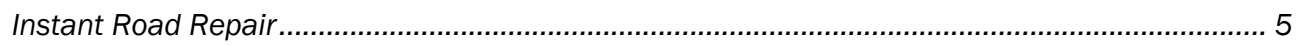

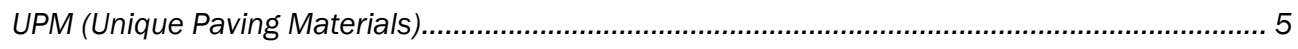

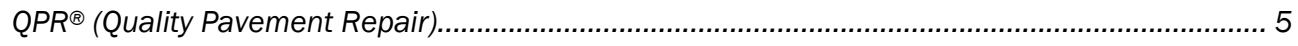

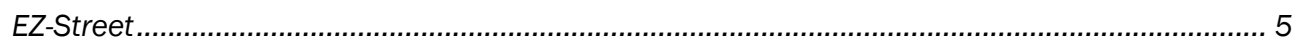

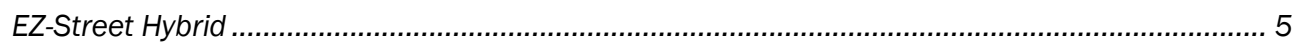

Wespro

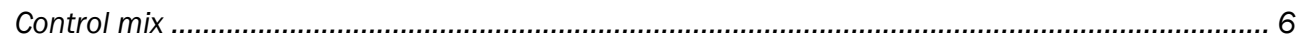

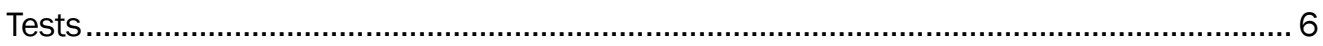

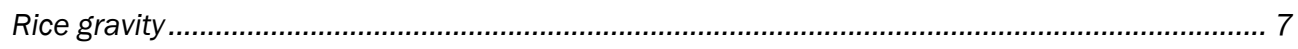

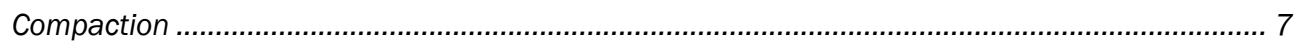

Static creep (flow time) and dynamic creep (flow number) ....................................................... 7

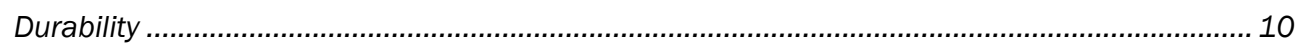

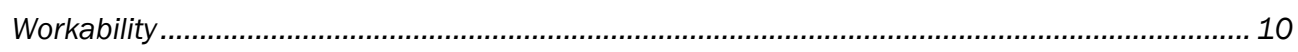

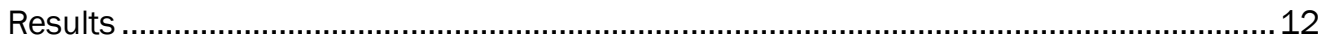

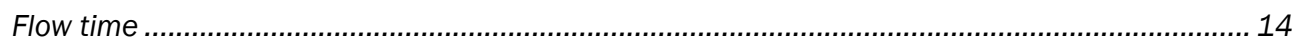

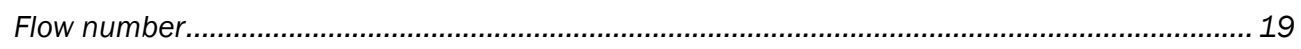

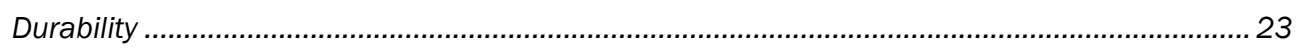

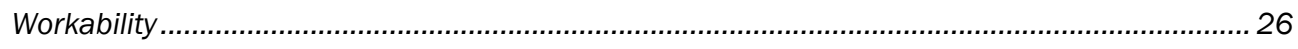

3 Field Testing.........................................................................................................29

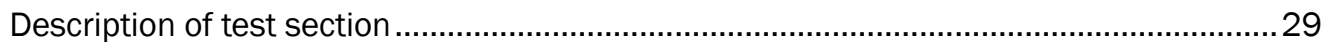

Pavement

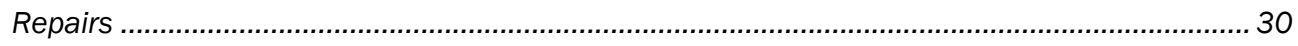

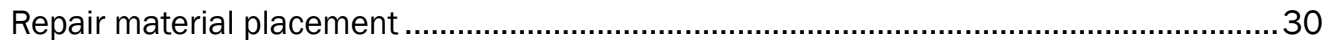

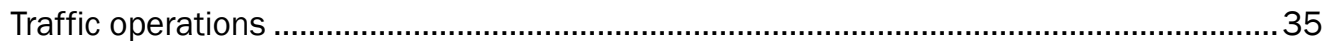

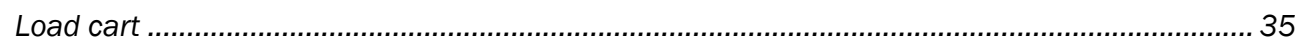

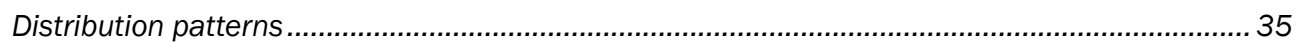

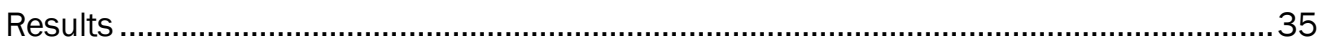


4 Laboratory Tests for Certification Test Protocol ..............................................................42

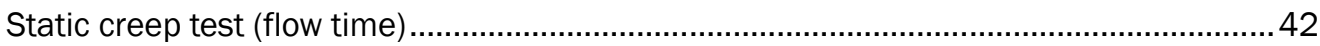

Dynamic creep test (flow number) ........................................................................ 43

Durability test (moisture susceptibility) ..................................................................... 43

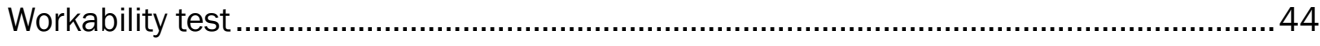

5 Conclusions and Recommendations ................................................................................46

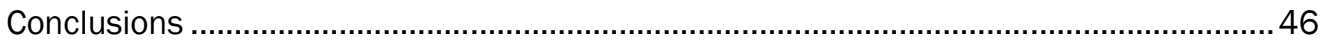

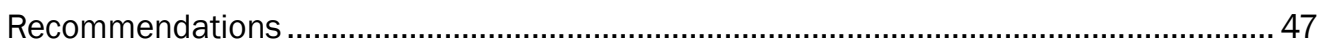

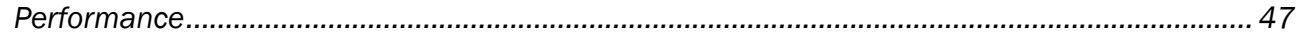

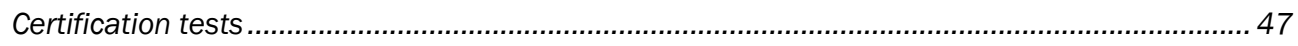

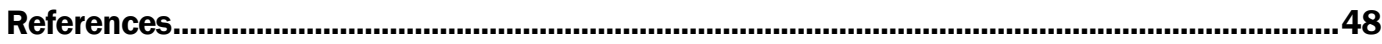

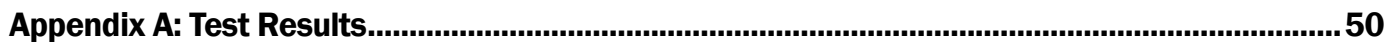

Appendix B: Field Test Repair Cross Sections...........................................................................55

Report Documentation Page 


\section{Figures and Tables}

\section{Figures}

Figure 1. Gyratory compactor.

Figure 2. IPC universal testing machine (UTM 25) and temperature chamber used for static and dynamic creep tests.

Figure 3. Test setup for confined creep tests.

Figure 4. Water bath used to condition the samples for the retained tensile strength test. ............ 11

Figure 5: Tensile splitting test..................................................................................................... 11

Figure 6. Workability test apparatus............................................................................................. 12

Figure 7. IRR sample after static creep test.............................................................................. 14

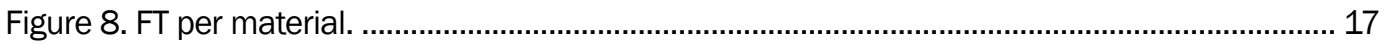

Figure 9. Permanent deformation under static creep loading for each material............................. 17

Figure 10. Creep modulus from static creep test for each material. ............................................. 18

Figure 11. Flow number per material......................................................................................... 21

Figure 12. Permanent deformation under dynamic creep loading for each material....................... 21

Figure 13. Resilient modulus from dynamic creep test for each material........................................2

Figure 14. Dry tensile strength of the four top-performing products.............................................. 23

Figure 15. Wet tensile strength of the four top-performing products................................................ 24

Figure 16. TSR comparison between the four top-performing products. ........................................ 24

Figure 17. Broken aggregate on an EZ-Street sample. .................................................................. 25

Figure 18: Workability test results. ............................................................................................. 28

Figure 19. Pavement structure in the test section......................................................................... 29

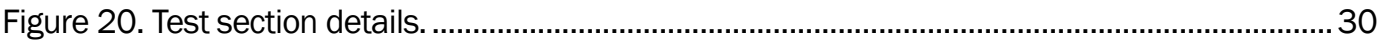

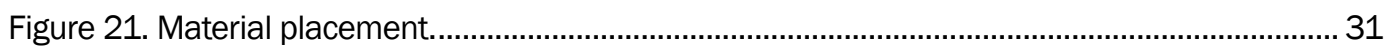

Figure 22. Spreading of the material. .................................................................................... 31

Figure 23. Pneumatic tamping compactor with a 5-in. circular head.............................................32

Figure 24. Vibratory plate compactor. ............................................................................................. 33

Figure 25. Core sample falling apart due to high air voids in the mix...............................................34

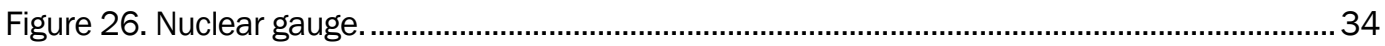

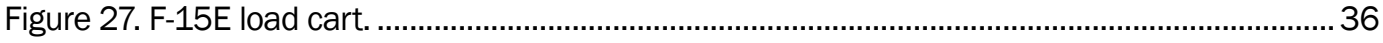

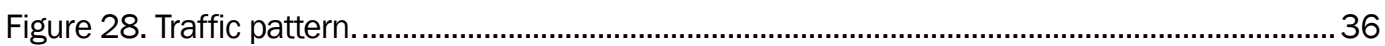

Figure 29. Damage in the EZ-Street Hybrid product.................................................................. 37

Figure 30. Deformation after the third pass over Instant Road Repair.............................................38

Figure 31. Failure in repair 1 EZ-Street. .....................................................................................39

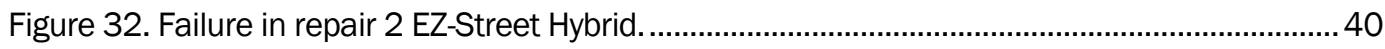

Figure 33. Failure in repair 3 Wespro.................................................................................... 40

Figure 34. Failure in repair 4 Instant Road Repair....................................................................... 41 
Figure 35. Overall photo of the repairs after 16 passes. ............................................................. 41

\section{Tables}

Table 1. Cold-Patch products selected for certification tests............................................................ 4

Table 2. Outline of tests for cold patch asphalt repair materials......................................................... 6

Table 3. Average compaction properties for all the materials. ....................................................... 13

Table 4. Typical material gradation ranges provided by the manufacturers...................................... 13

Table 5. Static creep test results for EZ-Street. ........................................................................ 15

Table 6. Static creep test results for EZ-Street Hybrid. ................................................................ 15

Table 7. Static creep test results for Instant Road Repair. ............................................................. 15

Table 8. Static creep test results for Wespro............................................................................. 16

Table 9.Static creep test results for the control mix..................................................................... 18

Table 10. Dynamic creep test data for EZ-Street. …………………………………………....... 19

Table 11. Dynamic creep test data for EZ-Street Hybrid. .................................................................. 19

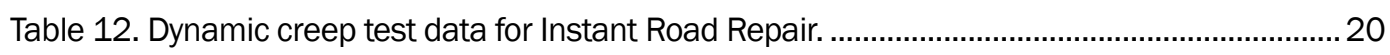

Table 13. Dynamic creep test data for Wespro. ............................................................................ 20

Table 14. Dynamic creep test data for the control mix ................................................................2

Table 15. Workability test results............................................................................................ 27

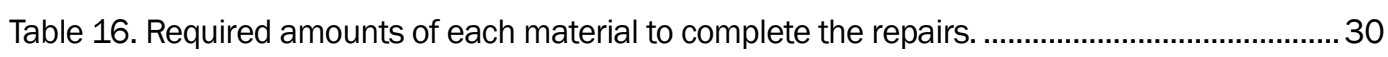

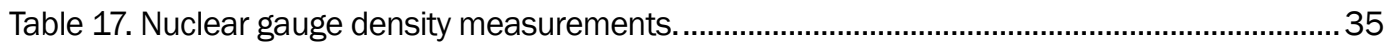

Table 18. Field compaction. .................................................................................................... 37

Table 19. Field test observations................................................................................................ 39 


\section{Preface}

The research project described in this report was sponsored by the U.S. Air Force Civil Engineer Support Agency (AFCESA), Tyndall Air Force Base, Florida. The technical manager for this project was Dr. Craig Rutland of the AFCESA.

This publication was prepared by personnel of the U.S. Army Engineer Research and Development Center (ERDC), Geotechnical and Structures Laboratory (GSL), Vicksburg, MS. The findings and recommendations presented in this report are based upon laboratory and field tests conducted from May through J uly 2009.

The principal investigator for this project was Mariely Mejías-Santiago of the Airfields and Pavements Branch (APB), GSL. Francisco del ValleRoldán assisted in laboratory and field investigations and data reduction. Timothy J . McCaffrey, APB, was the lead engineering technician for the project with technical assistance provided by Matthew R. Hall, Matthew D. Fisher, Charles L. Robinson, and Kevin Taylor of the APB.

This report was prepared by Mejías-Santiago and del Valle-Roldán, APB, with technical collaboration and review provided by Lucy P. Priddy. The testing and analyses were conducted under the supervision of Dr. Gary L. Anderton, Chief, APB; Dr. Larry N. Lynch, Chief, Engineering Systems and Materials Division; Dr. William P. Grogan, Deputy Director, GSL; and Dr. David W. Pittman, Director, GSL.

COL Gary E. J ohnston was Commander and Executive Director of ERDC. Dr. J effery P. Holland was Director.

Recommended changes for improving this publication in content and/ or format should be submitted on DA Form 2028 (Recommended Changes to Publications and Blank Forms) and forwarded to Headquarters, U.S. Army Corps of Engineers, ATTN: CECW-EW, 441 G Street NW, Washington, DC 20314. 


\section{Unit Conversion Factors}

\begin{tabular}{|l|l|l|}
\hline Multiply & \multicolumn{1}{l|}{ By } & To Obtain \\
\hline cubic feet & 0.02831685 & cubic meters \\
\hline degrees (angle) & 0.01745329 & radians \\
\hline degrees Fahrenheit & (F-32)/1.8 & degrees Celsius \\
\hline feet & 0.3048 & meters \\
\hline foot-pounds force & 1.355818 & joules \\
\hline gallons (U.S. liquid) & $3.785412 \mathrm{E}-03$ & cubic meters \\
\hline inches & 0.0254 & meters \\
\hline pounds (force) & 4.448222 & newtons \\
\hline pounds (force) per square inch & 6.894757 & kilopascals \\
\hline pounds (mass) & 0.45359237 & kilograms \\
\hline pounds (mass) per cubic foot & 16.01846 & kilograms per cubic meter \\
\hline pounds (mass) per square foot & 4.882428 & kilograms per square meter \\
\hline square feet & 0.09290304 & square meters \\
\hline square inches & $6.4516 \mathrm{E}-04$ & square meters \\
\hline tons (2,000 pounds, mass) & 907.1847 & kilograms \\
\hline
\end{tabular}




\section{Introduction}

\section{Background}

Rapid pavement repair technologies for airfield pavements, highway pavements, high-volume municipal roads, and urban freeways have become critical to pavement repair efforts, as the result of decreasing construction windows for pavement rehabilitation. Common rehabilitation efforts for pavements include full- and partial-depth repairs. Interruptions to service may lead to increased traffic flow problems, airport delays, safety hazards, and operational tempo reductions for military operations. Often the available time for runway closures may be as short as $4 \mathrm{hr}$, with similar windows for urban roadways and freeways. This window may be further reduced due to specific requirements. Because of these short repair windows, the proper selection of materials for repairing these pavements reduces the likelihood of accidents, delays, traffic problems, and future maintenance efforts due to the delays resulting from the selection of a poor-quality product.

Numerous commercial-off-the-shelf (COTS) products have become available for small surface repairs that provide shorter repair windows. The use of these materials is not new. Much research was focused on the development of methods of evaluation for the wide-spectrum of materials marketed to state departments of transportation (DOTs) and military pavement engineers over the last 20 years (Vaysburd et al. 1999; Shoenberger et al. 2005; Priddy et al. 2007). Concerns of using COTS products stemmed from poor repair preparation and habitual repackaging and reformulation by the manufacturer. This resulted in poor field performance of materials despite previous good results.

The use of unproven products and techniques poses significant risk to aircraft and vehicles due to foreign object debris (FOD) damage. This occurs when the repairs crumble, and the loosened material is projected at the aircraft (or vehicle) or potentially ingested into aircraft engines. Repairs with significant FOD potential require increased labor to maintain surfaces for aircraft operations and require additional closures of airfield or roadways for additional repair efforts. It is imperative that repair materials provide a long-lasting riding surface. 
Because it is unrealistic to conduct full-scale field trials on all repair materials, laboratory criteria may facilitate the selection of expedient repair materials in the future - as manufacturers continue to improve existing products while concurrently developing new products. Because of this need, the U.S. Air Force (USAF) initiated a program to certify airfield pavement repair materials in 2006.

Two initial studies focused on a survey of COTS materials and relevant literature: an initial laboratory examination of material properties, and fullscale traffic tests of full-depth patches using selected rigid and polymeric products on a simulated concrete runway. From this research two laboratory certification protocols were developed, including laboratory testing protocols for rigid repair materials (USAF ETL 08-02) and polymeric repair materials (USAF ETL 08-04). While more than 40 rigid and polymeric materials have been investigated since 2006, the program neglected another emerging repair material market such as COTS asphalt-based patching materials.

Due to short construction windows, the use of asphalt-based repair materials would be advantageous for asphalt runways. These materials have been used for small repairs on airfields such as core hole repairs during airfield evaluations and quality control efforts. The use of the materials on a larger scale for airfield use was questionable. Although the materials have been used extensively for road and parking lot repairs, the use of the materials for airfield repairs was unknown. The development of a laboratory selection protocol for these materials would reduce the likelihood of an airfield manager selecting a product that will not withstand aircraft traffic.

Shoenberger et al. (2005) investigated materials and methods with reduced logistics footprint to achieve rapid repair for sustainment of theater roadways. Material and method requirements were investigated with the goal of reduced material and time requirements when compared with standard repair techniques used to maintain roadways. Results of field tests indicated that cold patch mixes performed well in both wet and dry conditions and were able to carry the applied load without excessive displacement.

The project summarized in this report focused on conducting certification tests to develop a laboratory test protocol for the use of COTS cold patch materials for airfield pavement repairs. 


\section{Objectives}

The main objectives of this project were to

- conduct laboratory and field tests on commercially available materials to characterize material behavior,

- use test results to develop minimum performance acceptance criteria and to generate an asphalt repair laboratory testing protocol.

\section{Scope}

This project consisted of a selection of seven popular COTS cold patch asphalt repair materials of particular interest to the USAF Civil Engineer Support Agency. The selected materials were evaluated through laboratory tests and under controlled traffic conditions in the field to determine the ability of the repair materials to support the gross load of the F-15E aircraft. Tests were evaluated to determine their suitability for a test protocol to certify the use of cold patch materials on airfield pavements.

\section{Outline of chapters}

Chapter 1 provides background information regarding the current and future airfield damage repair challenges and the specific objectives and scope of the project. Chapter 2 presents a description and the results of the laboratory tests. Chapter 3 presents field testing results. Chapter 4 presents the analysis and discussion of the results, and Chapter 5 lists the conclusions and recommendations. Appendix A presents the sample data and test results from the simple performance and moisture susceptibility tests. Appendix B presents the repair cross sections taken during the field test before and after traffic. 


\section{Laboratory Testing}

Laboratory testing was conducted duringJ une 2009 at the U.S. Army Engineer Research and Development Center (ERDC), in Vicksburg, MS. The tests were conducted to determine the strength, workability, durability and compaction properties of seven COTS cold patch asphalt repair materials. A brief description of these materials is presented in the next section.

\section{Materials investigated}

The first steps in the project were to conduct a market survey of materials and a literature review. Through these efforts, a number of proprietary asphalt-based repair materials used to repair roadway pavements were identified that can generally be trafficked immediately after placement. Many products have been used successfully on airfields to repair potholes, utility cuts, and wide cracks. In 2005, Shoenberger et al. conducted a series of laboratory and field tests to evaluate expedient repair materials for roadway pavements. For the current project, the materials were selected based on the results from the laboratory and field tests carried out by Shoenberger et al. (2005) and also based on the recommendations of currently used materials from various DOTs. Products recommended by Shoenberger are noted in Table 1. Various additional material manufacturers were contacted regarding their products. Numerous vendors were interested in participating in this investigation and provided materials for both laboratory and field testing. The materials to be investigated are listed in Table 1 and briefly described in the next sections.

Table 1. Cold-Patch products selected for certification tests.

\begin{tabular}{|l|l|l|l|}
\hline Product & Manufacturer & Container & $\begin{array}{l}\text { Binder } \\
\text { Type }\end{array}$ \\
\hline Instant Road Repair ${ }^{1}$ & International Roadway Research & 5 -gal buckets & Cutback \\
\hline UPM Summer Grade & Unique Paving Materials Corporation & 50 -lb bags & Cutback \\
\hline UPM Warm Summer Grade & Unique Paving Materials Corporation & 50 -lb bags & Cutback \\
\hline Quality Pavement Repair $\left(\mathrm{QPR}^{\circledR}\right)^{1}$ & QPR $^{\circledR}$ & 50 -lb bags & Cutback \\
\hline EZ-Street ${ }^{\circledR 1}$ & EZ-Street $^{\circledR}$ & 50-lb bags & Cutback \\
\hline EZ-Street ${ }^{\circledR}$ Hybrid & EZ-Street $^{\circledR}$ & 50 -lb bags & Cutback \\
\hline Wespro & Wespro & 5-gal buckets & Emulsion \\
\hline
\end{tabular}

1 Products recommended by Shoenberger et al. (2005). 


\section{Instant Road Repair}

Instant Road Repair (referred to herein as IRR) is an all-weather, rapid-curing, durable, and ready-to-use permanent pothole patching material produced and manufactured by International Roadway Research. It is a special blend of asphaltic polymer adhesives and graded limestone that has been produced for federal and state Highway Departments for over 20 years. Its performance specification has been adopted by several DOTs, including Florida, Texas, Colorado, Oregon, Utah, and Georgia. It is transported in 5-gal buckets.

\section{UPM (Unique Paving Materials)}

UPM is a cold-mix patch material for asphalt and concrete pavements manufactured by Unique Paving Materials Corporation. The binder is a proprietary blend of cutback asphalt cement and other additives. UPM can be purchased with an open-graded aggregate mixture for cold weather applications or with dense-graded aggregate for warm weather applications. Two mixes were selected for testing: Summer Grade 4 and Warm Summer Grade 5. Both can be obtained in 50-lb bags.

\section{QPR $^{\circledR}$ (Quality Pavement Repair)}

QPR ${ }^{\circledR}$ Permanent Repair is a ready-to-use formula manufactured by Quality Pavement Repair QPR ${ }^{\circledR}$ for patching potholes, filling utility cuts, and repairing damaged asphalt. The manufacturer indicates that the material is workable from $-5^{\circ} \mathrm{F}$ to $105^{\circ} \mathrm{F}$, and it is approved for use by the DOTs in all 50 states. It can be obtained in 50 -lb plastic bags.

\section{EZ-Street}

EZ-Street is a polymer-modified cold asphalt manufactured by EZ-Street for patching potholes, utility cuts, overlays, and edge repairs in asphalt or concrete. It can be obtained in bulk or in 50 -lb bags. It is most pliable, workable, and compactable at air temperatures ranging from $50^{\circ} \mathrm{F}$ to $90^{\circ} \mathrm{F}$.

\section{EZ-Street Hybrid}

EZ-Street Hybrid Technology ${ }^{\mathrm{TM}}$ is a newer formulation of EZ-Street cold asphalt, which consists of replacing portions of the original ingredients with naturally occurring fuels, and then re-using crushed asphalt particles, reclaimed from the streets and roads. It is also available in 50 -lb bags. 


\section{Wespro}

Wespro (referred to herein as WP) is a cold mix asphalt for patching potholes and damaged areas and is manufactured by Wespro Asphalt Products, Inc. The binder is a proprietary special liquid blend from Wespro. It can be obtained in plastic bags, in plastic 5-gal pails, or in bulk.

\section{Control mix}

In addition to the cold mixes selected for testing, a control mix consisting of hot-mix asphalt (HMA) was used for comparison and to establish minimum performance criteria. The control mix used consisted of a PG 67-22 asphalt binder with aggregate meeting the Unified Facilities Guide Specifications 321215 criteria for airfields. This mix was only tested for static and dynamic creep and was trafficked in the field. Tests results are discussed later in this chapter.

\section{Tests}

Laboratory tests were conducted to evaluate the products' compaction, durability, workability, and creep properties. The tests were conducted in the asphalt laboratory of the Airfields and Pavements Branch of the ERDC Geotechnical and Structures Laboratory, in Vicksburg, MS. Tests are listed in Table 2 and briefly described in the next sections.

Table 2. Outline of tests for cold patch asphalt repair materials.

\begin{tabular}{|l|l|l|l|l|l|}
\hline $\begin{array}{l}\text { Material } \\
\text { Property }\end{array}$ & Test Method & $\begin{array}{l}\text { Test Standard/ } \\
\text { Reference }\end{array}$ & $\begin{array}{l}\text { No. } \\
\text { Replicates }\end{array}$ & $\begin{array}{l}\text { No. } \\
\text { Products }\end{array}$ & $\begin{array}{l}\text { Total No. } \\
\text { Tests }\end{array}$ \\
\hline Compaction & $\begin{array}{l}\text { Superpave Gyratory } \\
\text { Compactor Method }\end{array}$ & ASTM D7229-08 & 3 & 7 & 21 \\
\hline Rice gravity & $\begin{array}{l}\text { Theoretical Maximum } \\
\text { Specific Gravity and Density }\end{array}$ & ASTM D2041-03a & 2 & 7 & 14 \\
\hline Flow time & Static Creep & NCHRP 465 & 4 & $8^{1}$ & 32 \\
\hline Flow number & Dynamic Creep & NCHRP 465 & 4 & $8^{1}$ & 32 \\
\hline Durability & Retained Tensile Strength & AASHTO T 283-07 & 6 & 4 & 24 \\
\hline Workability & Workability Test & ASTM D6704 & 3 & 4 & 12 \\
\hline
\end{tabular}

1 Total number of products tested including the control mix. 


\section{Rice gravity}

This test was conducted for the purpose of determining the maximum theoretical specific gravity and density of uncompacted mixtures. The maximum theoretical specific gravity and density are fundamental properties for which values are influenced by the composition of the mixture in terms of type of aggregate and bituminous material, and the amount of bituminous material. The maximum specific gravity is used in calculating the percentage of air voids in compacted samples, in calculating the amount of bitumen absorbed by the aggregate, and in providing target values for the compaction of paving mixtures (ASTM D2041).

A weighed sample of oven-dry cold patch mixture in the loose condition was placed in a tared vacuum vessel. Sufficient water at a temperature of $77^{\circ} \mathrm{F}$ is added to completely submerge the sample. Vacuum is gradually applied to reduce the residual pressure in the vacuum vessel to $1.2 \mathrm{in}$. of $\mathrm{Hg}$ or less and then held for $15 \mathrm{~min}$ after which the vacuum was gradually released. The volume of the sample was obtained by immersing the vacuum container with the sample in a water bath and weighing. Temperature and mass were measured at that time. From those measurements, the maximum theoretical specific gravity was calculated.

\section{Compaction}

For this work, a Pine Instruments Company model AFGC125X gyratory compactor with a 4-in.-diam mold was used to produce cylindrical asphalt concrete specimens. Compaction was performed using a ram pressure of $87 \mathrm{psi}$ and an internal angle of gyration of $1.16 \mathrm{deg} \pm 0.02 \mathrm{deg}$. Asphalt mixtures were compacted to 30 gyrations at a rate of 30 revolutions per minute. Specimens were tested according to ASTM D7229 to determine the bulk specific gravity and density. The measured specific gravity after compaction and the maximum theoretical specific gravity were used to determine the air voids. Figure 1 shows the gyratory compactor machine used in this study.

\section{Static creep (flow time) and dynamic creep (flow number)}

Flow time (FT) and flow number (FN) tests were conducted under confined test conditions using four replicate test specimens for each product. All test specimens were compacted using the gyratory compactor and a 3.4-in.-diam mold. 


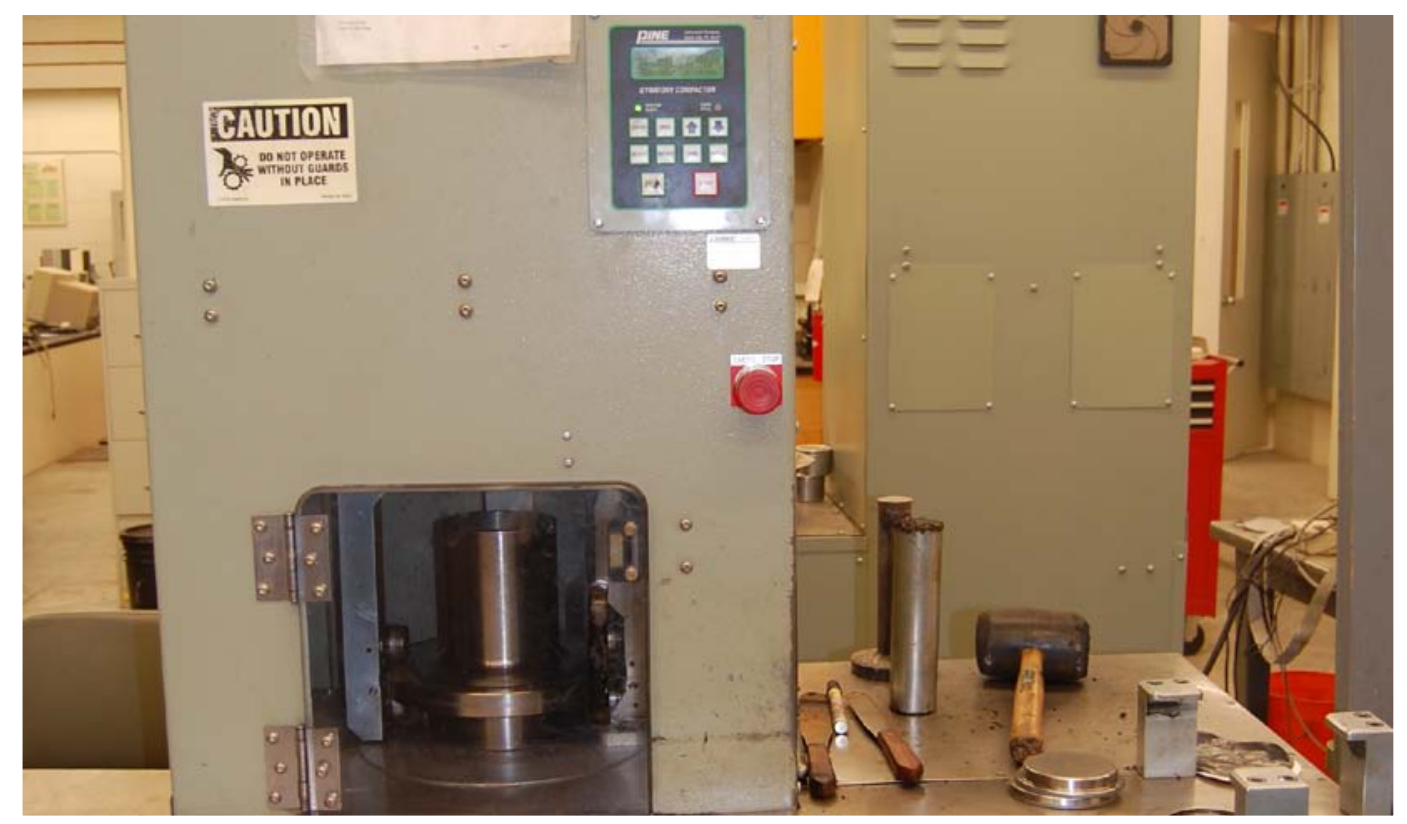

Figure 1. Gyratory compactor.

For the static creep tests, a static constant load was applied to the specimens until tertiary flow occurred. These tests were carried out under a controlled temperature of $77^{\circ} \mathrm{F}$. At the beginning of the test, a confining air pressure of 10 psi was applied to the specimens. A preload stress of 5 psi was then applied for 60 sec to the specimens, and the deviator stress of 90 psi was applied. The test was terminated when $4 \%$ strain was reached or after $48 \mathrm{hr}$, whichever occurred first.

For the dynamic creep tests, a haversine pulse width of $0.1 \mathrm{sec}$ and $0.9 \mathrm{sec}$ dwell (rest period) was applied. These tests were also carried out under a controlled temperature of $77^{\circ} \mathrm{F}$ and using the same test parameters as the FT tests. This test was also terminated at $4 \%$ strain or at 172800 cycles, whichever occurred first.

An IPC universal testing machine (UTM 25) electropneumatic system (Figure 2) was used to test the specimens. The machine has the capacity to apply a confining pressure of up to $90 \mathrm{psi}$ and a maximum vertical load of up to 5,500 lb. The load was measured with a load cell, and the deformations were measured through spring-loaded linear variable differential transformers (LVDTs). The tests were conducted within an environmentally controlled chamber that was set to a constant temperature of $77^{\circ} \mathrm{F}$ throughout the testing sequence. Figure 3 shows a picture of one specimen testing setup. 


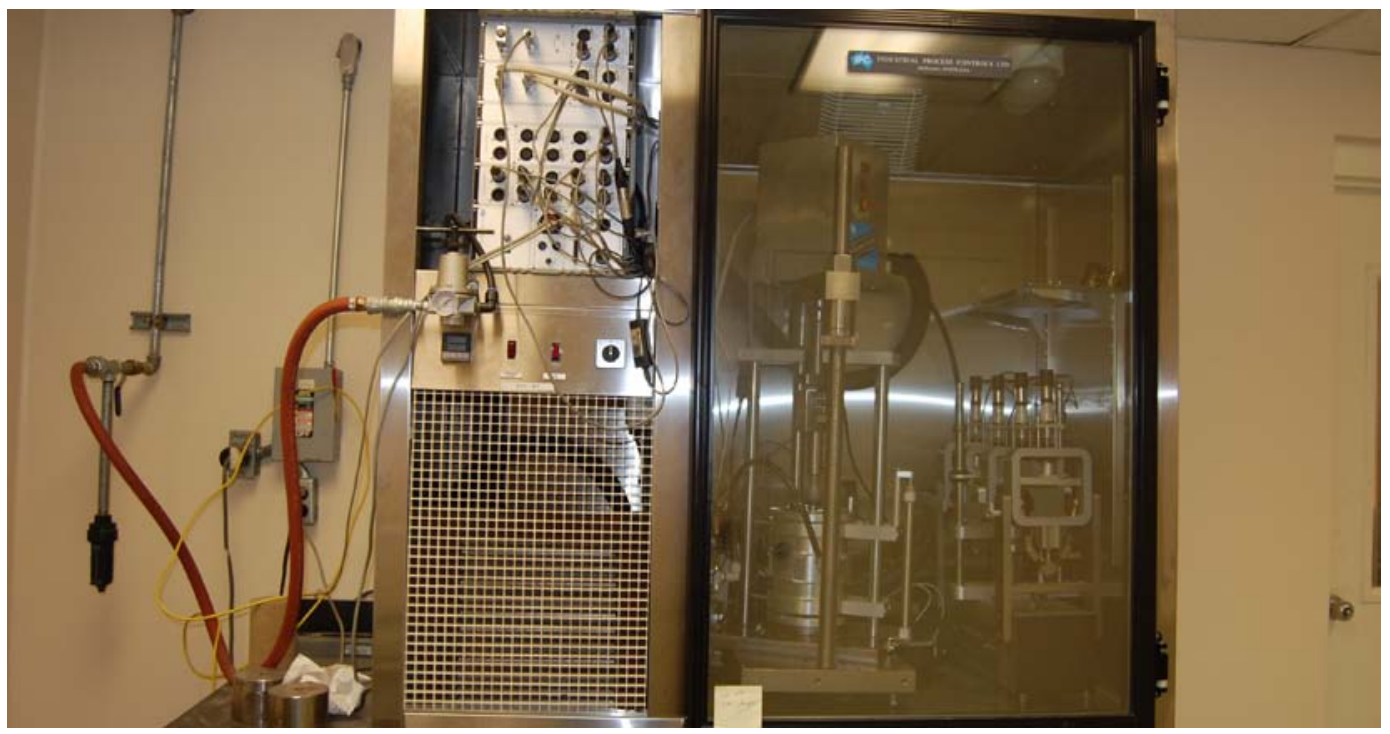

Figure 2. IPC universal testing machine (UTM 25) and temperature chamber used for static and dynamic creep tests.

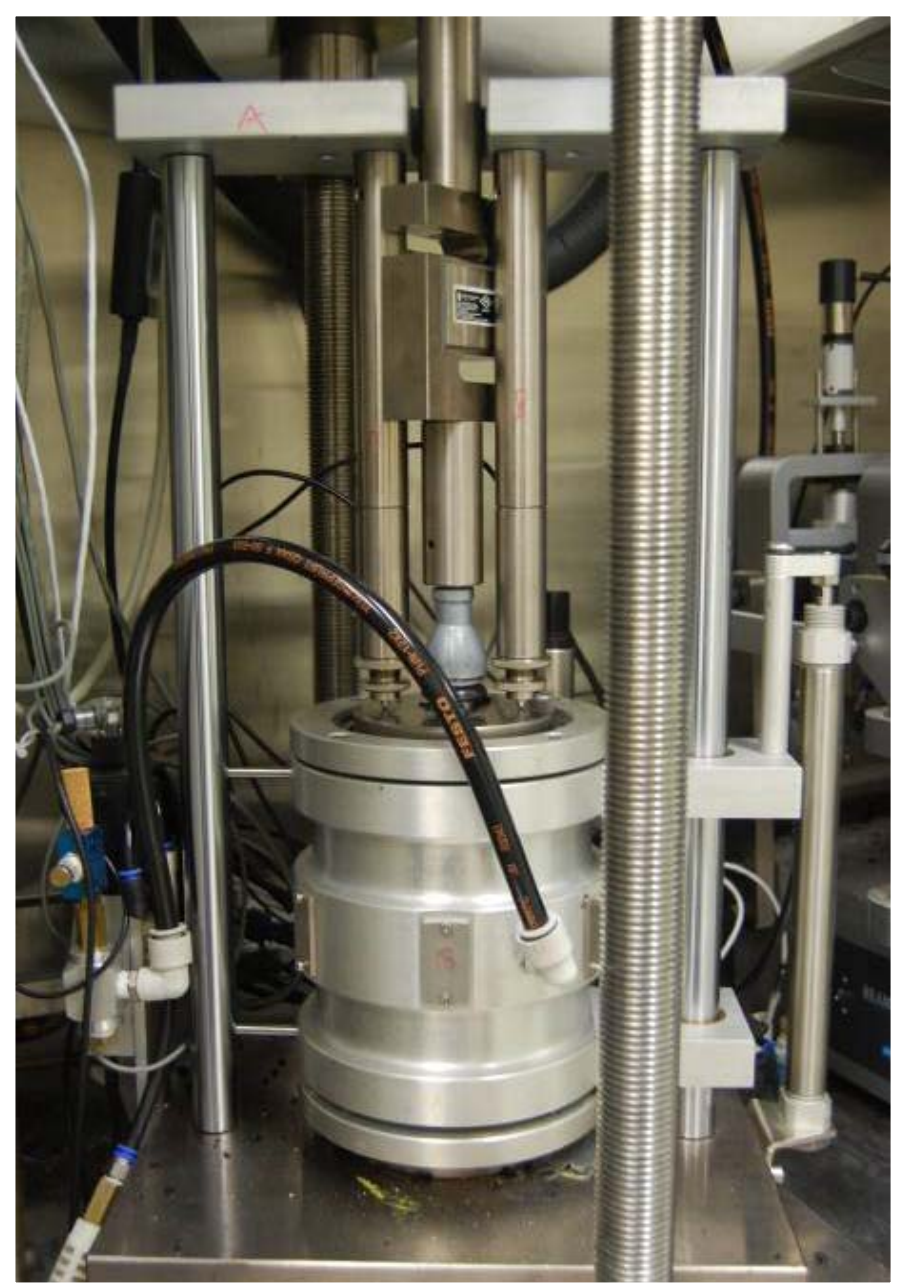

Figure 3. Test setup for confined creep tests. 


\section{Durability}

The main purpose of the durability test is to determine how moisture affects the tensile strength of mixes. Moisture damage in asphalt concrete pavements is associated with loss of adhesion and loss of cohesion. The loss of adhesion is due to water getting between the asphalt and the aggregate and stripping away the asphalt film. The loss of cohesion is due to a softening of asphalt cement in the presence of water, which weakens the bond between the asphalt cement and the aggregate.

The susceptibility to moisture damage was determined by preparing two sets of laboratory-compacted specimens and following the test method AASHTO T 283-07. The mixes had variable voids, which did not allow for compacting to a certain void level. Therefore, compaction was performed by controlling the compaction effort to 30 gyrations of the gyratory compactor. The air voids were calculated for all the samples, and then they were divided in two sets of approximately equal air voids. One set remained dry while the other was partially saturated with water and moisture-conditioned (Figure 4). The tensile strength of each sample was determined by the tensile splitting test (Figure 5). The potential for moisture damage was determined by the ratio of the tensile strength of the wet samples to that of the dry samples.

\section{Workability}

Workability, regarding cold patch materials, can be considered as the amount of effort required to properly construct a pavement repair with the mixture. The repair procedure includes placing the material in the void and compacting it to the desired density. Various methods of defining workability have been used, including the subjective estimate of effort involved in penetrating a stockpile of mixture with a shovel or other object, or using conventional asphalt mixture test equipment to produce a parameter relating to workability.

The ASTM D6704 defines workability as the average maximum resistance to penetration by a designed penetrometer into a compacted asphalt cold mix that is confined in a designated box. Three specimens per product were evaluated. The materials were compacted in the box with two blows of a flat tamping foot compaction hammer and the compacted samples were placed in a freezer at $14^{\circ} \mathrm{F}$ for $24 \mathrm{hr}$. The materials were then tested to measure the resistance to penetration using the test apparatus shown in Figure 6. 


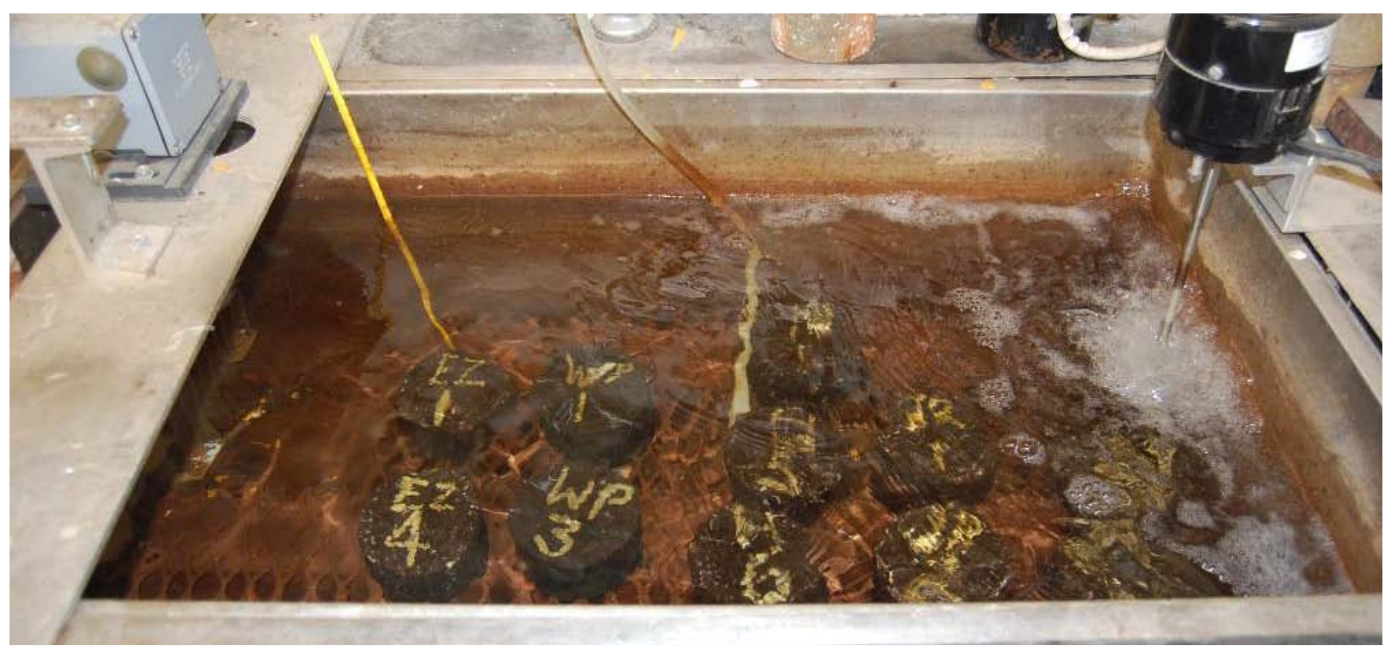

Figure 4. Water bath used to condition the samples for the retained tensile strength test.

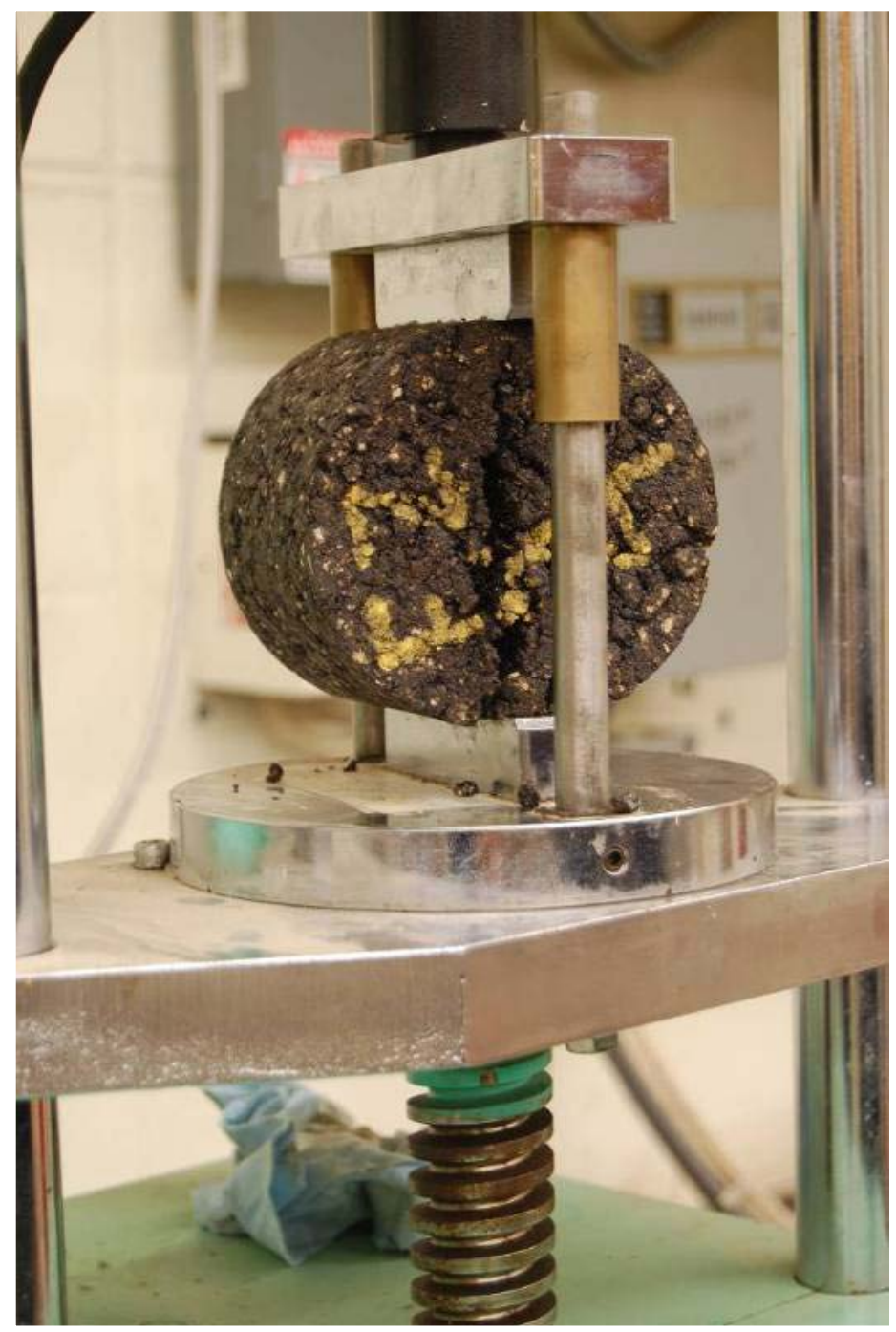

Figure 5: Tensile splitting test. 


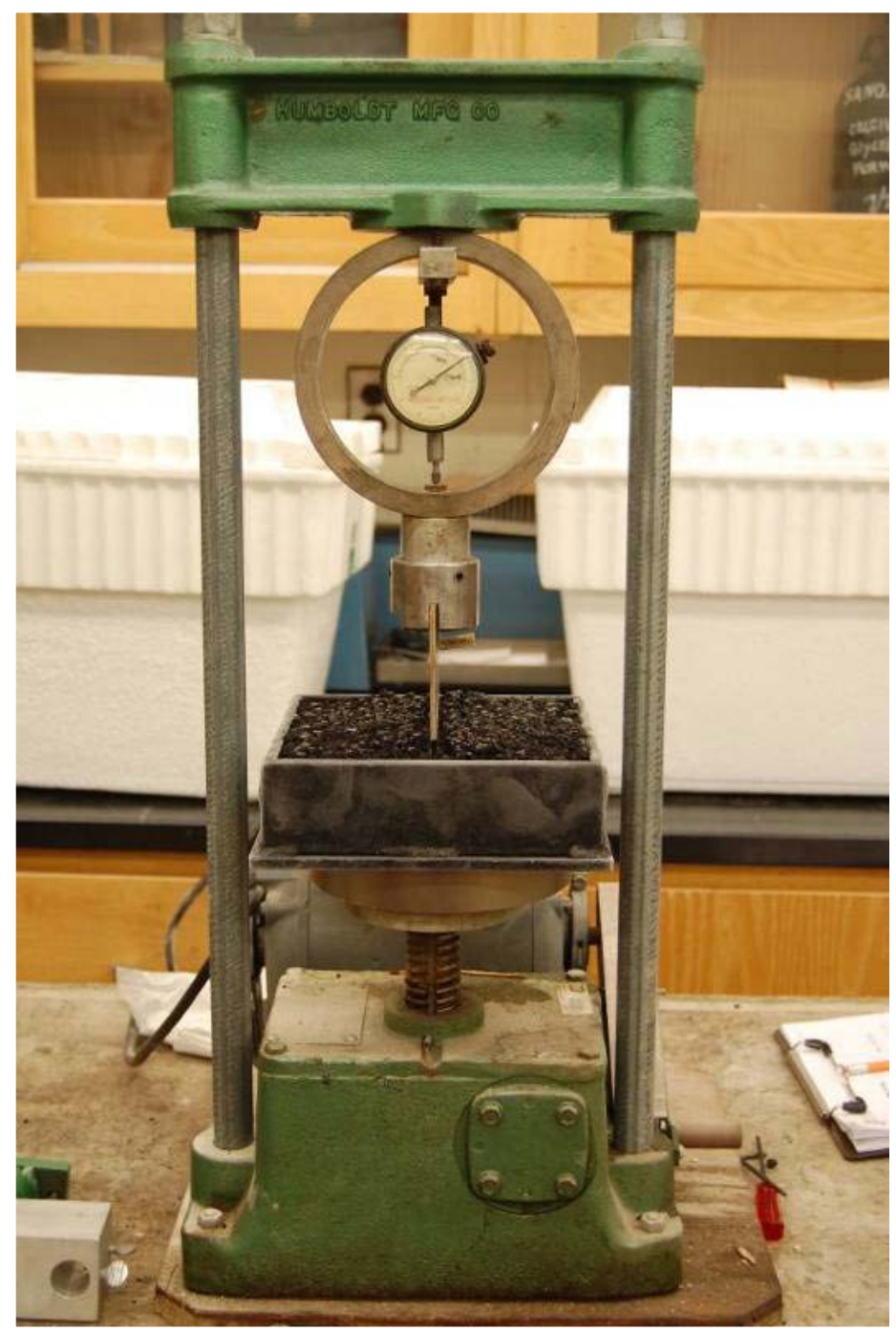

Figure 6. Workability test apparatus.

\section{Results}

A summary of the compaction properties and specific gravity is presented in Table 3. The air voids on EZ-Street and Wespro were significantly lower than the other products and, thus, the compaction densities were higher. This was attributed to excessive moisture that was observed in these materials before and after compaction. Manufacturers were contacted regarding this issue, and they attributed the excess moisture to packaging the mix while it was still warm. This excess moisture caused the laboratory densities of these two materials to be high. 
Table 3. Average compaction properties for all the materials.

\begin{tabular}{|l|l|l|l|l|}
\hline Material & $\begin{array}{l}\text { Theoretical Maximum } \\
\text { Specific Gravity }\end{array}$ & $\begin{array}{l}\text { Bulk Density } \\
\text { pcf }\end{array}$ & $\begin{array}{l}\text { Bulk Specific } \\
\text { Gravity }\end{array}$ & $\begin{array}{l}\% \text { Air } \\
\text { Voids }\end{array}$ \\
\hline QPR & 2.71 & 152.63 & 2.45 & $10 \%$ \\
\hline Wespro Hybrid & 2.65 & 156.55 & 2.51 & $5 \%$ \\
\hline UPM 4.0 & 2.61 & 138.96 & 2.23 & $15 \%$ \\
\hline UPM 5.0 & 2.56 & 146.25 & 2.34 & $9 \%$ \\
\hline Instant Road Repair & 2.45 & 135.20 & 2.17 & $11 \%$ \\
\hline EZ-Street Hybrid & 2.38 & 133.18 & 2.13 & $10 \%$ \\
\hline EZ-Street & 2.37 & 142.71 & 2.29 & $3 \%$ \\
\hline
\end{tabular}

Typical aggregate gradation ranges were provided by the manufacturers and are shown in Table 4. Some mixes ranges were on the well-graded side while others were on the poorly graded side. Mixes with well-graded particle distributions compact better because the finer particles fill the voids between the larger particles. In poorly graded mixes, the particle distribution is more uniform, meaning that all the aggregate particles are about the same size. In these cases, there is a lower amount of finer particles to fill the voids between the larger particles, causing compaction levels to be lower.

Table 4. Typical material gradation ranges provided by the manufacturers.

\begin{tabular}{|l|c|c|c|c|c|c|}
\hline $\begin{array}{l}\text { Percent Passing } \\
\text { Sieve Size }\end{array}$ & IRR & WP & QPR & $\begin{array}{l}\text { UPM } \\
4.0 / 5.0\end{array}$ & $\begin{array}{l}\text { EZ-S/ } \\
\text { EZ-SH }\end{array}$ & $\begin{array}{l}\text { Control } \\
\text { Mix }\end{array}$ \\
\hline $3 / 4$ in. & 100 & - & - & - & - & 100 \\
\hline $1 / 2$ in. & $95-100$ & 100 & --- & -- & 100 & 98.8 \\
\hline $3 / 8$ in. & $75-100$ & 95 & 100 & 100 & $90-100$ & 88.0 \\
\hline $1 / 4$ in. & -- & -- & -- & -- & --- & -- \\
\hline No. 4 & $40-75$ & 44 & $20-85$ & $85-100$ & $64-74$ & 61.3 \\
\hline No. 8 & -- & 16 & $2-40$ & $10-40$ & $41-49$ & 39.3 \\
\hline No. 10 & $8-30$ & -- & -- & -- & -- & -- \\
\hline No. 16 & -- & 9 & $0-10$ & $0-10$ & $25-33$ & 28.3 \\
\hline No. 30 & -- & 5 & --- & -- & $16-22$ & 20.6 \\
\hline No. 40 & $3-15$ & --- & --- & -- & -- & -- \\
\hline No. 50 & -- & 3 & $0-6$ & $0-5$ & $10-16$ & 11.5 \\
\hline No. 80 & $2-10$ & -- & -- & -- & -- & -- \\
\hline No. 100 & --- & 2 & -- & -- & $4-11$ & 7.0 \\
\hline No. 200 & $0-6$ & 0.7 & $0-2$ & -- & $1.5-4.5$ & 6.0 \\
\hline
\end{tabular}


Material properties such as gradations, air voids, and specific gravity were highly variable within the products evaluated. For example, the range in specific gravities observed was from 2.37 to 2.71 , and the range in air voids was from $3 \%$ to $15 \%$. This variability made it difficult to establish threshold material properties for cold patch repair materials to meet minimum acceptance criteria for airfields.

\section{Flow time}

Figure 7 shows the shear deformation of an IRR specimen after the static creep test was completed. Once each test was terminated, the software presented a value for FT in the screen, and created an Excel data sheet with the tests results including deformation, microstrain, and creep modulus. These results are summarized in Tables 5- 8 for the four top-performing products, and complete test data are given in Appendix A.

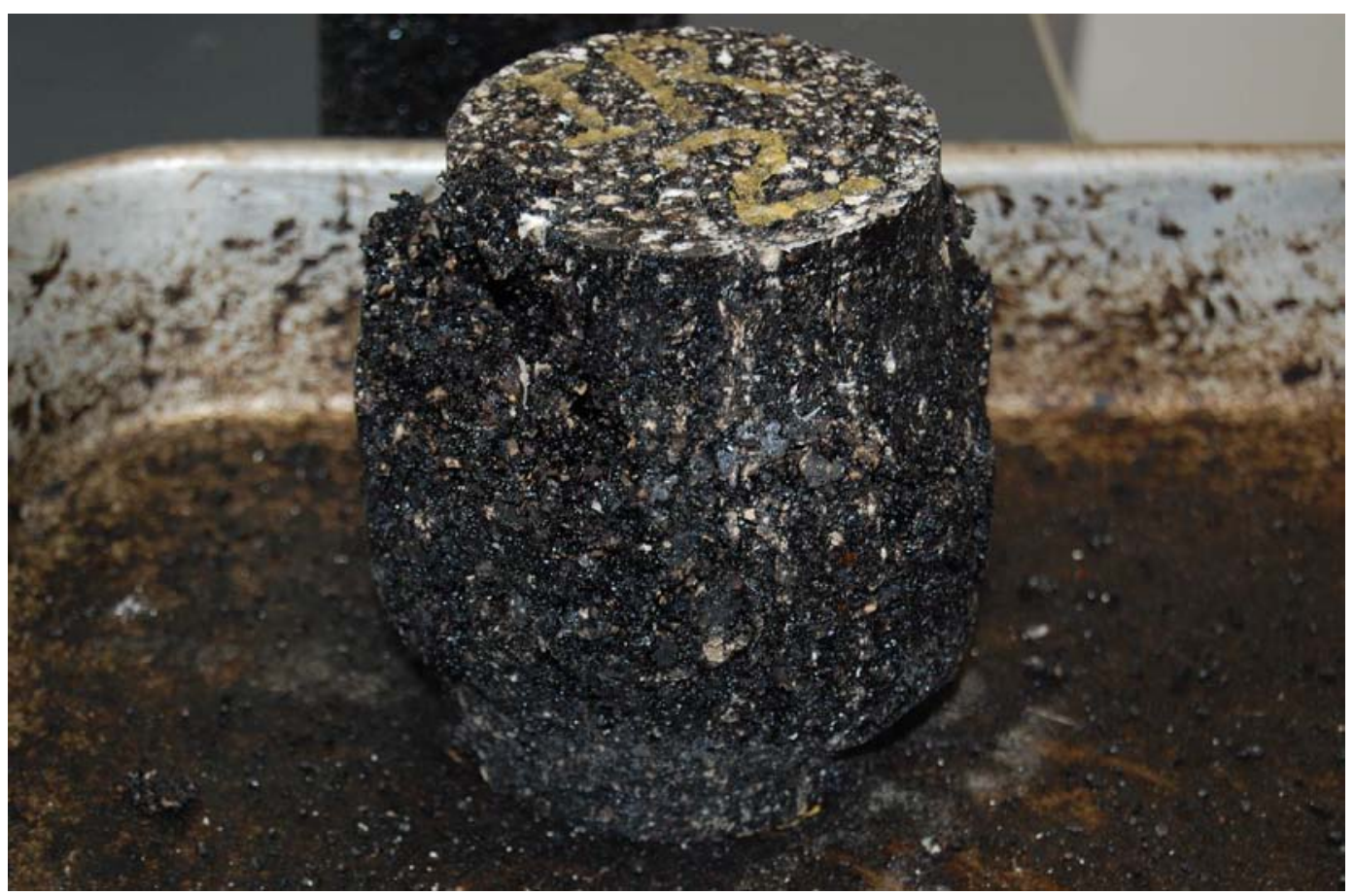

Figure 7. IRR sample after static creep test. 
Table 5. Static creep test results for EZ-Street.

\begin{tabular}{|l|l|l|l|}
\hline Sample ID & Flow Time & Creep Modulus, psi & Permanent Deformation, in. \\
\hline 1 & 1872 & 3771 & 0.092 \\
\hline 2 & 2079 & 3916 & 0.088 \\
\hline 3 & 128 & 2161 & 0.159 \\
\hline 4 & 246 & 2219 & 0.158 \\
\hline \hline Range & $128-2079$ & $2161-3916$ & $0.088-0.159$ \\
\hline Average & 1081 & 3016.8 & 0.124 \\
\hline STDEV & 1037 & 956.7 & 0.040 \\
\hline C.V. $\%$ & $96 \%$ & $32 \%$ & $32 \%$ \\
\hline
\end{tabular}

Table 6. Static creep test results for EZ-Street Hybrid.

\begin{tabular}{|l|l|l|l|}
\hline Sample ID & Flow Time & Creep Modulus, psi & Permanent Deformation, in. \\
\hline 1 & 621 & 2190 & 0.158 \\
\hline 2 & 215 & 2176 & 0.159 \\
\hline 3 & 606 & 2205 & 0.158 \\
\hline 4 & 126 & 2205 & 0.160 \\
\hline \hline Range & $126-621$ & $2176-2205$ & $0.158-0.160$ \\
\hline Average & 392 & 2193.7 & 0.159 \\
\hline STDEV & 258 & 13.9 & 0.001 \\
\hline C.V. $\%$ & $66 \%$ & $0.6 \%$ & $0.6 \%$ \\
\hline
\end{tabular}

Table 7. Static creep test results for Instant Road Repair.

\begin{tabular}{|l|l|l|l|}
\hline Sample ID & Flow Time & Creep Modulus, psi & Permanent Deformation, in. \\
\hline 1 & 40 & 2089 & 0.1659 \\
\hline 2 & 51 & 2132 & 0.1655 \\
\hline 3 & 32 & 2074 & 0.1674 \\
\hline 4 & 127 & 2205 & 0.1592 \\
\hline \hline Range & $32-127$ & $2074-2205$ & $0.1592-0.1674$ \\
\hline Average & 63 & 2124.8 & 0.165 \\
\hline STDEV & 44 & 58.6 & 0.004 \\
\hline C.V. $\%$ & $70 \%$ & $2.8 \%$ & $2.2 \%$ \\
\hline
\end{tabular}


Table 8. Static creep test results for Wespro.

\begin{tabular}{|l|l|l|l|}
\hline Sample ID & Flow Time & Creep Modulus, psi & Permanent Deformation, in. \\
\hline 1 & 64 & 2190 & 0.161 \\
\hline 2 & 13 & 1958 & 0.180 \\
\hline 3 & 159 & 2234 & 0.159 \\
\hline 4 & 53 & 2176 & 0.162 \\
\hline \hline Range & $13-159$ & $1958-2234$ & $0.159-0.180$ \\
\hline Average & 72 & 2139.3 & 0.165 \\
\hline STDEV & 62 & 123.4 & 0.010 \\
\hline C.V. \% & $86 \%$ & $5.8 \%$ & $6.1 \%$ \\
\hline
\end{tabular}

Variability was observed in the test data. In general, the FT values had a coefficient of variation (C.V.) range from $66 \%$ to $96 \%$ and a standard deviation (STDEV) range from 44 to 1037, with EZ-Street being the material with the highest variability. Creep modulus and permanent deformation data did not vary as much. Therefore, variability in FT values could be attributed to how the test method predicts the FT based on the behavior of these materials.

Figure 8 presents the average FT for each product as recorded during the tests. Figure 9 shows the average permanent deformation of each product at the FT point; the average creep modulus is shown in Figure 10.

UPM 4.0 is not included in these plots because samples failed during the initial phase of the test when the preload stress was applied. Therefore, it was not possible to test this material for static creep.

It can be observed that EZ-Street showed a very high FT value compared with the other products. This could indicate that this product has the potential to resist permanent deformation better than the others. However, a large variability was observed in the results of the EZ-Street samples. Two samples showed high FT values while the other two showed low values. The high values could have been considered outliers since the low values were within the range of FT for the rest of the materials. However, there was no observation that would justify classifying these values as outliers. Furthermore, EZ-Street was the material with the highest creep modulus, which indicates that, compared with the other materials, EZ-Street has a lower susceptibility to permanent deformation. 


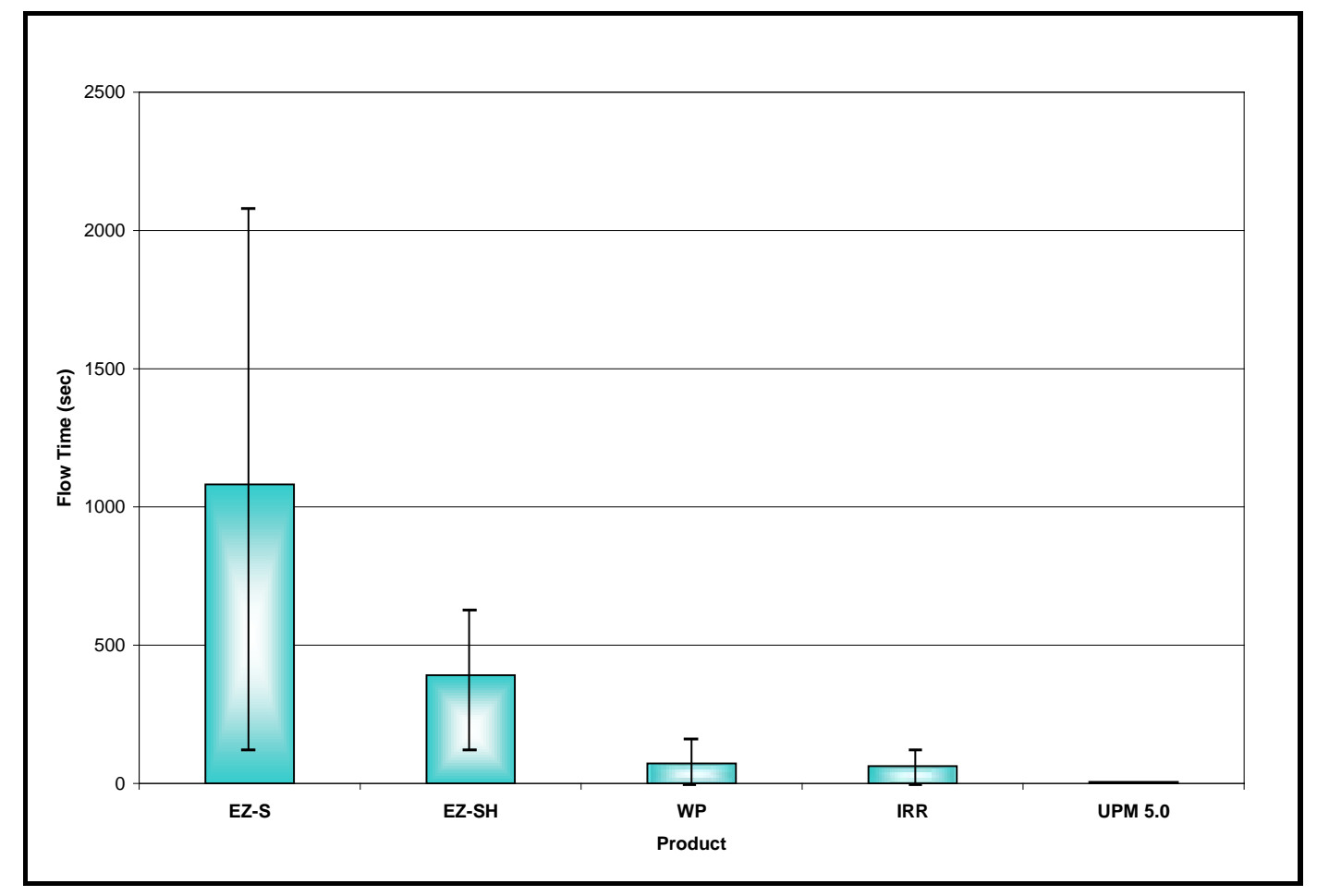

Figure 8. FT per material.

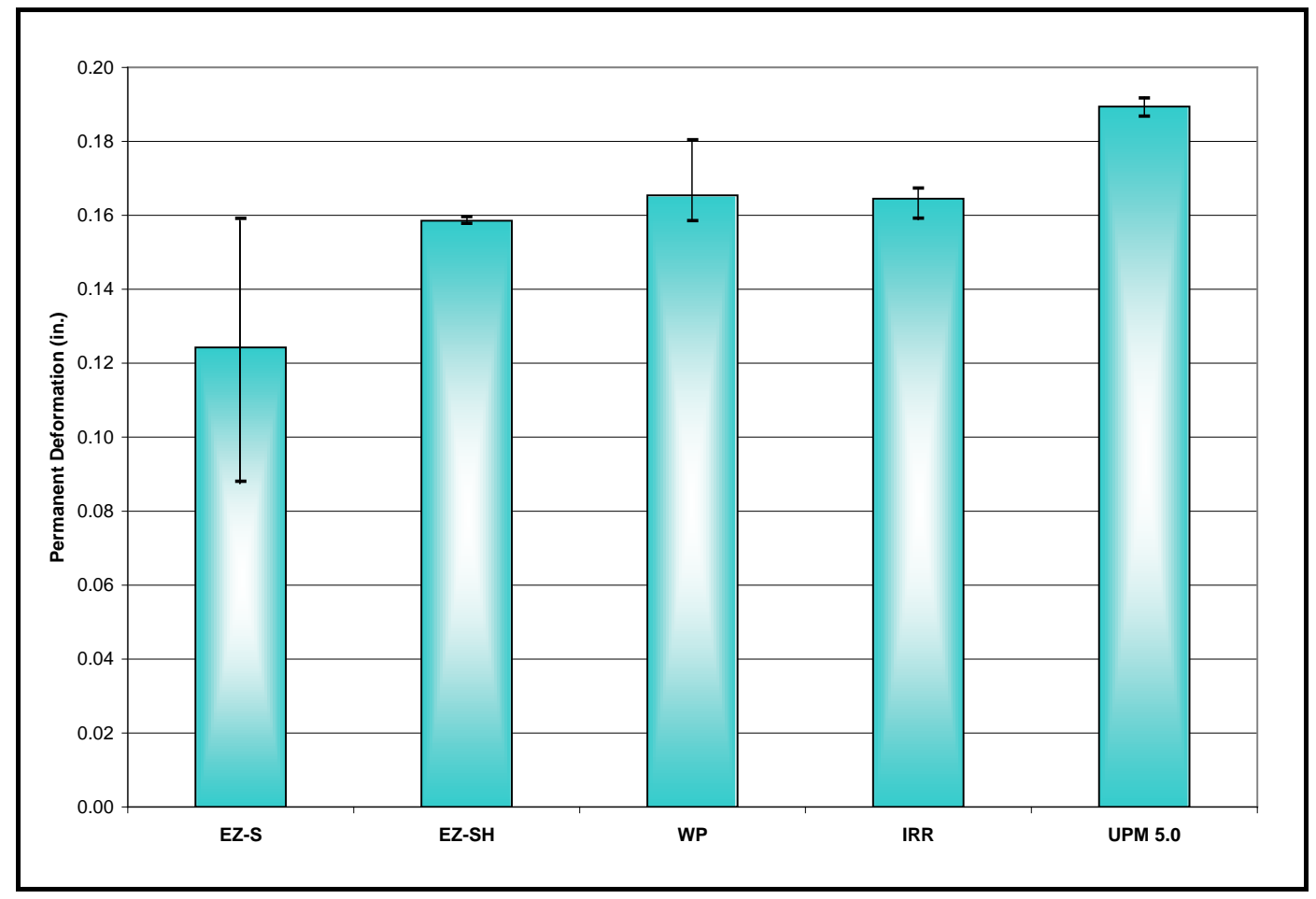

Figure 9. Permanent deformation under static creep loading for each material. 


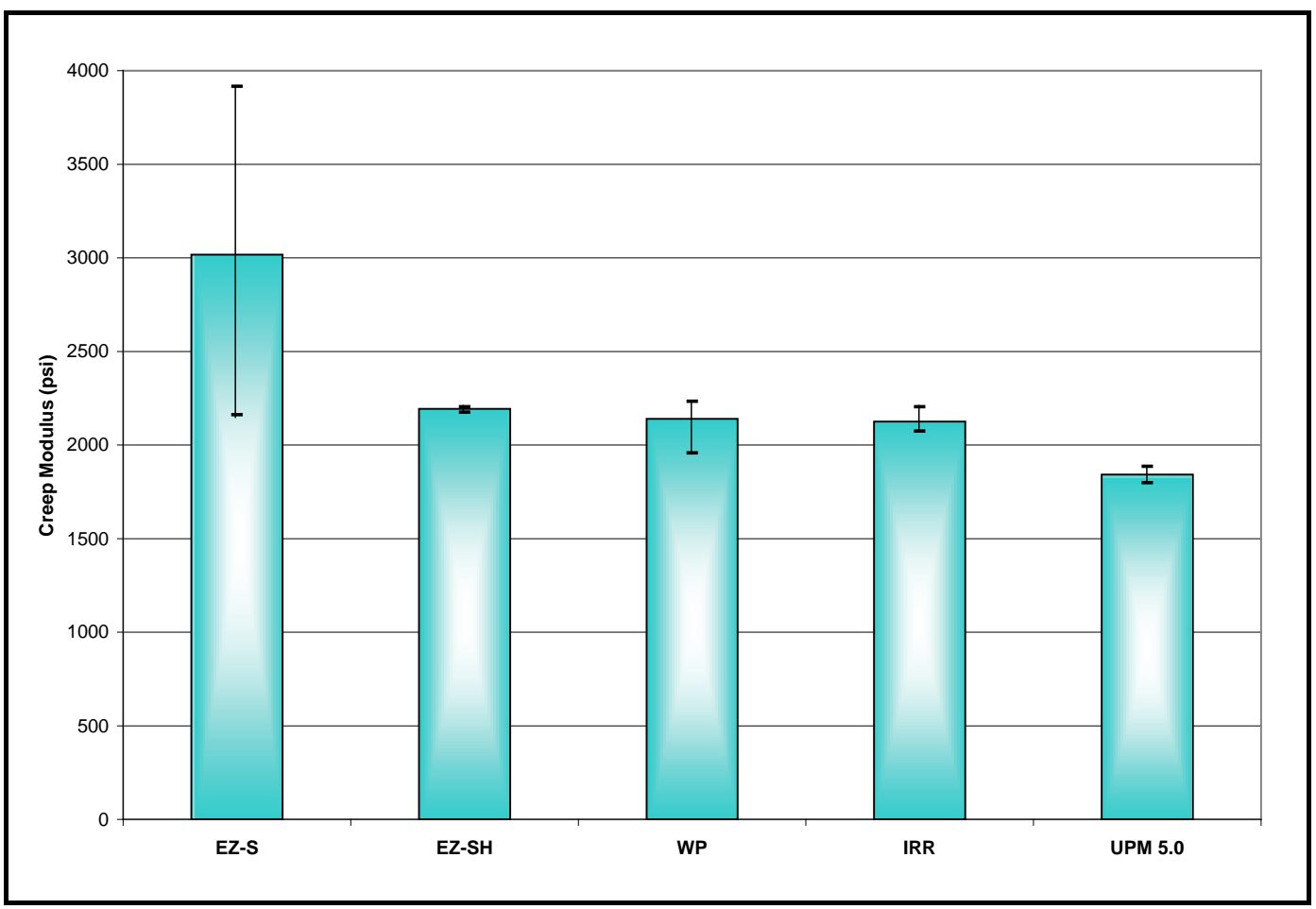

Figure 10. Creep modulus from static creep test for each material.

The control mix was tested at the same temperature at which the cold patch mixes were tested $\left(77^{\circ} \mathrm{F}\right)$, using the same test parameters. For this material, tests were terminated after $72 \mathrm{hr}$. Results from the static creep test on the control mix are presented in Table 9. It was observed that the FT values for this mix were significantly higher than the FT values of the cold patch materials. This shows the low performance that can be expected from the cold patch mixes compared with HMA.

Table 9. Static creep test results for the control mix.

\begin{tabular}{|l|l|l|l|}
\hline Sample ID & Flow Time & Creep Modulus, psi & Permanent Deformation, in. \\
\hline 1 & 83380 & 2263 & 0.141 \\
\hline 2 & 229194 & 12865 & 0.027 \\
\hline 3 & 251189 & 5758 & 0.061 \\
\hline \hline Range & $83380-251189$ & $2263-12865$ & $0.027-0.141$ \\
\hline Average & 187921 & 6962 & 0.077 \\
\hline STDEV & 91201 & 5403 & 0.059 \\
\hline C.V. $\%$ & $49 \%$ & $78 \%$ & $77 \%$ \\
\hline
\end{tabular}




\section{Flow number}

Once the dynamic creep test was terminated, the software presented an FN value in the screen, as well as test results including deformation, microstrain, and resilient modulus, in a separate Excel data sheet. These results are summarized in Tables 10-13 for the four top-performing products, and complete test data are presented in Appendix A.

Variability was also observed in these data. The FN values had a C.V. range from $12 \%$ to $66 \%$ and the standard deviations varied from 14 to 277 , with EZ-Street being the material with the highest variability again. This behavior indicates variability in the mix properties as well as in the test method. Comparing the variability in the data from the FN test and the data from the FT test, it was determined that the FN test is a more reliable method to predict the behavior of these materials under creep loading.

Table 10. Dynamic creep test data for EZ-Street.

\begin{tabular}{|l|l|l|l|l|}
\hline Sample ID & Flow Number & $\begin{array}{l}\text { Resilient } \\
\text { Modulus, psi }\end{array}$ & $\begin{array}{l}\text { Creep } \\
\text { Modulus, psi }\end{array}$ & $\begin{array}{l}\text { Permanent } \\
\text { Deformation, in. }\end{array}$ \\
\hline 1 & 823 & 50219 & 3163 & 0.0068 \\
\hline 2 & 241 & 46979 & 3245 & 0.0071 \\
\hline 3 & 376 & 47721 & 3178 & 0.0071 \\
\hline 4 & 235 & 42986 & 3229 & 0.0078 \\
\hline \hline RANGE & $235-823$ & $42986-50219$ & $3163-3245$ & $0.0068-0.0078$ \\
\hline AVG & 419 & 46976 & 3203.8 & 0.0072 \\
\hline STDEV & 277 & 3000 & 39.2 & 0.0005 \\
\hline C.V. $\%$ & $66 \%$ & $6.4 \%$ & $1.2 \%$ & $6.3 \%$ \\
\hline
\end{tabular}

Table 11. Dynamic creep test data for EZ-Street Hybrid.

\begin{tabular}{|l|l|l|l|l|}
\hline Sample ID & Flow Number & $\begin{array}{l}\text { Resilient } \\
\text { Modulus, psi }\end{array}$ & $\begin{array}{l}\text { Creep } \\
\text { Modulus, psi }\end{array}$ & $\begin{array}{l}\text { Permanent } \\
\text { Deformation, in. }\end{array}$ \\
\hline 1 & 379 & 50419 & 3184 & 0.0067 \\
\hline 2 & 310 & 51010 & 3213 & 0.0067 \\
\hline 3 & 337 & 52209 & 3198 & 0.0065 \\
\hline 4 & 280 & 55284 & 3242 & 0.0062 \\
\hline \hline Range & $280-379$ & $50419-55284$ & $3184-3242$ & $0.0062-0.0067$ \\
\hline Average & 327 & 52230 & 3209.0 & 0.0065 \\
\hline STDEV & 42 & 2167 & 25.1 & 0.0002 \\
\hline C.V. $\%$ & $13 \%$ & $4.1 \%$ & $0.8 \%$ & $3.6 \%$ \\
\hline
\end{tabular}


Table 12. Dynamic creep test data for Instant Road Repair.

\begin{tabular}{|l|l|l|l|l|}
\hline Sample ID & Flow Number & $\begin{array}{l}\text { Resilient } \\
\text { Modulus, psi }\end{array}$ & $\begin{array}{l}\text { Creep Modulus } \\
\text { psi }\end{array}$ & $\begin{array}{l}\text { Permanent } \\
\text { Deformation, in. }\end{array}$ \\
\hline 1 & 145 & 52726 & 3257 & 0.0064 \\
\hline 2 & 121 & 54806 & 3286 & 0.0062 \\
\hline 3 & 106 & 49796 & 3362 & 0.0069 \\
\hline 4 & 121 & 50725 & 3353 & 0.0068 \\
\hline 5 & 118 & 50303 & 3280 & 0.0067 \\
\hline \hline Range & $106-145$ & $49796-54806$ & $3257-3362$ & $0.0062-0.0069$ \\
\hline Average & 122 & 51671 & 3307.5 & 0.0066 \\
\hline STDEV & 14 & 2075 & 46.8 & 0.0003 \\
\hline C.V. $\%$ & $12 \%$ & $4.0 \%$ & $1.4 \%$ & $4.3 \%$ \\
\hline
\end{tabular}

Table 13. Dynamic creep test data for Wespro.

\begin{tabular}{|l|l|l|l|l|}
\hline Sample ID & Flow Number & $\begin{array}{l}\text { Resilient } \\
\text { Modulus, psi }\end{array}$ & $\begin{array}{l}\text { Creep Modulus } \\
\text { psi }\end{array}$ & $\begin{array}{l}\text { Permanent } \\
\text { Deformation, in. }\end{array}$ \\
\hline 1 & 139 & 41951 & 3270 & 0.0081 \\
\hline 2 & 88 & 37308 & 3351 & 0.0091 \\
\hline 3 & 169 & 40964 & 3265 & 0.0084 \\
\hline 4 & 286 & 46657 & 3202 & 0.0073 \\
\hline \hline Range & $88-286$ & $37308-46657$ & $3202-3351$ & $0.0073-0.0091$ \\
\hline Average & 171 & 41720 & 3271.9 & 0.0082 \\
\hline STDEV & 84 & 3850 & 61.1 & 0.0008 \\
\hline C.V. $\%$ & $49 \%$ & $9.2 \%$ & $1.9 \%$ & $9.3 \%$ \\
\hline
\end{tabular}

Figure 11 presents the average FN for each product as recorded during the tests. Figure 12 shows the average permanent deformation of each product at the FT point; the average resilient modulus is shown in Figure 13.

UPM 4.0 and 5.0 and QPR are not included in these plots because the samples of these materials failed during the initial phase of the test when the preload stress was applied. Therefore, it was not possible to test these materials for dynamic creep. Because of the early failure of these products, and considering that the test conditions were not extreme, these materials were eliminated from consideration for further testing.

The FN values were consistent with the results obtained from the static creep test, in that EZ-Street proved to be the material with highest FN. However, this did not mean that this material resisted permanent deformation under repeated loading better than the others. EZ-Street actually had a higher permanent deformation and lower resilient modulus 


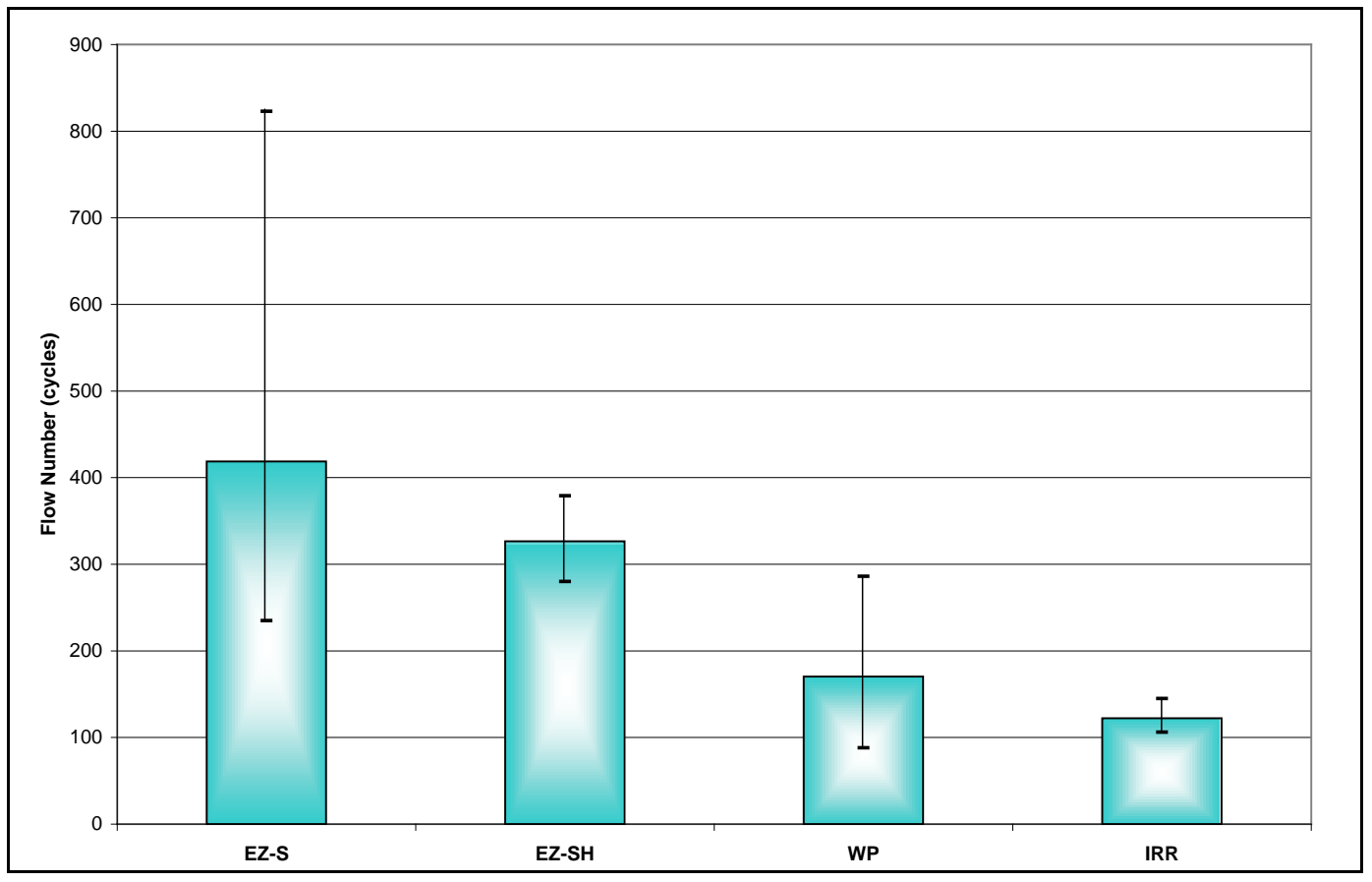

Figure 11. Flow number per material.

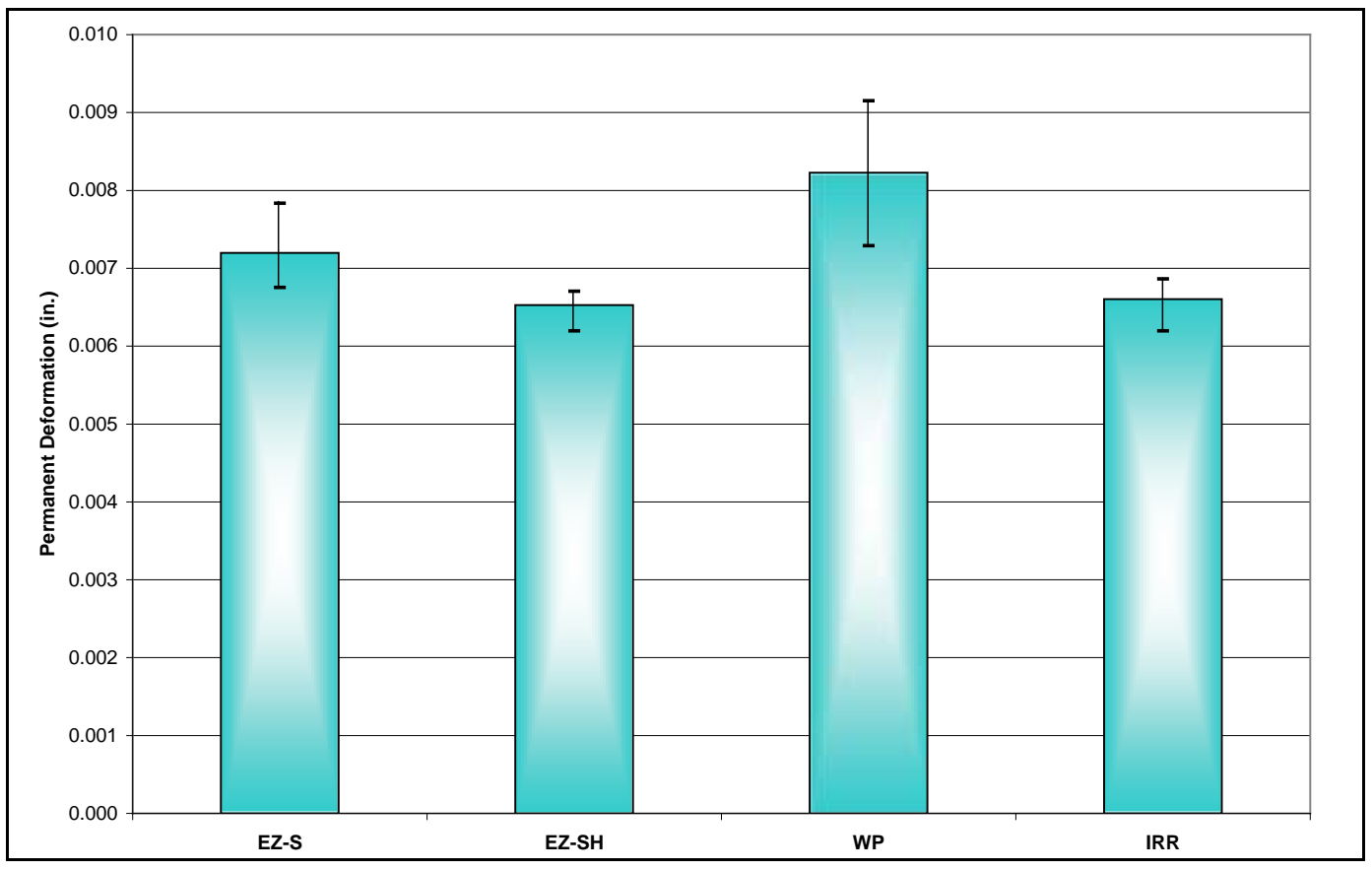

Figure 12. Permanent deformation under dynamic creep loading for each material. 


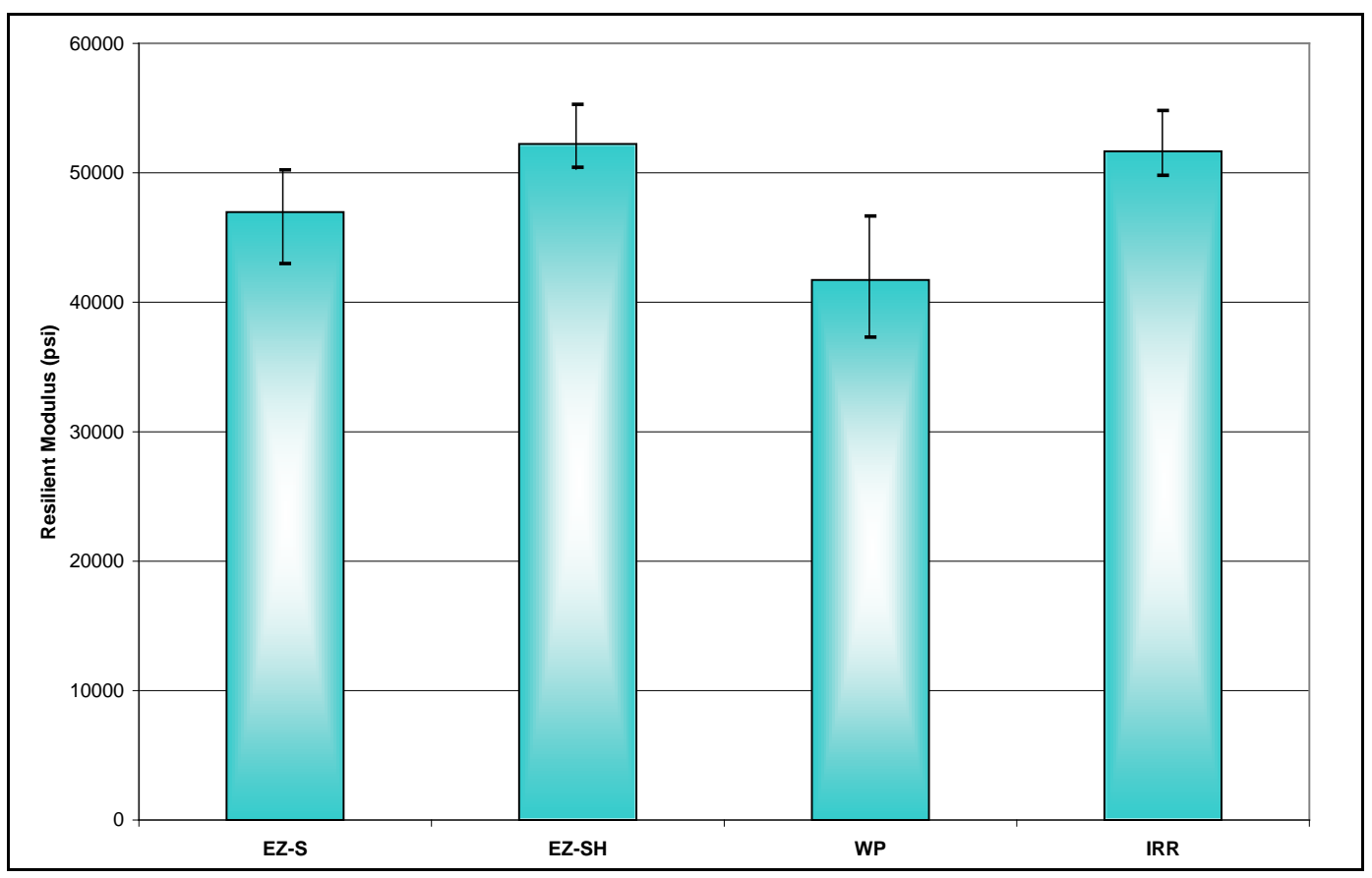

Figure 13. Resilient modulus from dynamic creep test for each material.

than EZ-Street Hybrid and Instant Road Repair. This would indicate that the last two products performed better under repeated load than did EZ-Street. This discrepancy between FN data and permanent deformation could be attributed to the variability observed and discussed before. Results from Wespro samples indicated that, of the four materials tested, this material would experience the highest deformation under repeated load.

The results for the HMA are presented in Table 14. This mix was tested at the same temperature as the cold patch mixes $\left(77^{\circ} \mathrm{F}\right)$, and using the same test procedures. As observed in the static creep test, the FN values for this mix were significantly higher than the FN values of the cold patch materials.

Table 14. Dynamic creep test data for the control mix.

\begin{tabular}{|l|l|l|l|l|}
\hline Sample ID & $\begin{array}{l}\text { Flow } \\
\text { Number }\end{array}$ & $\begin{array}{l}\text { Resilient } \\
\text { Modulus, psi }\end{array}$ & $\begin{array}{l}\text { Creep } \\
\text { Modulus, psi }\end{array}$ & $\begin{array}{l}\text { Permanent } \\
\text { Deformation, in. }\end{array}$ \\
\hline 1 & 161662 & 362288 & 36975 & 0.0010 \\
\hline 2 & 66622 & 328120 & 35585 & 0.0011 \\
\hline 3 & 72190 & 301021 & 44029 & 0.0012 \\
\hline \hline Range & $66622-161662$ & $2075-2498$ & $245-304$ & $0.0245-0.0295$ \\
\hline Average & 100158 & 330476 & 38863 & 0.0011 \\
\hline STDEV & 53337 & 30701 & 4527 & 0.0001 \\
\hline C.V. $\%$ & $53 \%$ & $9.3 \%$ & $12 \%$ & $9.1 \%$ \\
\hline
\end{tabular}




\section{Durability}

The four top-performing cold patch products were tested for moisture damage. Two sets of specimens were exposed to different temperature and moisture conditions to evaluate the effect on the tensile strength of the materials and the bonding between the aggregate and the binder. The complete results are listed in Appendix A and summarized in Figures 14- 16.

From Figure 14, it can be observed that the product with the highest tensile strength under dry conditions was Instant Road Repair. From Figure 15, Instant Road Repair was also the product with the highest wet tensile strength. However, when comparing the tensile strength ratio (TSR) of all the materials (Figure 16), EZ-Street Hybrid was the one with the highest ratio, i.e. the effect of moisture on this material's tensile strength is less than in the others. Wespro samples broke apart as soon as they were taken out the water bath. Therefore, the wet tensile strength test could not be run for this material. From this, it was concluded that Wespro is not suitable for repairing potholes filled with water, and the product is most likely to have durability problems.

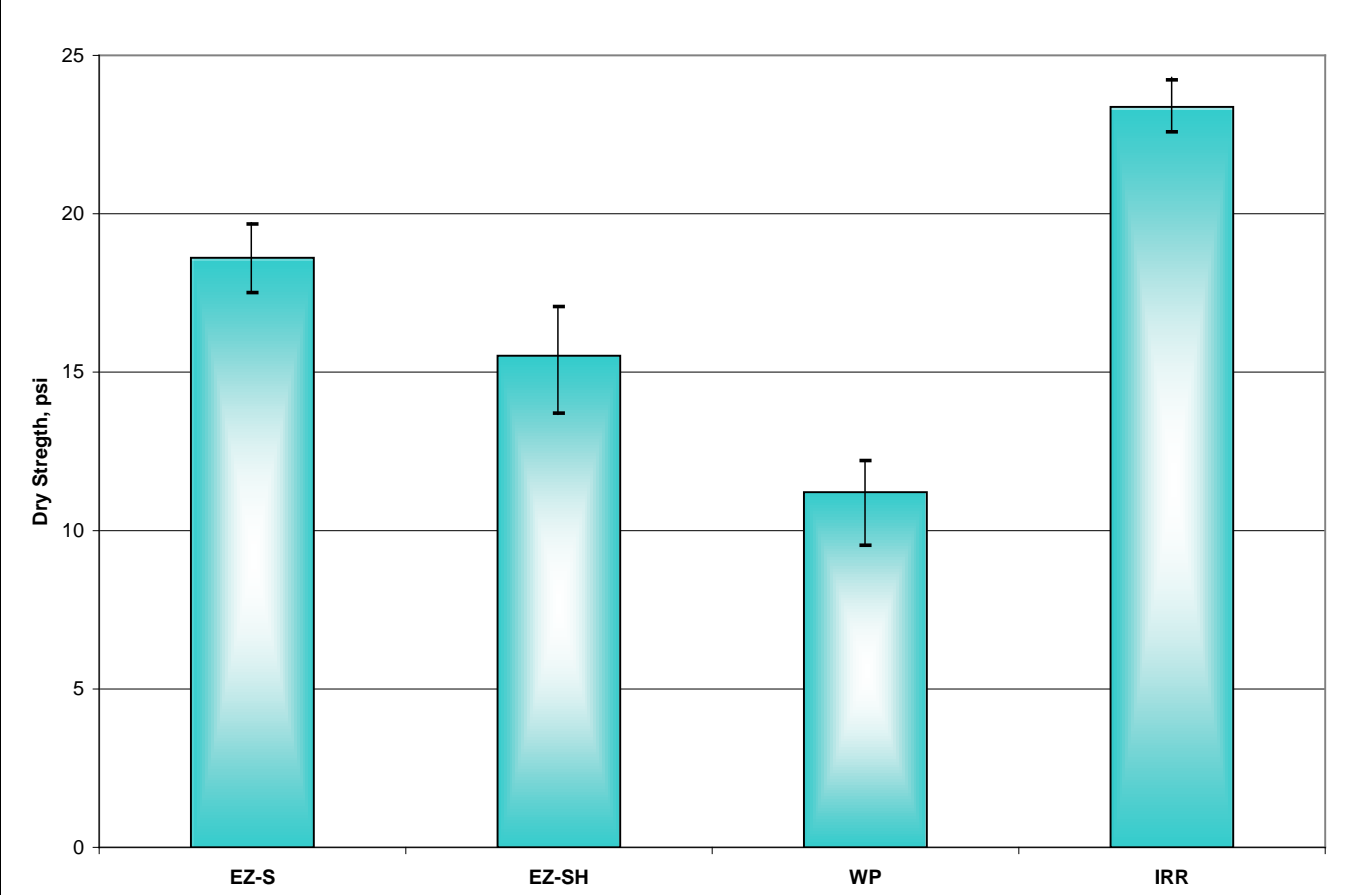

Figure 14. Dry tensile strength of the four top-performing products. 


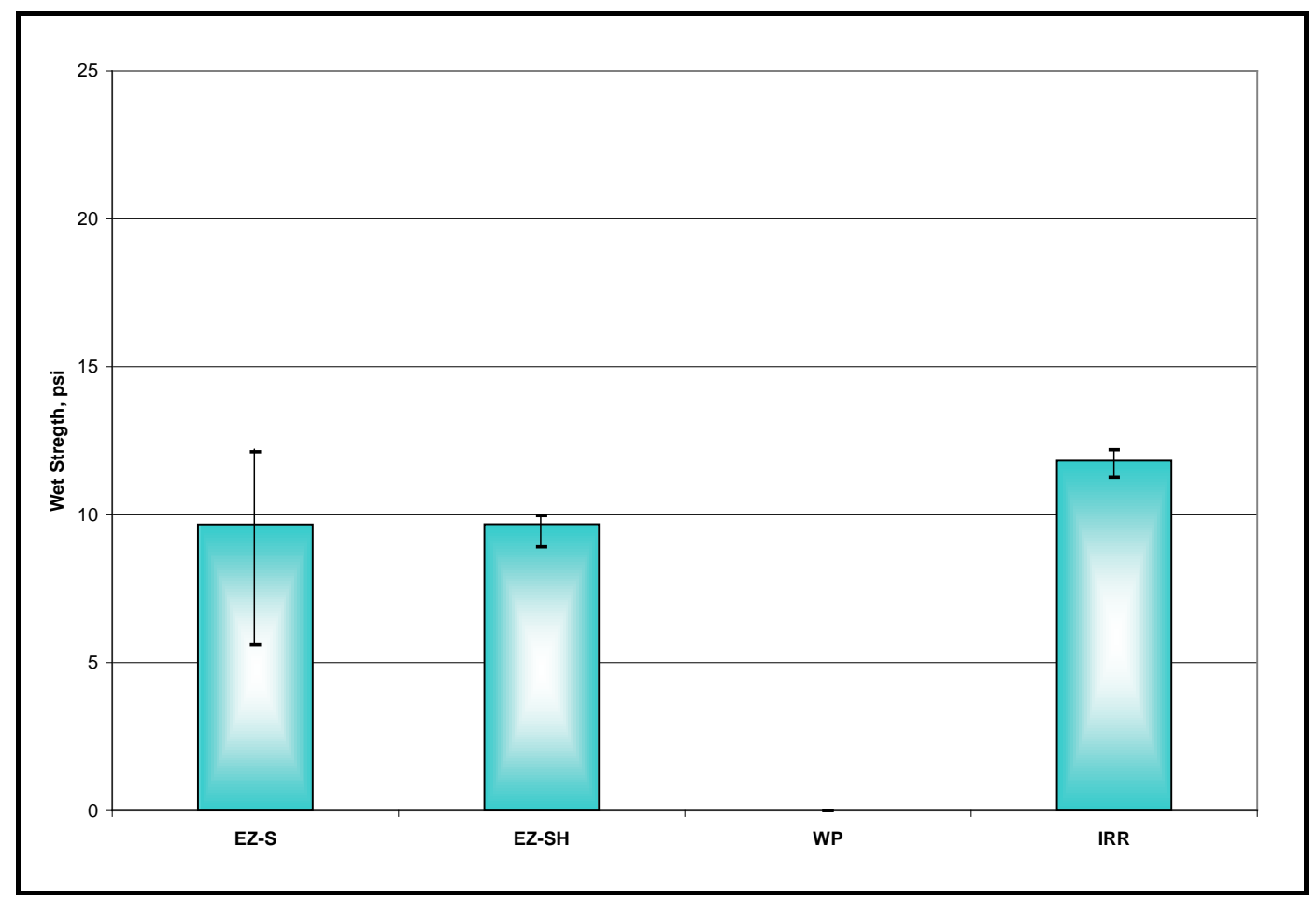

Figure 15. Wet tensile strength of the four top-performing products.

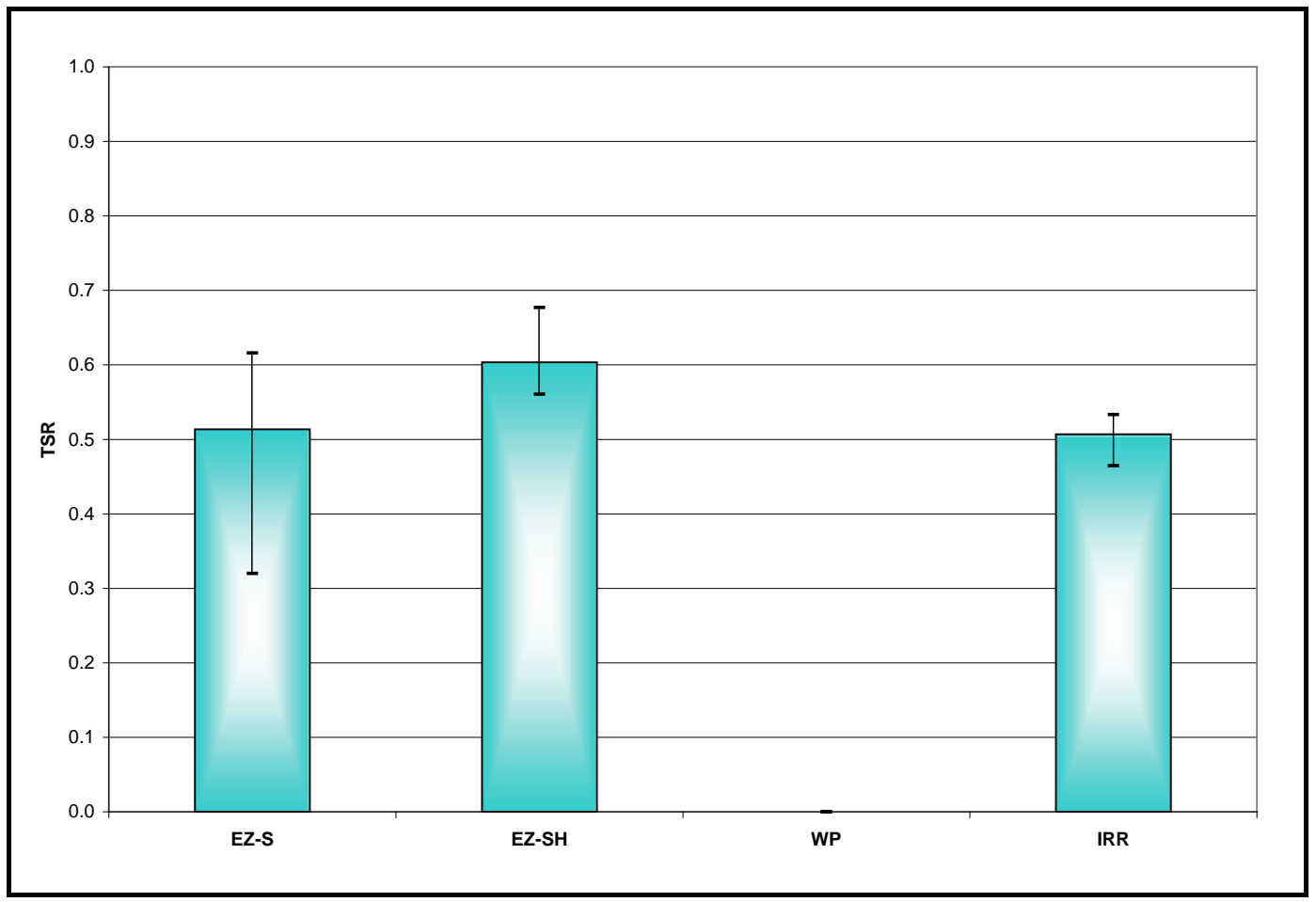

Figure 16. TSR comparison between the four top-performing products. 
Specimens were loaded until they fractured. Then, the samples were split to visually estimate the degree of moisture damage. All the surfaces were inspected for evidence of cracked or broken aggregate. Figure 17 shows an EZ-Street specimen split for visual inspection. Most of the specimens examined exhibited broken aggregates, and stripping of the binder from the aggregates was also observed.

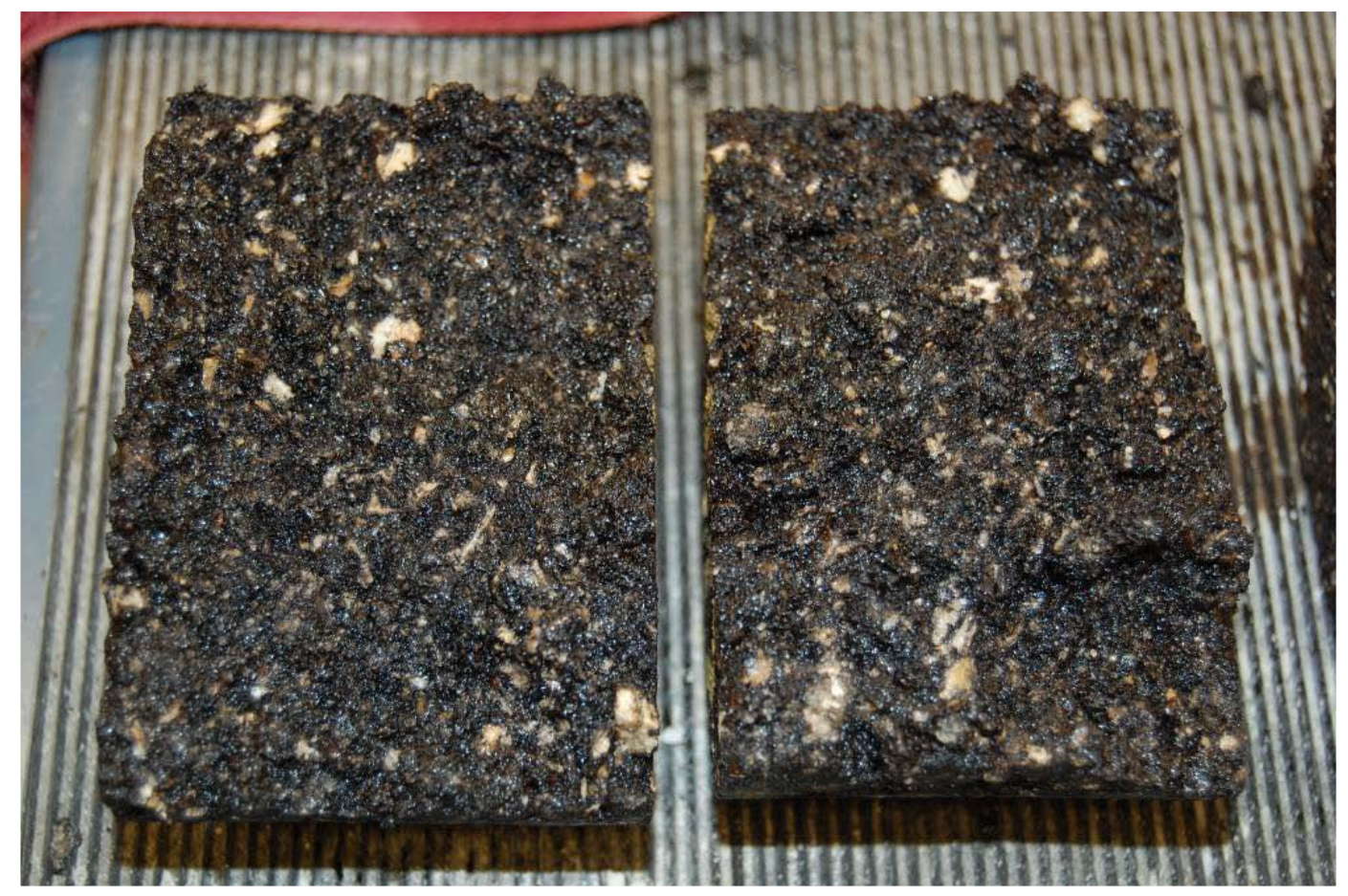

Figure 17. Broken aggregate on an EZ-Street sample.

On average, it was observed that moisture damage reduced the tensile strength of the cold patch mixes evaluated by more than $50 \%$. This shows that these materials are very susceptible to durability problems. The tensile strength reduction in the presence of water could be attributed to the quality of the aggregate, loss of cohesion, and loss of adhesion. The presence of broken aggregates in the specimens led to the conclusion that the aggregate quality was poor since the load level at failure was not very high. Also, some specimens broke apart immediately upon removal from the water bath or while placing them on the test apparatus. This could have been caused by water infiltration between the asphalt and the aggregate, and stripping away of the asphalt film (loss of adhesion). It could also have been caused by softening of the asphalt cement in presence of water, which may have weakened the bond between the asphalt cement and the aggregate (loss of cohesion) causing the samples to fall apart during handling. The use of 
admixtures such as hydrated lime is commonly recommended to improve aggregate-asphalt bonding and to reduce stripping potential.

\section{Workability}

Workability is one of the main factors that influences the suitability of cold patch products for use as an asphalt pavement repair material. The workability of the cold patch products was tested in the laboratory by determining the resistance to penetration by a designated penetrometer into the compacted cold patch mix specimen that was confined in a designated box.

The results of this test for the four top-performing products are presented in Table 15 and Figure 18. The most workable product was Instant Road Repair, which had the lowest resistance to penetration. EZ-Street and Wespro had very high values of resistance to penetration, which indicates that these products are less workable. It should be noted that both of these products had excess moisture in the packages. This moisture could have influenced the results, as the excess water could have frozen, creating ice lenses with a very high resistance to penetration. The likelihood of having this kind of problem could be seen as one disadvantage to using a test method that involves freezing the specimens prior to testing to evaluate workability. Ice lenses could cause variability in the test results.

This test method may not be considered representative of the workability of the cold patch materials when they are to be used for a repair straight from the package. This method is more representative of evaluating how easily it would be to work with the cold mixes that have been stockpiled at very low temperatures before used for repairs. However, this is the only test method that has been developed to date to evaluate the workability of cold patch asphalt mixes. There are various methods of evaluating the workability of asphalt mixes by simple observation in the field, but these methods are more useful for construction purposes than for establishing a test protocol for material acceptance.

Methods that have been developed for evaluating workability of HMA should be considered for possible adaptation for use in evaluating workability of cold patch asphalt mixes. For example, Gudimettla et al. (2003) developed a method to measure the laboratory workability of HMA mixes that consisted of immersing a paddle into a sample of HMA. The torque required to keep the paddle rotating at a constant speed within the sample was measured, and the workability was defined as the inverse of the torque required 
to rotate the paddle within the sample of HMA. That study also established that the workability of HMA was affected by aggregate type and properties, nominal maximum aggregate size of the gradation, and binder type. The same parameters that have been evaluated for determining the workability of HMA should be considered when developing methods to evaluate the workability of cold patch mixes, especially aggregate quality and binder type.

Temperature is another important parameter to be considered when evaluating the workability of cold patch mixes. From the ASTM D6704-08, the cold patch mixes evaluated in this study are workable in the ambient temperature ranges listed in Table 15. All the products tested were summer grade mixes; therefore, the workability temperature range would be expected to be between $70^{\circ} \mathrm{F}$ and $110^{\circ} \mathrm{F}$. The temperature ranges corresponding to the workability of the all products were between these values, with the exception of Wespro. This could be related to the excess moisture problem described before, which caused the workability of this mix to be low compared with the other mixes.

Table 15. Workability test results.

\begin{tabular}{|c|c|c|c|c|c|c|}
\hline Material & $\begin{array}{l}\text { Specimen } \\
\text { Number }\end{array}$ & $\begin{array}{l}\text { Resistance to } \\
\text { Penetration, Ibf }\end{array}$ & $\begin{array}{l}\text { Average } \\
\text { psi }\end{array}$ & STDEV & $\begin{array}{l}\mathrm{CV} \\
\text { (\%) }\end{array}$ & $\begin{array}{l}\text { Temperature } \\
\text { Range a } \\
\left({ }^{\circ} \mathrm{F}\right)\end{array}$ \\
\hline \multirow{3}{*}{ IRR } & 1 & 759 & \multirow{3}{*}{881} & \multirow{3}{*}{163} & \multirow{3}{*}{18} & \multirow{3}{*}{$50-90$} \\
\hline & 2 & 1066 & & & & \\
\hline & 3 & 818 & & & & \\
\hline \multirow{3}{*}{$\begin{array}{l}\text { EZ-Street } \\
\text { Hybrid }\end{array}$} & 1 & 949 & \multirow{3}{*}{1051} & \multirow{3}{*}{141} & \multirow{3}{*}{13} & \multirow{3}{*}{$70-110$} \\
\hline & 2 & 1212 & & & & \\
\hline & 3 & 993 & & & & \\
\hline \multirow{3}{*}{ EZ-Street } & 1 & 1416 & \multirow{3}{*}{1718} & \multirow{3}{*}{381} & \multirow{3}{*}{22} & \multirow{3}{*}{$70-110$} \\
\hline & 2 & 1591 & & & & \\
\hline & 3 & 2146 & & & & \\
\hline \multirow{3}{*}{ WESPRO } & 1 & 3577 & \multirow{3}{*}{3660} & \multirow{3}{*}{169} & \multirow{3}{*}{5} & \multirow{3}{*}{$>110$} \\
\hline & 2 & 3548 & & & & \\
\hline & 3 & 3854 & & & & \\
\hline
\end{tabular}

a Workability temperature ranges from ASTM D6704-08. 


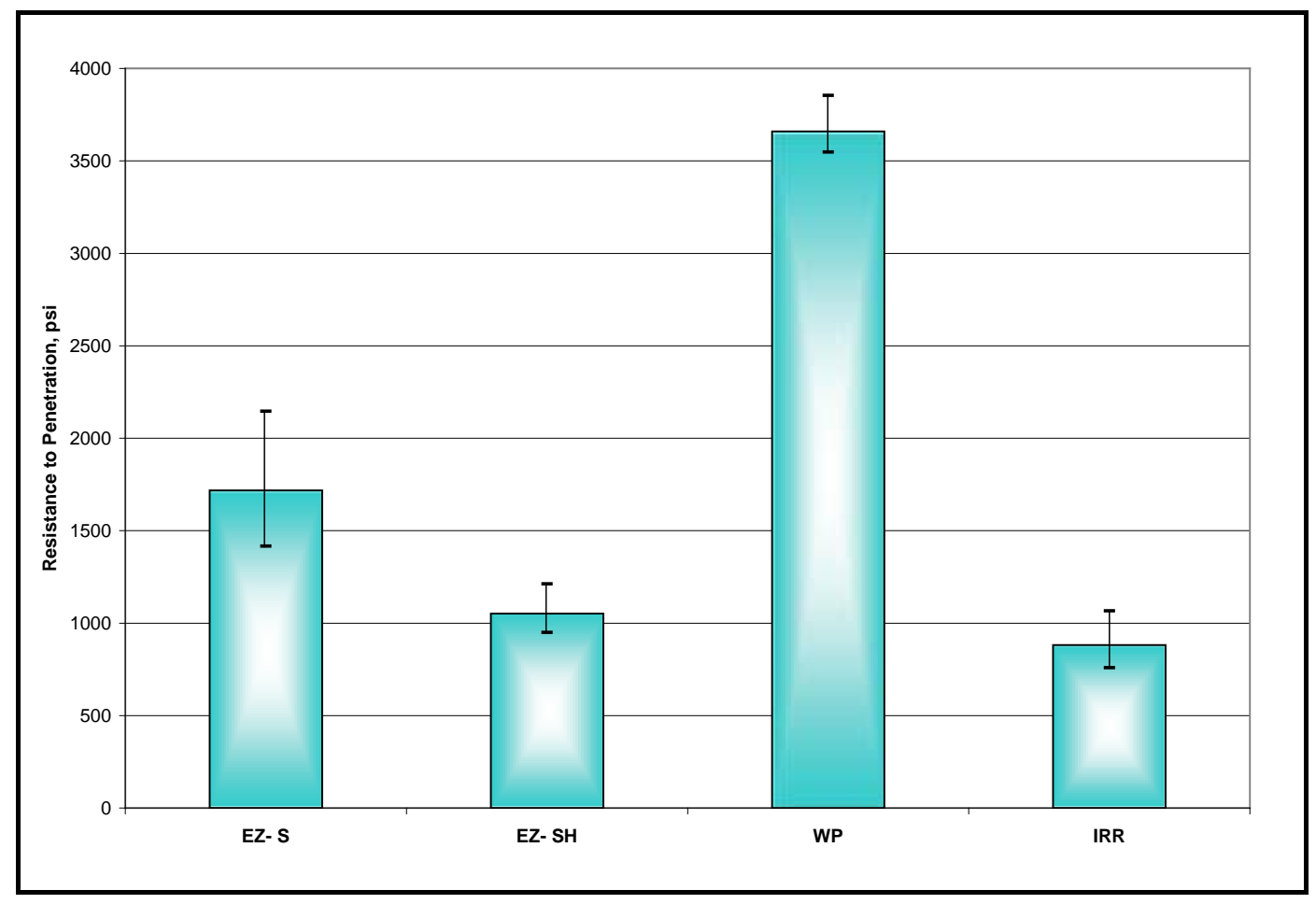

Figure 18 . Workability test results. 


\section{Field Testing}

A field evaluation was conducted to verify the laboratory results and to provide information regarding the placement and handling of cold patch asphalt repair materials. The top-performing products from the laboratory tests were selected for the field test. The products selected were Instant Road Repair (IRR), Wespro (WP), EZ-Street (EZS), and EZ-Street Hybrid (EZS-H). The next sections describe the test section, the repair preparation, the trafficking and, finally, the results of the field evaluation.

\section{Description of test section}

\section{Pavement}

The field test was conducted on a HMA pavement section located at the ERDC. The test section was originally designed to withstand 50,000 passes of a C-17 aircraft. The pavement structure consisted of $5 \mathrm{in}$. of HMA over 8 in. of limestone, 6 in. of stabilized clay gravel, 16 in. of clay gravel and, finally, the subgrade (Figure 19). The area selected for the test was located at the southeast corner of the HMA pavement section.

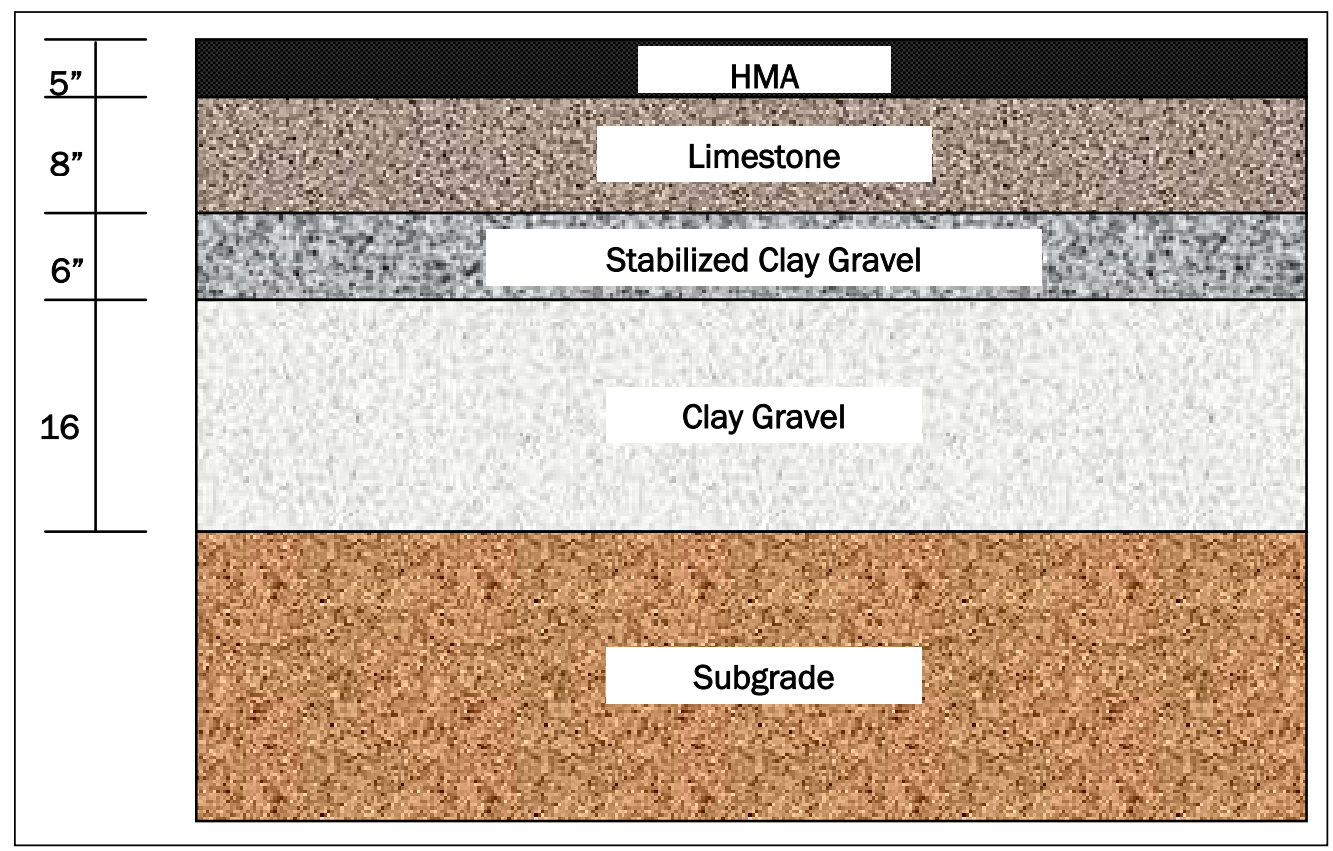

Figure 19. Pavement structure in the test section. 


\section{Repairs}

The test area consisted of four repairs, each $5 \mathrm{ft}$ long by $3 \mathrm{ft}$ wide by $5 \mathrm{in}$. deep (Figure 20). The repairs were prepared by cutting through the HMA surface with a dry-cut saw and clearing the debris. To determine the amount of material required to fill each hole, the total volume of each hole was calculated by measuring the average depth and multiplying it by the known repair area. Manufacturers' usage guides were consulted to calculate the amount of material required to fill each hole. Table 16 presents these amounts for each material. In general, the required amount of cold patch asphalt was three buckets or three bags per cubic foot of repair for all four products.

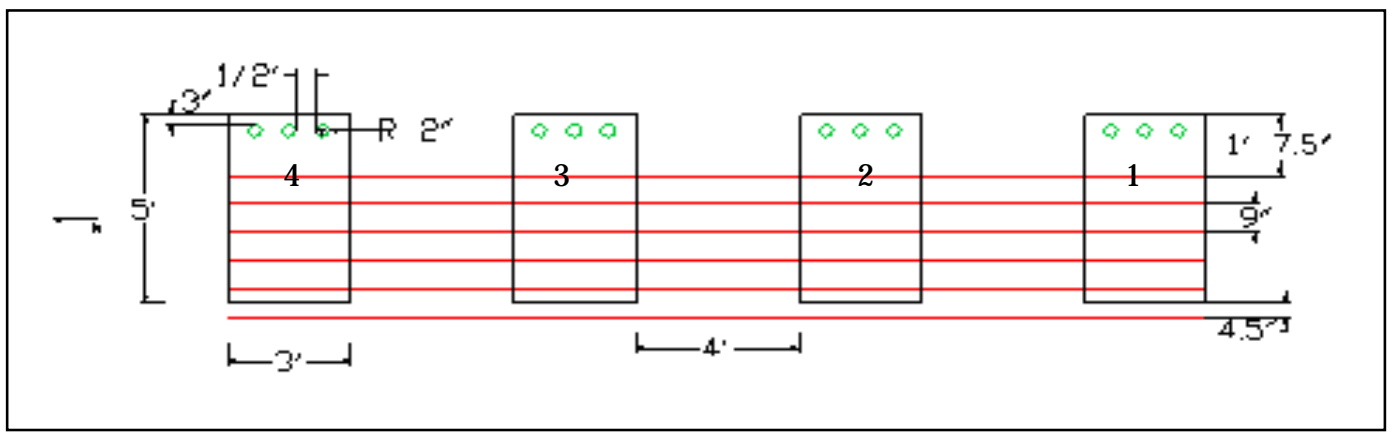

Figure 20. Test section details.

Table 16. Required amounts of each material to complete the repairs.

\begin{tabular}{|l|l|l|l|}
\hline Repair No. & Product & $\begin{array}{l}\text { Total Repair Volume } \\
\mathrm{ft}^{3}\end{array}$ & $\begin{array}{l}\text { Total Required Amount } \\
\text { of Material }\end{array}$ \\
\hline 1 & EZ-Street & 6.45 & 14.5 bags \\
\hline 2 & EZ-Street Hybrid & 6.29 & 14.5 bags \\
\hline 3 & Wespro & 5.80 & 13 buckets \\
\hline 4 & IRR & 6.26 & 14 buckets \\
\hline
\end{tabular}

\section{Repair material placement}

Manufacturer guidelines were followed in placing the products, to guarantee the correct repair technique. Before placing the materials, the holes were cleared of any debris or water, as recommended by the manufacturer. Material was placed straight from the manufacturer's packaging into the holes (Figure 21) and then was compacted in two 2-in.-deep layers. A rake was used to uniformly distribute the material (Figure 22). 


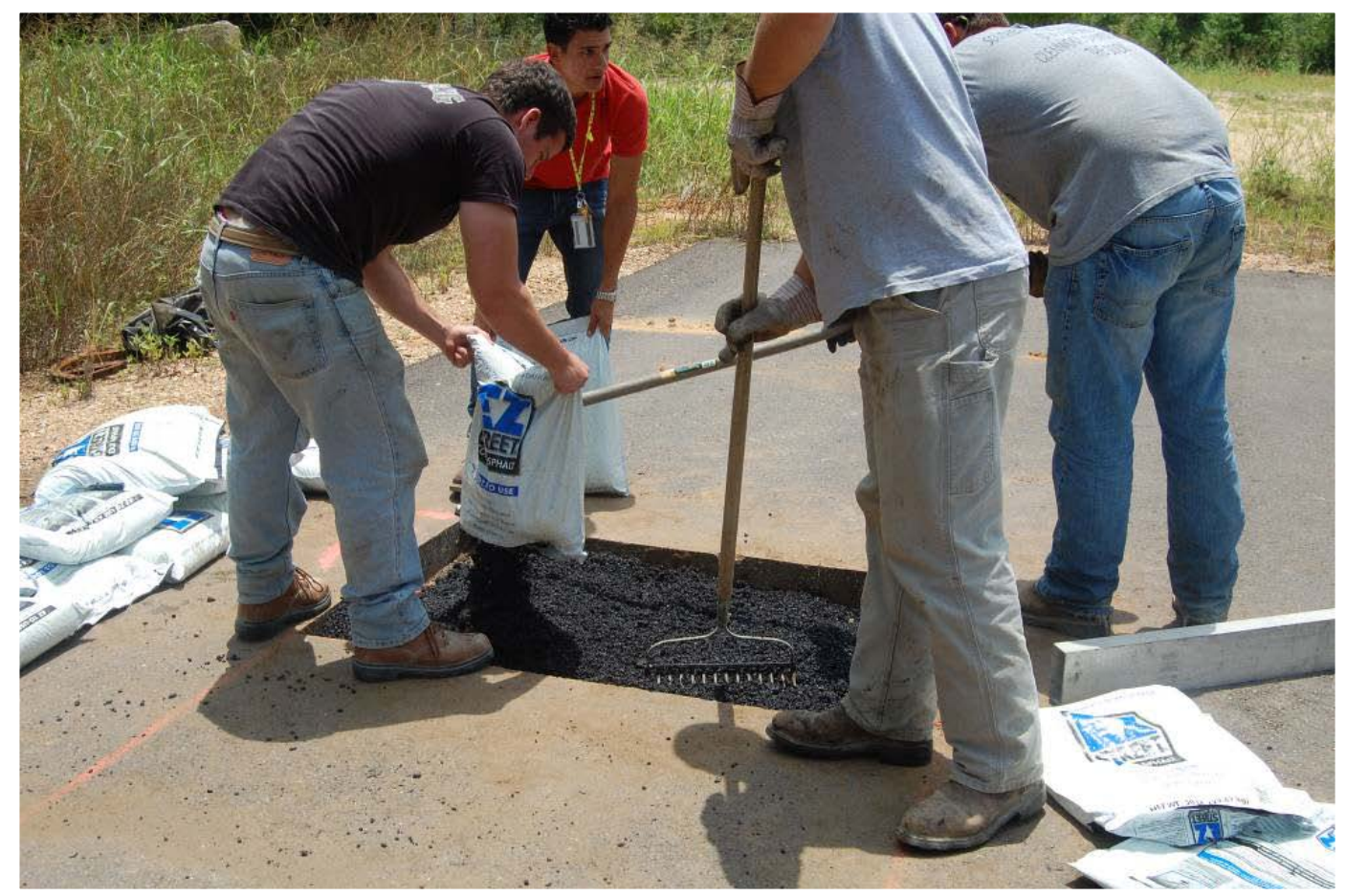

Figure 21. Material placement.

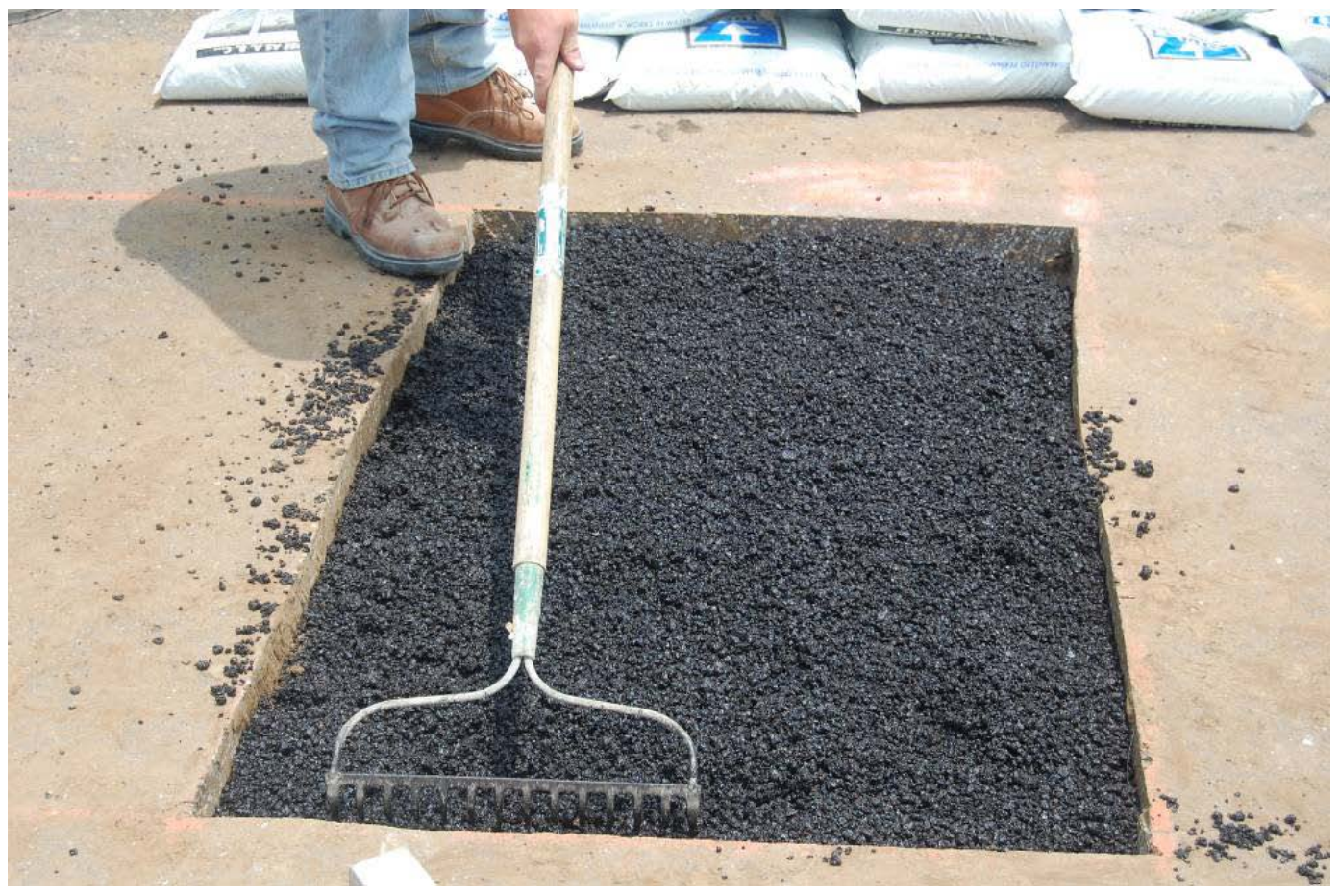

Figure 22. Spreading of the material. 
Compaction consisted of using a plate compactor and a pneumatic tamping compactor, which was representative of the equipment to be used in an expedient pavement repair operation, i.e., trafficable repair in a minimal amount of time. However, a roller would have provided better compactive efforts and higher densities.

For each repair, the first lift of material was compacted initially with several coverages of the pneumatic tamping compactor with a 5-in. circular head (Figure 23). The remaining compaction of the first lift was accomplished with about 10 to 12 coverages with a vibratory plate compactor (Figure 24). The second lift was compacted by using only the vibratory plate compactor. Material placement and compaction was performed one day, and the products were trafficked the next day.

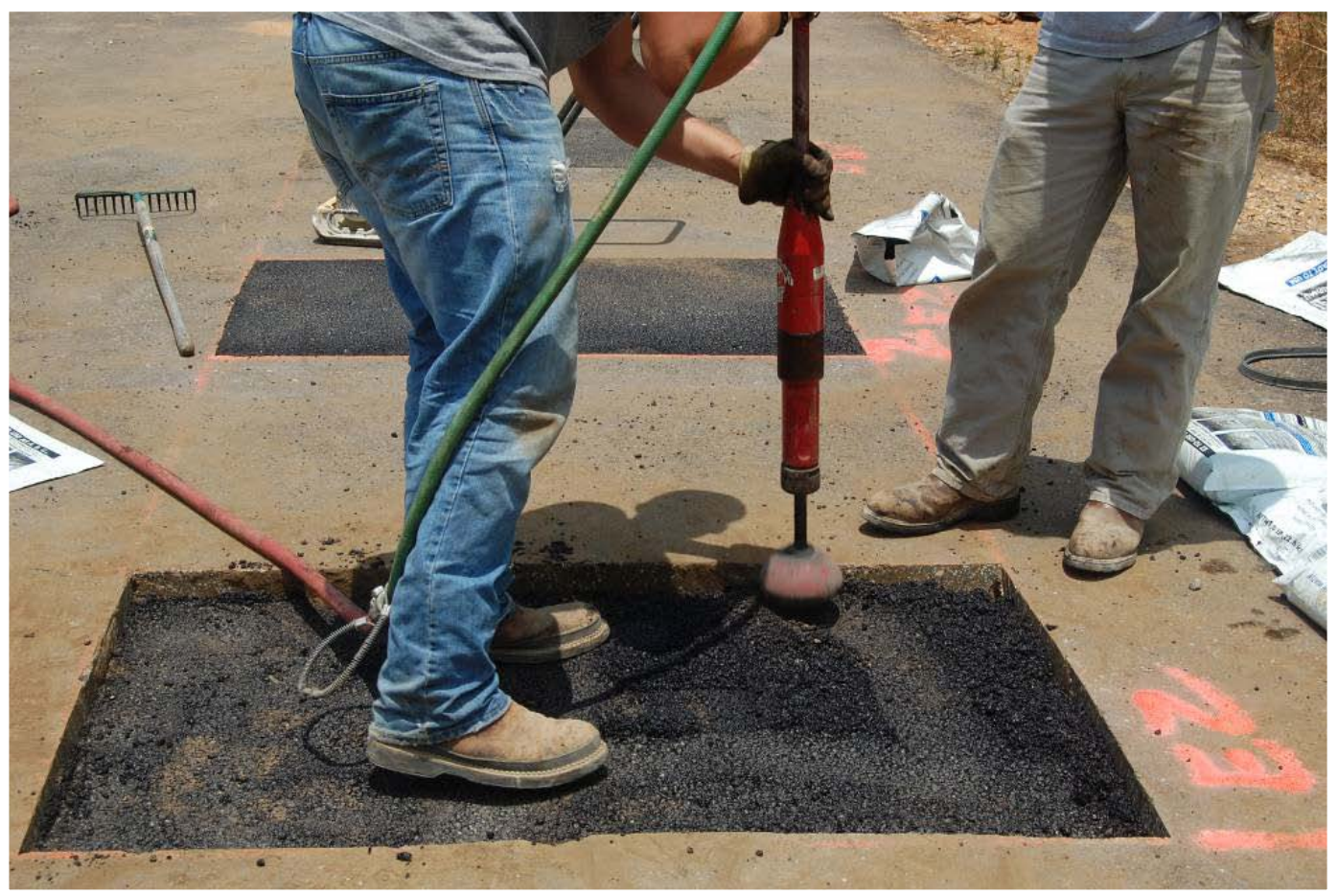

Figure 23. Pneumatic tamping compactor with a 5-in. circular head.

The first product placed was Instant Road Repair at an approximate air temperature of $86^{\circ} \mathrm{F}$. Seven buckets of the product per lift were used to complete the repair, which was completed in $1 \mathrm{hr}$. The second product was Wespro, and it was placed at an air temperature of $87^{\circ} \mathrm{F}$. The repair required 13 buckets of the product, 5 in the first lift and 8 in the second lift. This repair was completed in $30 \mathrm{~min}$. The next product was EZ-Street Hybrid, and it was placed at an air temperature of $90^{\circ} \mathrm{F}$. In this case, 14.5 bags of the 


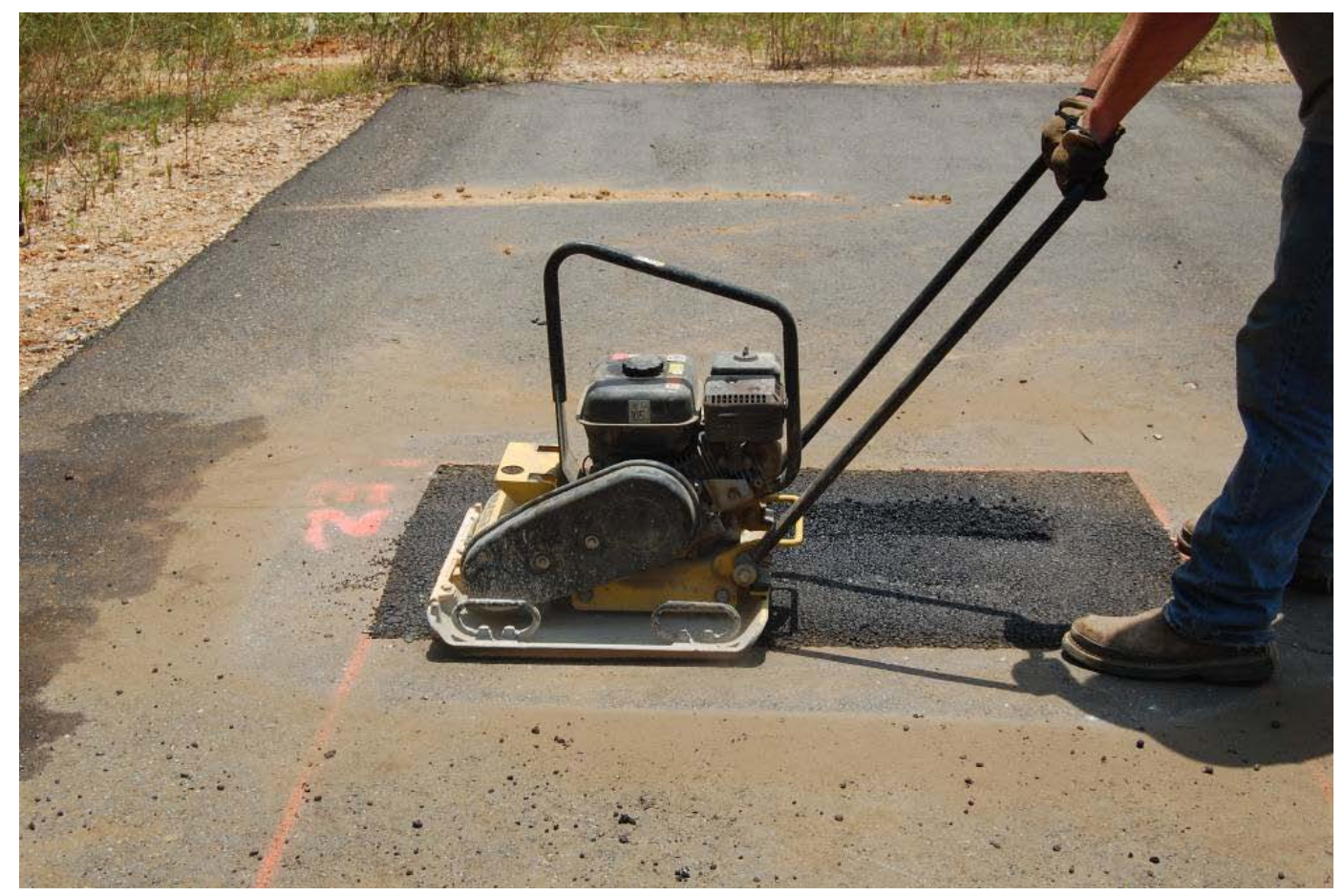

Figure 24. Vibratory plate compactor.

product were used, 7 for the first lift and 7.5 in the second lift. The last product was EZ-Street, and it was placed when the air temperature was $97^{\circ} \mathrm{F}$. At total of 14.5 bags of the product were used, 7 for the first lift and 7.5 for the second lift. Completion of the repairs with EZ-Street Hybrid and EZ-Street required 30 and $20 \mathrm{~min}$, respectively. The same compaction procedure was followed for each repair; however, maximum material compaction was achieved in less time as the air temperature increased from $86^{\circ} \mathrm{F}$ to $97^{\circ} \mathrm{F}$.

The testing plan called for taking at least three cores from each repair to determine more accurately the initial air voids content and compaction density. However, it was not possible to obtain uniform core samples (as shown in Figure 25). This could have been attributed to a cold mix issue such as low laboratory air voids or a low field density issue. No measurements of the initial air voids were available, and initial compaction could not be determined more accurately. However, density measurements were taken with a nuclear gauge to have an estimate of the in situ density of the materials after compaction (Figure 26). These measurements are presented in Table 17. 


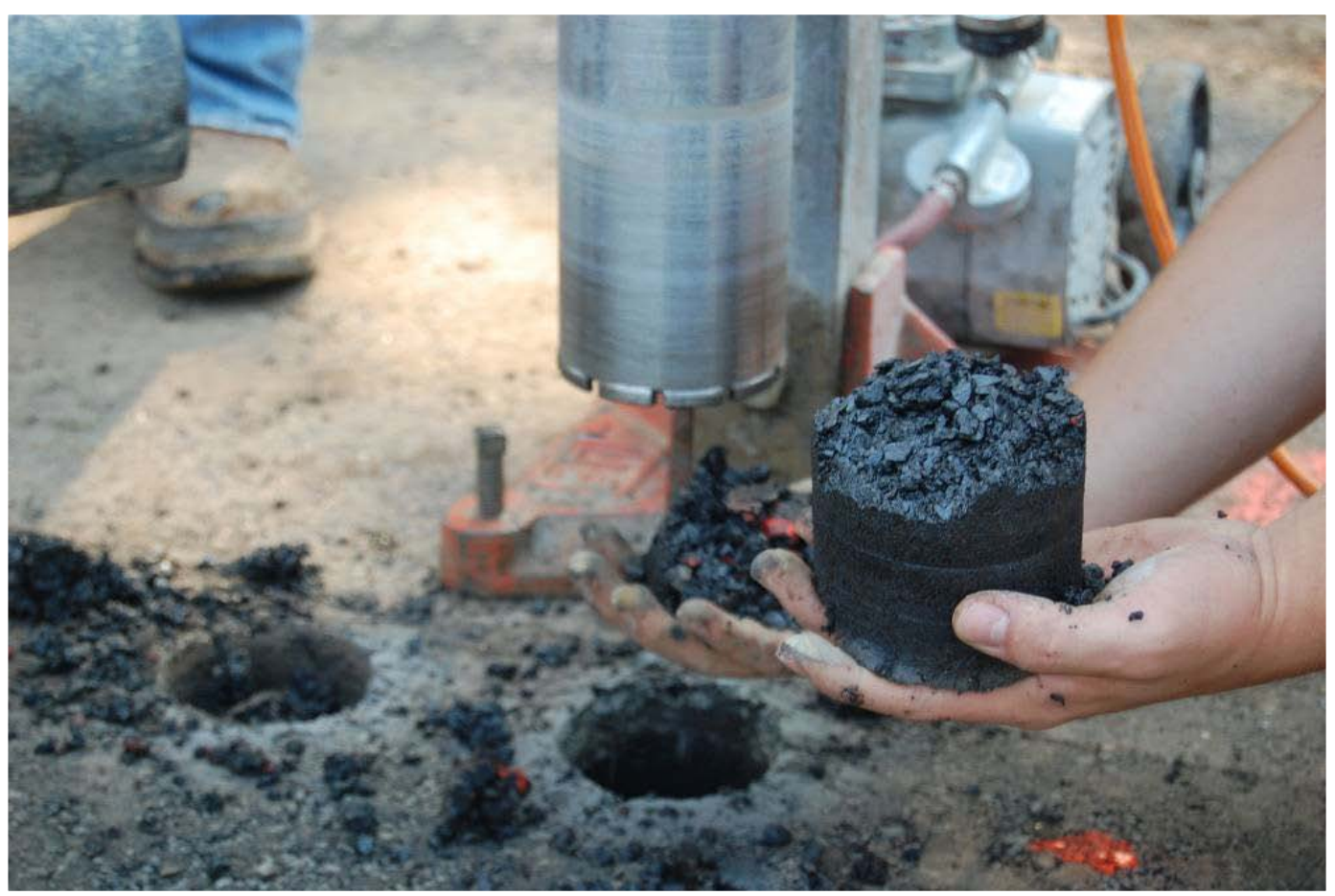

Figure 25. Core sample falling apart due to high air voids in the mix.

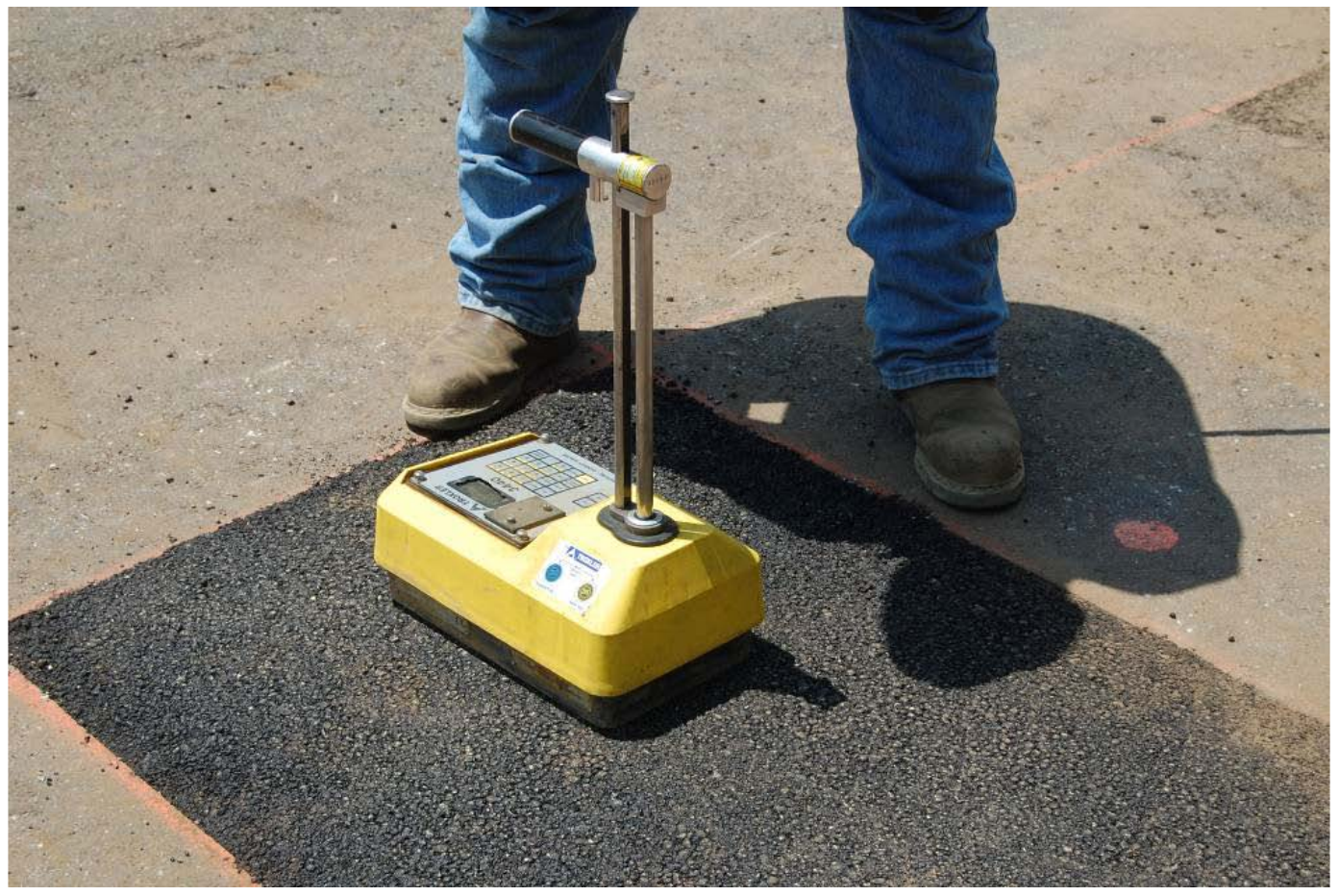

Figure 26. Nuclear gauge. 
Table 17. Nuclear gauge density measurements.

\begin{tabular}{|l|l|l|l|}
\hline Repair No. & Product & Wet Density, pcf & Dry Density, pcf \\
\hline 1 & EZ-S & 131 & 120 \\
\hline 2 & EZ-SH & 124 & 117 \\
\hline 3 & WP & 149 & 139 \\
\hline 4 & IRR & 134 & 128 \\
\hline
\end{tabular}

\section{Traffic operations}

\section{Load cart}

A specially designed single-wheel load cart was used to simulate F-15E aircraft traffic. This load cart is equipped with a 36-in.-diam, 11-in.-wide, 18-ply tire inflated to $325 \mathrm{psi}$ and loaded so that the single test wheel supported 35,235 lb. The load cart is powered by the front half of a U.S. Army 2.5-ton transport truck with an outrigger wheel to prevent overturning. The truck portion of the cart was used only for steering. Figure 27 shows the load cart used for the field evaluation.

\section{Distribution patterns}

The distribution pattern of the F-15 traffic simulation is shown in Figure 28. The normally distributed traffic patterns were simplified for ease-of-use by the load cart operator. Trafficking consisted of driving the load cart forward and then backward in the same wheel path, then moving laterally approximately the tire width ( 9 in.). Each traffic pattern consisted of 16 passes, and the objective was to achieve a minimum of 100 passes over each repair before failure or $1 \mathrm{in}$. of measured rut depth. The air temperature during traffic was around $97^{\circ} \mathrm{F}$.

\section{Results}

After compaction, all the products were allowed to cure for approximately $24 \mathrm{hr}$ before trafficking. During trafficking, deterioration of the repaired surface was monitored to document damage and mode of failure. Rutting measurements were taken by measuring the maximum rut depth using a straight edge. A surveyor's level was used to measure permanent deformation. Permanent in situ deformations were measured by determining the difference between the initial and final profiles. 


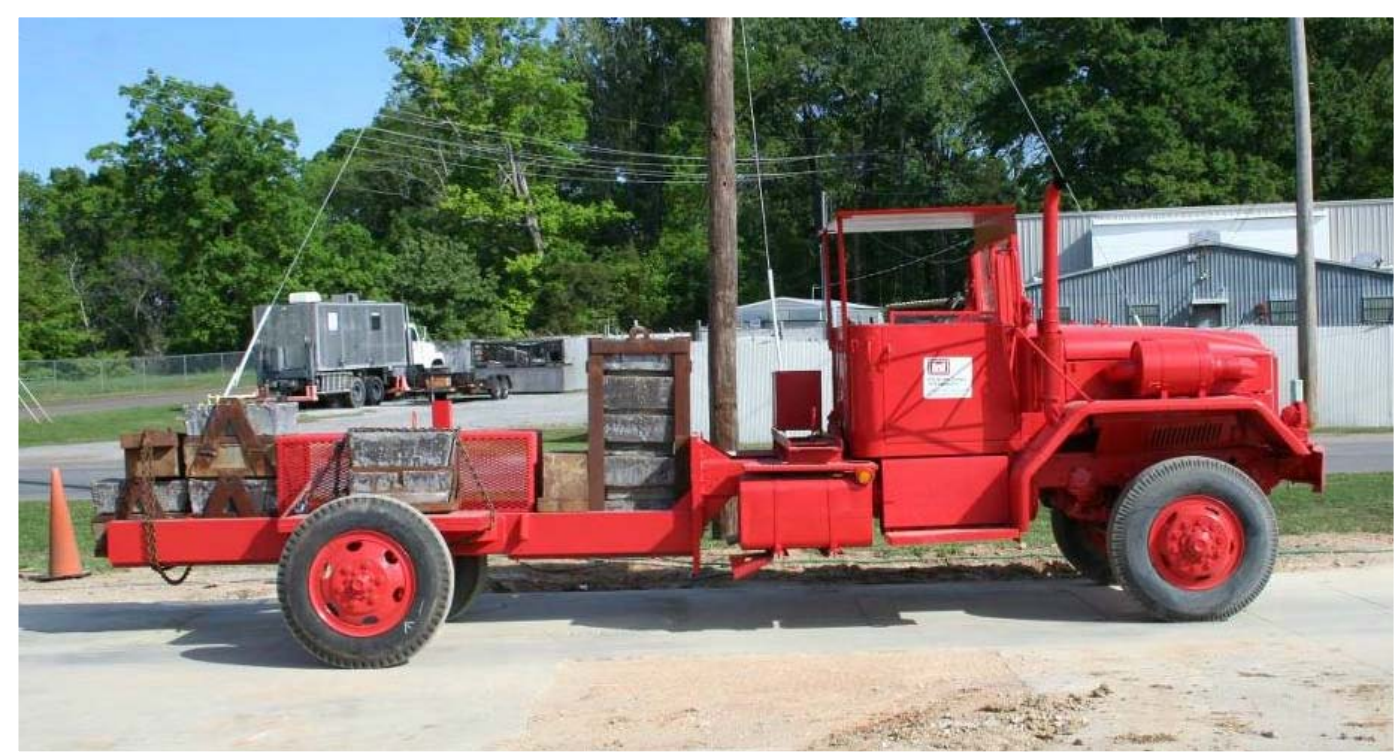

Figure 27. F-15E load cart.

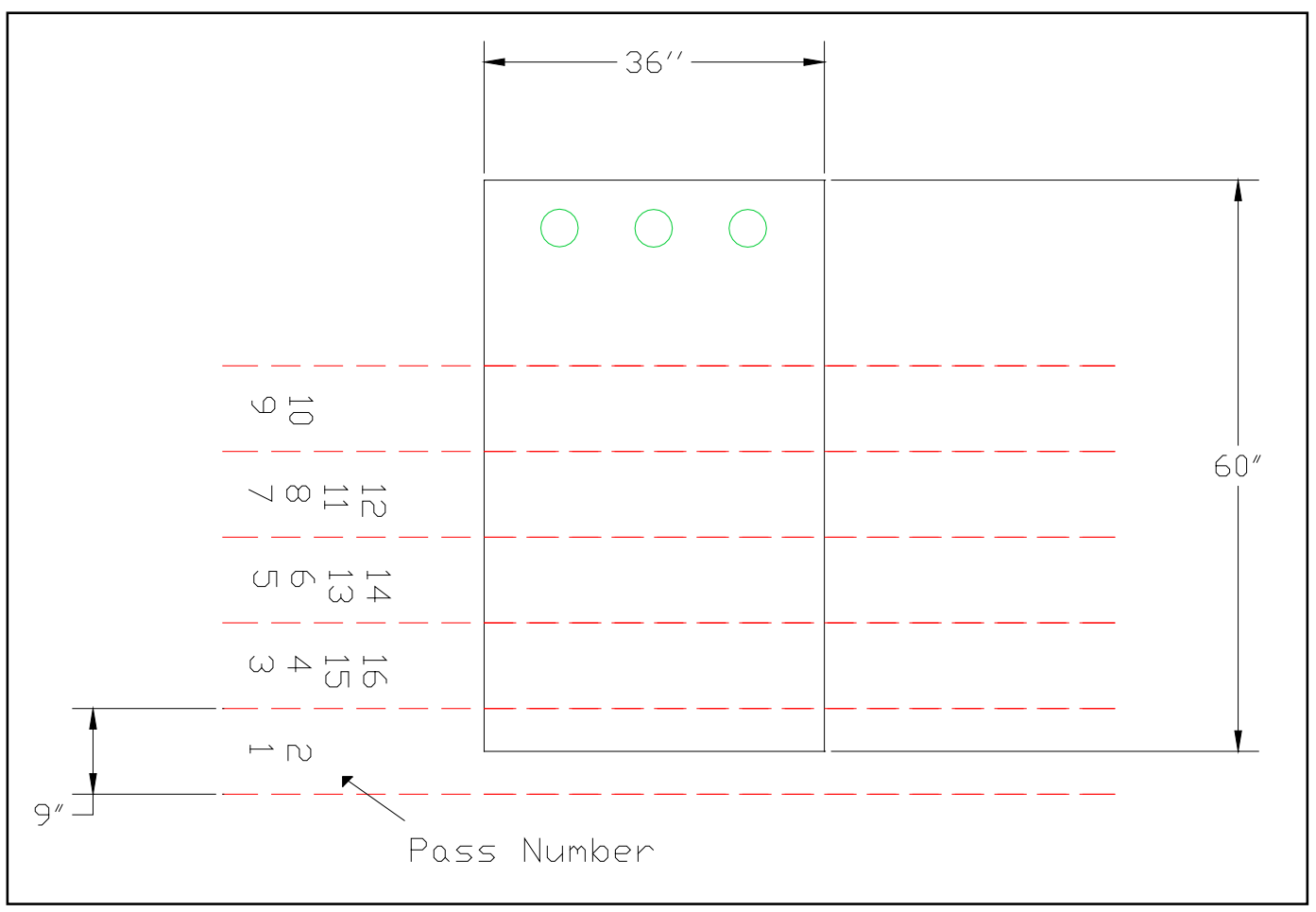

Figure 28. Traffic pattern.

The cross sections showing the original surface and the permanent deformation along the repair section after products were subjected to 16 passes of the F-15 aircraft load cart are presented in Appendix B.

During the initial alignment of the load cart in the traffic lanes, one of the front wheels of the truck ran over the EZ-Street Hybrid repair area during 
a turn. While the wheel was turning and moving at the same time, the material in the repair was dragged by the wheel, causing some of the material to loosen, as shown in (Figure 29). This surface failure gave an indication of a mode of failure that could be expected from this material when subjected to traffic. Also, this failure could have been a product of low compaction or inadequate cohesion of the mix. Table 18 presents the amount of compaction obtained for each repair determined as a percentage of bulk density of laboratory compacted samples. Compaction for EZ-Street Hybrid was low and, in this case, could have been caused by poor compaction procedures or problems with the mix, such as low amount of fines or poor bonding between the aggregates and the asphalt binder. Low compaction was also observed for EZ-Street with $92 \%$ of laboratory density.

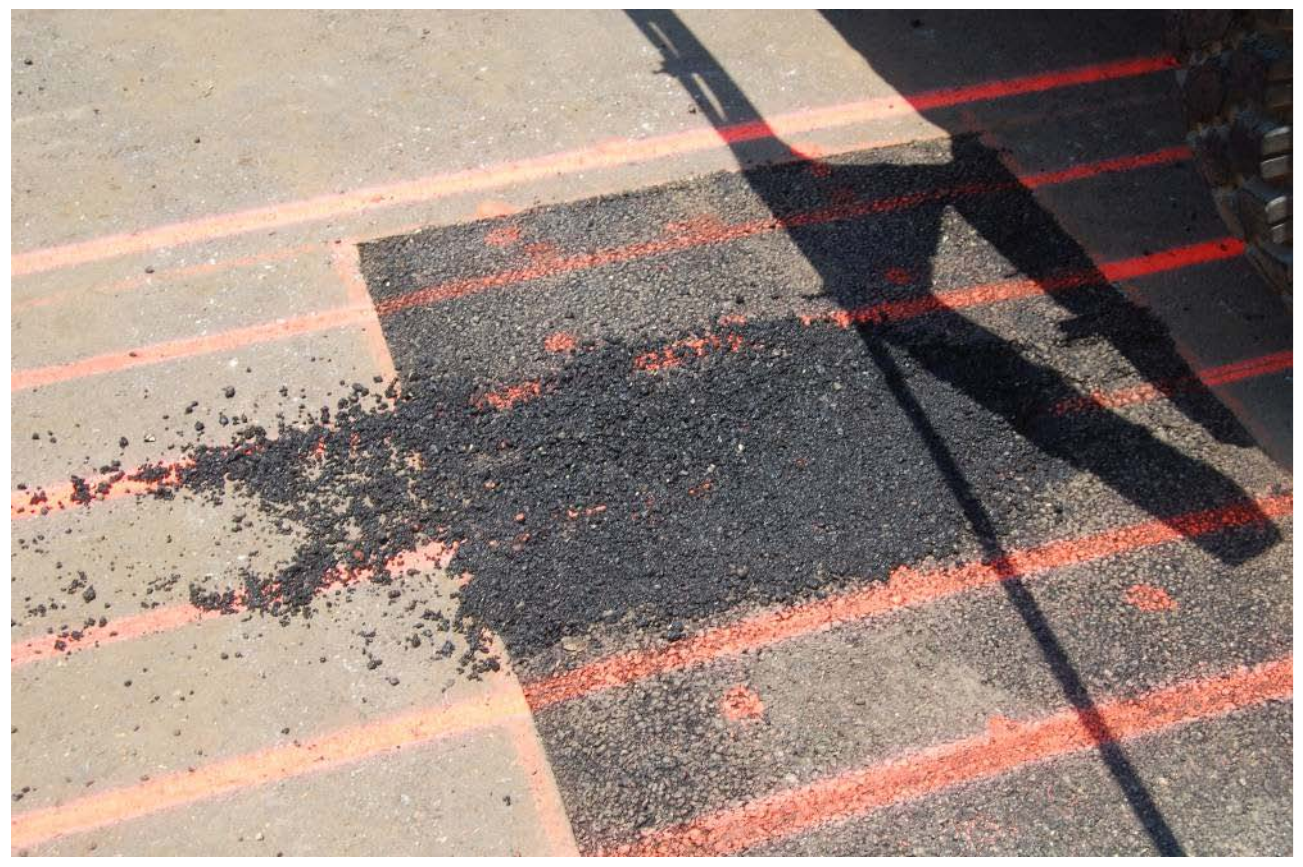

Figure 29. Damage in the EZ-Street Hybrid product.

Table 18. Field compaction.

\begin{tabular}{|c|c|c|c|c|}
\hline \multirow[b]{2}{*}{ Material } & \multicolumn{2}{|l|}{ Laboratory } & \multicolumn{2}{|l|}{ Field } \\
\hline & Bulk Density, pcf & \% Air Voids & $\begin{array}{l}\text { Field Density } \\
\text { pcf }\end{array}$ & $\begin{array}{l}\text { Compaction } \\
\text { (Percentage of } \\
\text { Bulk Density) }\end{array}$ \\
\hline Instant Road Repair & 135.2 & 11 & 134.2 & 99 \\
\hline Wespro Hybrid & 156.6 & 5 & 148.9 & 95 \\
\hline EZ-Street Hybrid & 133.2 & 10 & 123.8 & 93 \\
\hline EZ-Street & 142.7 & 3 & 130.7 & 92 \\
\hline
\end{tabular}


After the first three passes, each of the repairs exhibited large deformations causing significant rutting along the first traffic lanes (Figure 30). This rutting continued in all lanes during the test and, because of excessive deformations, only one pattern of 16 passes was completed for each repair. The products failed due to two conditions: a rut depth greater than 1 in. and a significant amount of loose material. The bonding between the binder and the aggregates was not strong enough to hold the aggregate in place during traffic loading. For airfield use, loose material represents high FOD potential and was therefore considered as a failure mode. The product for which the lowest amount of loose material was observed was Instant Road Repair.

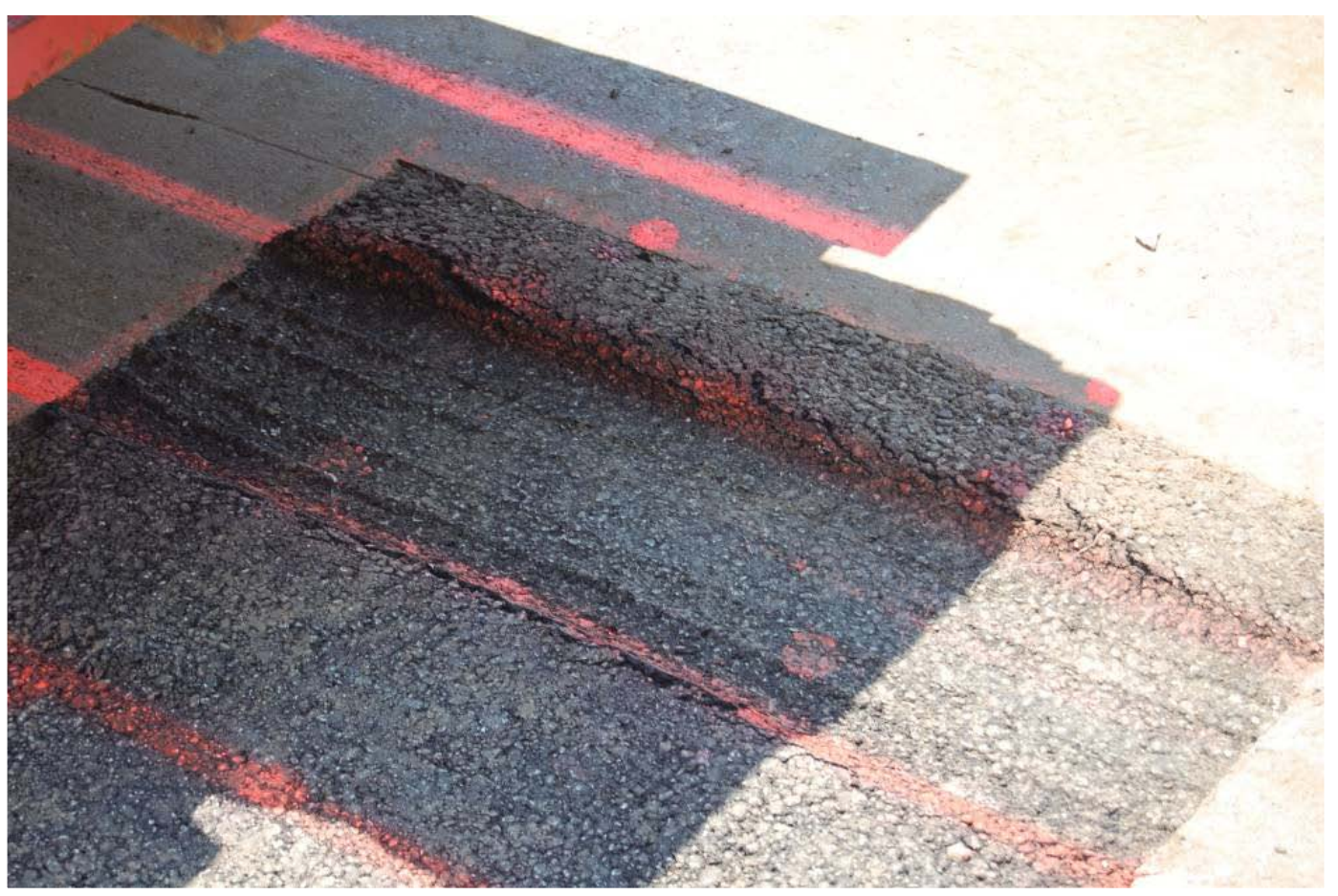

Figure 30. Deformation after the third pass over Instant Road Repair.

Table 19 shows the permanent deformation, the maximum rut depth measured after 16 passes, and the rutting severity for each repair. Rutting severity was categorized according to the UFC 3-270-06. All products had a high-severity rutting. EZ-Street Hybrid was the product with the least depth of rutting, and Wespro was the product with the greatest depth. These field observations agree with the results from the dynamic creep tests, where EZ-Street Hybrid was the product with the smallest deformations and Wespro the one with the largest. 
Table 19. Field test observations.

\begin{tabular}{|c|c|c|c|c|c|c|c|}
\hline Patch & Product & $\begin{array}{l}\text { Load } \\
\text { Cart }\end{array}$ & $\begin{array}{l}\text { Load } \\
\text { kips }\end{array}$ & Passes & $\begin{array}{l}\text { Permanent } \\
\text { Deformation }{ }^{1} \\
\text { in. }\end{array}$ & $\begin{array}{l}\text { Max. Rut } \\
\text { Depth² } \\
\text { in. }\end{array}$ & $\begin{array}{l}\text { Rutting } \\
\text { Severity }\end{array}$ \\
\hline 1 & EZ-Street & \multirow{4}{*}{ F-15E } & \multirow{4}{*}{35.3} & \multirow{4}{*}{16} & 1.32 & 2.50 & High \\
\hline 2 & EZ-Street Hybrid & & & & 0.48 & 1.75 & High \\
\hline 3 & Wespro & & & & 2.88 & 3.75 & High \\
\hline 4 & Instant Road Repair & & & & 0.72 & 2.25 & High \\
\hline
\end{tabular}

1 Permanent deformation was measured as the difference between initial and final profiles from rod and level measurements.

2 Maximum rut depth measured with straight edge after 16 passes.

In the case of EZ-Street Hybrid, the significant amount of loose material was also identified as a failure mode. It was considered that this amount of loose material would be significant enough to prevent any aircraft operation on an airfield due to the FOD potential that it could represent. The repair failures are shown in Figure 31- Figure 35.

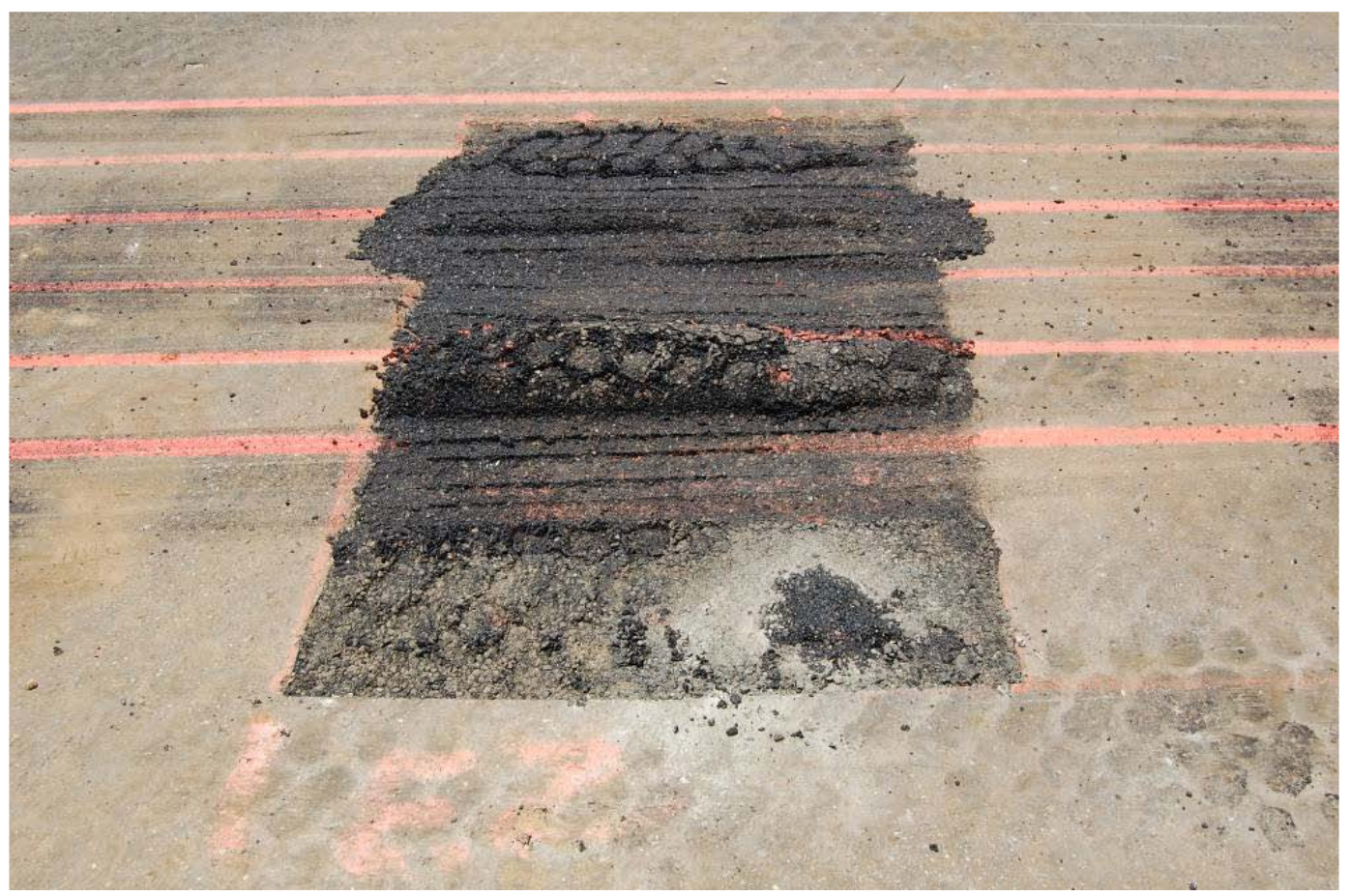

Figure 31. Failure in repair $1 \mathrm{EZ-Street.}$ 


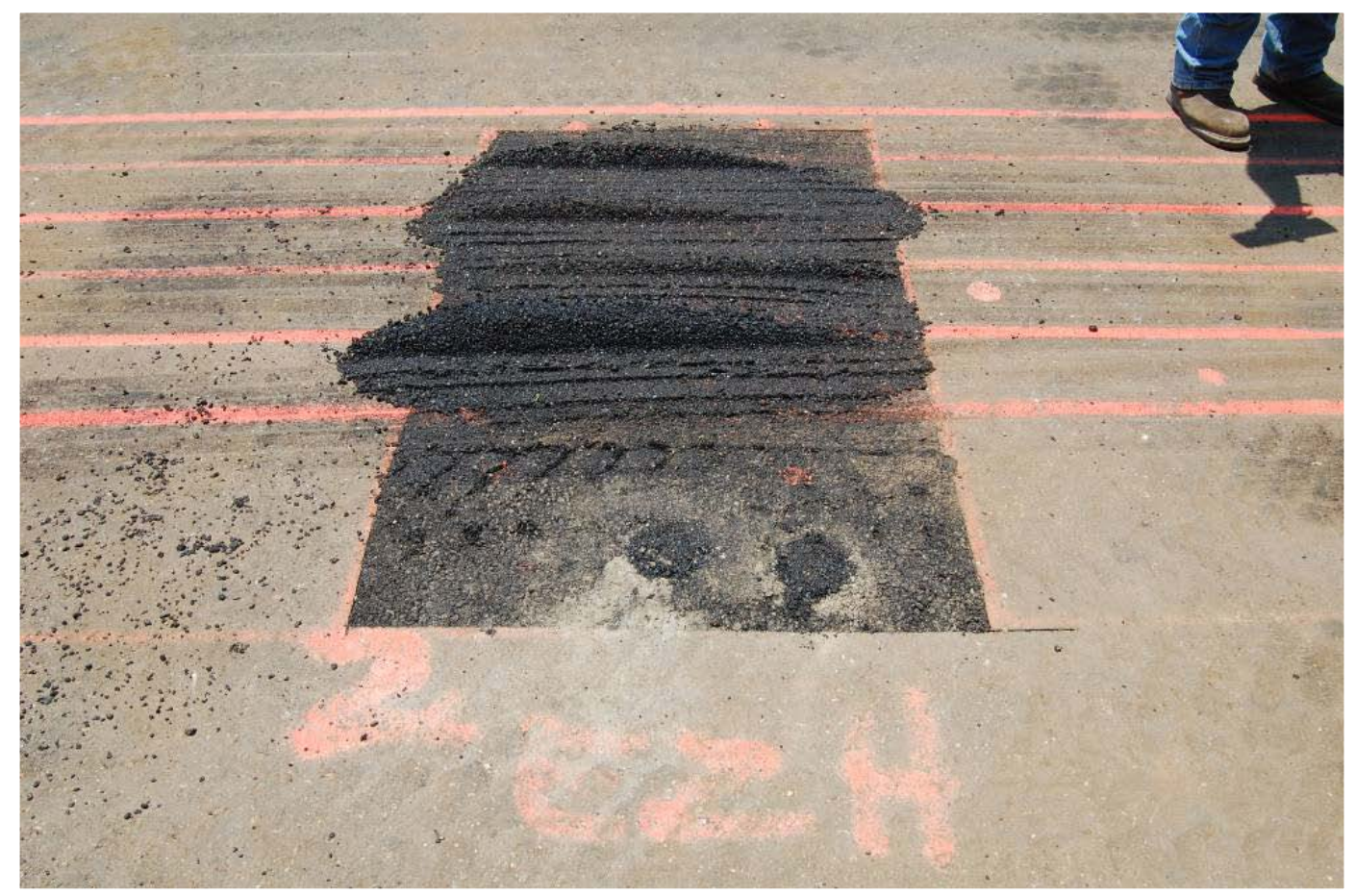

Figure 32. Failure in repair 2 EZ-Street Hybrid.

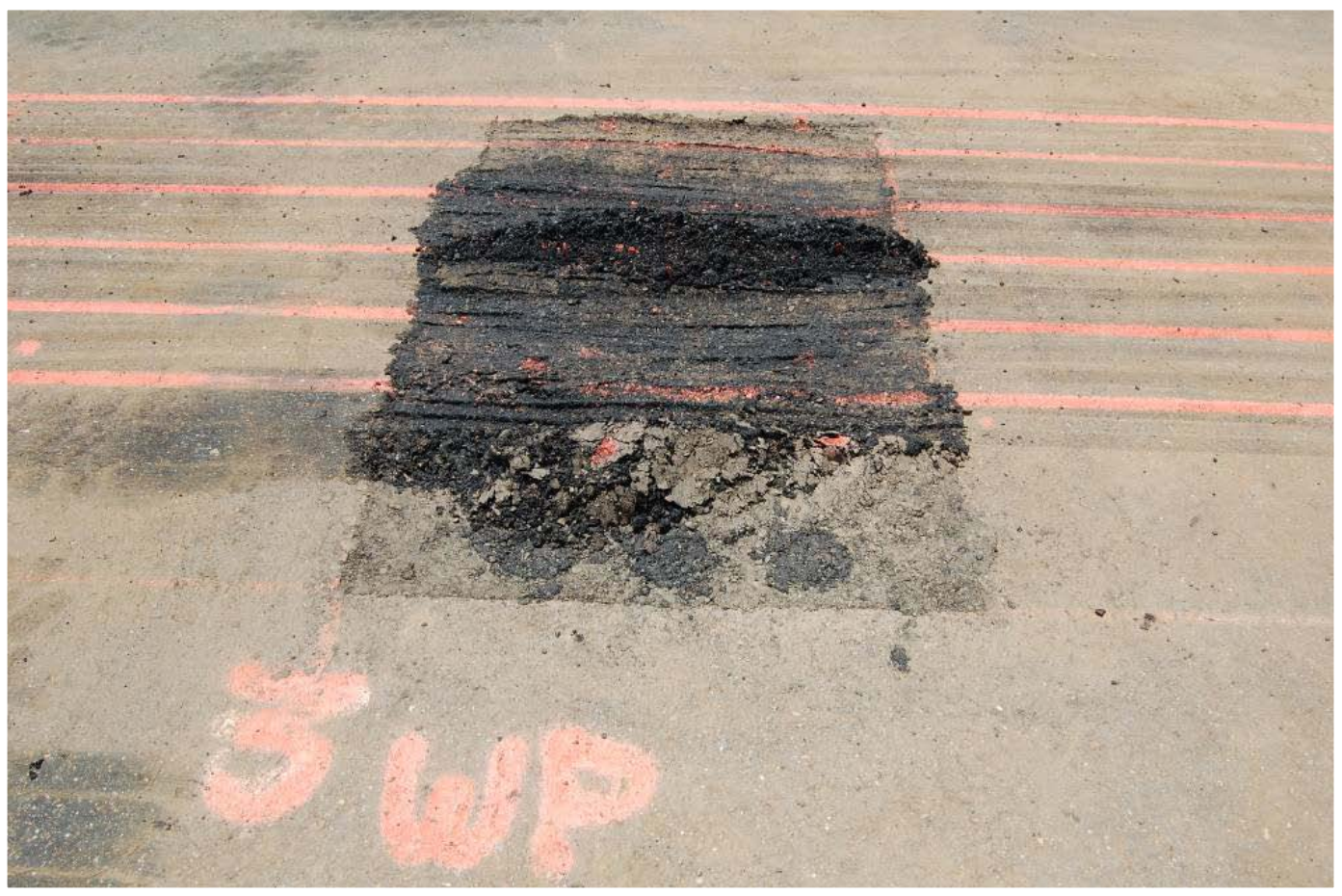

Figure 33. Failure in repair 3 Wespro. 


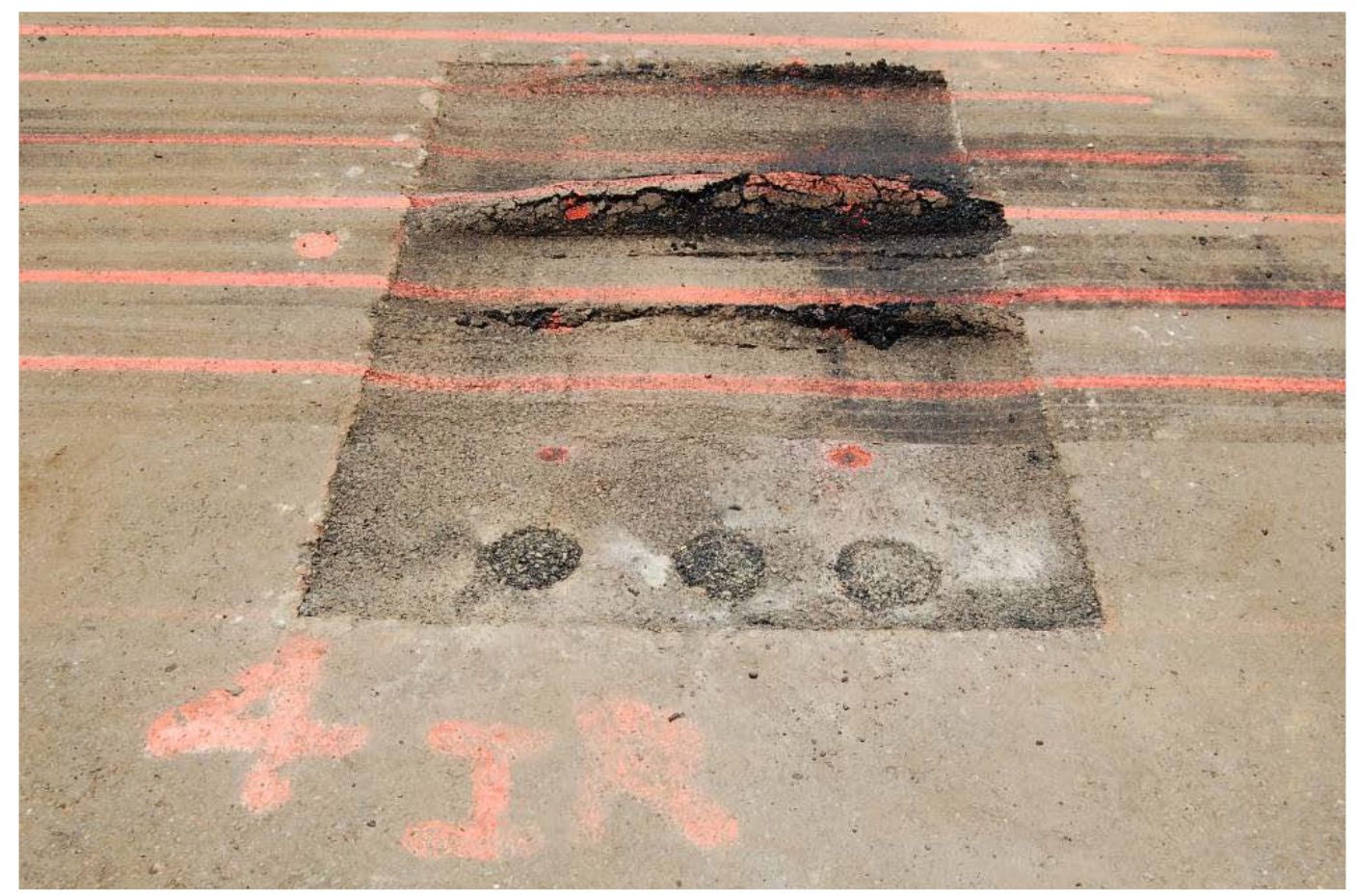

Figure 34. Failure in repair 4 Instant Road Repair.

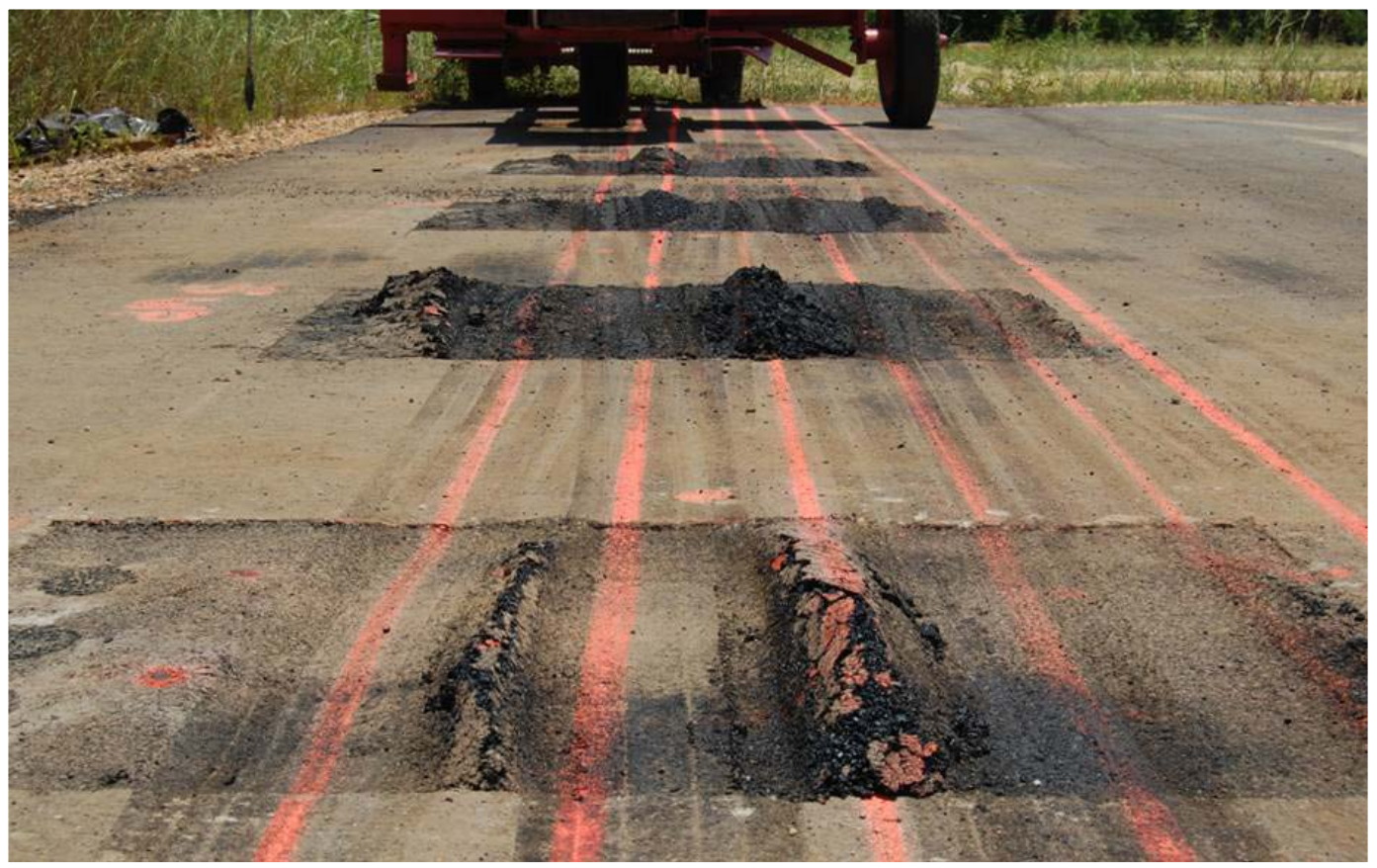

Figure 35. Overall photo of the repairs after 16 passes. 


\section{Laboratory Tests for Certification Test Protocol}

A suite of laboratory tests was conducted on cold patch asphalt repair products to evaluate material properties and performance. The ability of these tests to predict performance was also evaluated with the objective of developing a test protocol for certifying the use of these materials in asphalt repair of airfield pavements. Laboratory performance tests included static creep, repeated loading or dynamic creep, moisture susceptibility test, and workability test.

\section{Static creep test (flow time)}

The static creep test consisted of applying a static constant load to the specimens until tertiary flow occurred. At the beginning of the test, a confining pressure of 10 psi was applied to the specimens, then a preload stress of 5 psi was applied for $60 \mathrm{sec}$, and finally a deviator stress of 90 psi was applied. From the static creep test, a flow time (in seconds) and the permanent deformation are determined - to predict the amount of rutting that a pavement will experience in the field under traffic. But, since the load is static, this test could probably better represent the type of the loading condition that would exist in a parking apron for an airfield. However, parking apron pavements are commonly constructed of portland cement concrete.

A study conducted at the Auburn University by Gabrielson (1992) disregarded the static creep tests for performance prediction of HMA due to large variability and low strain levels that were not indicative of in situ levels. Results from this test on cold patch materials showed a significant range of variability between tests on specimens from the same mix. (The C.V. ranged from $66 \%$ to $96 \%$.) Test results were not consistent enough to be used to draw conclusions regarding the performance behavior of the cold patch materials under static creep loading. Furthermore, this test is not very representative of critical loading conditions in an airfield for a flexible airfield pavement. Therefore, the static creep test was not recommended for inclusion in a test protocol to certify cold patch products for airfield pavement repairs. 


\section{Dynamic creep test (flow number)}

The same input parameters used for the static creep test were used for the dynamic creep test, but in this case the load was applied repeatedly by using a haversine pulse width of $0.1 \mathrm{sec}$ and 0.9 -sec dwell (rest period). This test was conducted to determine the number of cycles of repeated creep loading that each cold mix specimen could withstand before experiencing shear deformation.

Results from the dynamic creep test on cold patch materials were less variable than results from the static creep test. (The C.V. ranged from $12 \%$ to $66 \%$ ). The test method is more representative of the critical loading conditions in flexible pavements in taxiways and runways. In these airfield areas the pavement is subjected to repeated loading and, if traffic is mostly heavy aircraft with high tire pressures, rutting is a major concern. However, the data obtained from the products evaluated did not produce good relationships that could be used to predict rutting from laboratory tests results. The variability still affected the data, and acceptable relationships between laboratory strain and rutting were not achieved.

Literature confirms that this test tends to be a better predictor of the performance of asphalt mixes than under creep loading. Identifying a laboratory test that better predicts performance of a mix with regard to deformation (rutting) has been the primary objective of several studies in the past. Gabrielson (1992) concluded that, compared with the static creep test, the repeated load test configuration predicted better in situ permanent deformations.

This test was recommended for a test protocol to certify the use of cold patch products in airfield pavements.

\section{Durability test (moisture susceptibility)}

This test was used to determine the potential for moisture damage and to determine the effectiveness of the antistripping agents in the cold mixes under critical moisture conditions. Results from this test could be used to predict long-term stripping susceptibility of the cold patch mixes. However, the purpose of this project was to evaluate cold patch asphalt materials for temporary pavement repairs. The goal was to get at least 100 passes of the F-15 load cart after repairing a pavement with these materials in a minimal amount of time. In this case, durability is not a concern. Another use of this 
test is to determine if the products are suitable for application in wet conditions (that is, to repair a pothole filled with water).

On average, it was observed that moisture conditioning reduced the tensile strength of the cold patch mixes evaluated by more than $50 \%$. This shows that these materials were very likely to have durability problems. The tensile strength reduction after water conditioning could be attributed to the quality of the aggregate or the compatibility of the asphalt cement and aggregate.

The moisture susceptibility test is very important for identifying durability issues with asphalt mixes. However, durability issues are not a concern for temporary pavement repairs (at least 100 passes of F- 15 required). The test could be included in a test protocol developed for certification of cold patch mixes for use in airfield pavement repairs, but it would not be a requirement.

\section{Workability test}

The workability test was conducted to determine the amount of effort that would be required to properly construct a repair with each cold patch mixture. The test method consisted of compacting and freezing the samples prior to testing for penetration. The workability, as defined, is directly related to the penetration of a specially designed blade into the mix. That is, the higher the penetration the more workable the material becomes.

Some variability was observed in the results from this test, and it was attributed to the likelihood that the results were affected by initial material conditions and test temperature (in this case, $14^{\circ} \mathrm{F}$ ). For example, two products (EZ-Street and Wespro) initially contained excess moisture in the mix that was apparently a result of poor quality control during packaging. This moisture could have influenced the results of the workability test as the excess water could have frozen at $14^{\circ} \mathrm{F}$, creating ice lenses with a very high resistance to penetration. The susceptibility of having this type of problem can be seen as one disadvantage of using a test method that involves freezing the samples prior to testing. However, so far this is the only test method that has been developed to evaluate the workability of cold patch asphalt mixes. 
There are various methods to evaluate the workability of asphalt mixes by simple observation in the field. These methods are useful for construction purposes but not to establish a test protocol for material acceptance.

The same parameters that have been evaluated for determining the workability of HMA should be considered when developing new methods to evaluate the workability of cold patch mixes, especially aggregate quality and binder type.

Methods that have been developed for HMA should be appropriately adapted and evaluated to determine their ability to predict workability of cold patch asphalt mixes. A good example to consider would be the test method developed by Gudimettla et al. (2003) which consisted of immersing a paddle into a sample of HMA and measuring the torque required to keep the paddle rotating at a constant speed within the sample. The workability was defined as the inverse of the torque required to rotate the paddle within the sample of HMA. 


\section{Conclusions and Recommendations}

The ERDC conducted laboratory and field tests on several COTS cold patch asphalt repair products to determine if they are suitable for airfield pavement repairs. Testing included a suite of material property tests that were compared with results from small-scale field tests. Laboratory tests included determination of maximum theoretical specific gravities, compaction density, durability, workability, static creep, and dynamic creep. The field evaluation consisted of four repairs that were trafficked $24 \mathrm{hr}$ after compaction under controlled traffic conditions to determine the ability of the repairs to support the gross load of an F-15 aircraft. Both the laboratory and full-scale traffic tests were conducted at the ERDC in Vicksburg, MS, from May to J uly 2009.

Relevant conclusions from the laboratory and field testing are noted below. Recommendations for improving the cold patch mixes to meet minimum performance criteria are also provided below.

\section{Conclusions}

The following conclusions were derived from the evaluation of cold patch asphalt repair materials:

- The poor performance of the cold mixes evaluated in this project showed that these materials are not suitable for asphalt repairs on airfield pavements, especially in heavy traffic areas or areas mainly trafficked by high-tire pressure aircraft, such as the F-15E.

- There were wide ranges of maximum theoretical specific gravity, bulk density, and air voids between the products evaluated, making it difficult to establish threshold properties for product acceptance. These wide ranges also caused test results to be dispersed enough that developing performance predictions based on laboratory testing is difficult.

- The static creep test had a significant variability compared with the dynamic creep test. The latter test seems to be a more consistent and representative method of predicting in situ performance.

- In general, the tensile strength of the cold patch mixes evaluated was reduced by $50 \%$ or more when exposed to moisture conditioning. Therefore, these materials are not suitable for long-term use in wet 
conditions. If the materials are to be used in temporary pavement repairs (at least 100 passes of $\mathrm{F}-15 \mathrm{E}$ required), this durability issue is not a concern.

- Acceptance criteria for cold patch mixes could not be developed due to the wide variations in mix properties and the poor performance of these materials during the certification tests.

\section{Recommendations}

Based on laboratory and field testing completed by ERDC personnel, the following recommendations are provided:

\section{Performance}

- Considering their poor performance, cold patch asphalt products are not recommended for airfield pavement repairs in heavy traffic areas or areas mainly trafficked by high-tire pressure aircrafts, such as the F-15E.

- The cold patch mixes evaluated in this project need improvements to achieve the requirements for their use on airfield pavements. Recommended areas of improvements include antistripping agents, aggregate type (quality), aggregate gradations, and stiffer binder.

- Further investigations based on results from tests on improved cold patch mixes are needed to more accurately determine minimum performance requirements.

\section{Certification tests}

- Results from the dynamic creep test on cold patch materials were more consistent than results from the static creep test. Therefore, the dynamic creep test is recommended as a performance test for a test protocol to certify the use of cold patch asphalt in airfield pavements.

- The moisture susceptibility test could be included in a test protocol to certify the use of cold patch mixes for temporary airfield pavement repairs, but it would not be a requirement since durability issues are not a concern in temporary pavement repairs ( $\geq 100$ passes of F- $15 \mathrm{E}$ required).

- Other methods to evaluate the workability of cold patch mixes are needed. Methods that have been developed for HMA should be appropriately adapted and evaluated to determine their ability to predict workability of cold patch asphalt mixes. A good example to consider would be the test method developed by Gudimettla et al. (2003), which defines the workability of a mix as the inverse of the torque required to rotate a paddle within a sample of HMA. 


\section{References}

American Association of State Highway and Transportation Officials (AASHTO). 2008. Resistance of compacted hot mix asphalt (HMA) to moisture-induced damage. Designation T283-07. Washington, DC.

American Society for Testing and Materials (ASTM). 2008. Standard test method for preparation and determination of bulk specific gravity of dense-graded cold mix asphalt (CMA) specimens by means of Superpave gyratory compactor. Designation D7229-08. West Conshohocken, PA.

. 2003. Standard test method for theoretical maximum specific gravity and density of bituminous paving mixtures. Designation D2041-03a. West Conshohocken, PA.

2008. Standard test method for determining the workability of asphalt cold mix patching material. Designation D6704-08. West Conshohocken, PA.

Gabrielson, J . R. 1992. Evaluation of hot-mix asphalt (HMA) static creep and repeated load tests. PhD thesis, Auburn Univ., Auburn, AL.

Gudimettla, J . M., L. A. Cooley, and E. R. Brown. 2003. Workability of hot mix asphalt. NCAT Report 03-03. Auburn, AL: National Center for Asphalt Technology.

Headquarters, Departments of the Army, Navy, and Air Force. 2001. Paver asphalt surfaced airfields pavement condition index (PCI). Unified Facilities Criteria UFC 3-270-06. Washington, DC.

Priddy, L. P., J . S. Tingle, T. J . McCaffrey, and R. S. Rollins. 2007. Laboratory and field investigations of small crater repair technologies. ERDC/ GSL TR-07-27. Vicksburg, MS: U.S. Army Engineer Research and Development Center.

Shoenberger, J . E., W. D. Hodo, C. A. Weiss, P. G. Malone, and T. S. Poole. 2005. Expedient repair materials for roadway pavements. ERDC-GSL TR-05-07. Vicksburg, MS: U.S. Army Engineer Research and Development Center.

U.S. Air Force. 2008a. Testing protocol for rigid spall repair materials. Engineering Technical Letter (ETL) 08-2. Tyndall AFB, FL: Headquarters, Air Force Civil Engineer Support Agency.

. 2008b. Testing protocol for polymeric spall repair materials. Engineering Technical Letter (ETL) 08-4. Tyndall AFB, FL: Headquarters, Air Force Civil Engineer Support Agency.

Vaysburd, A. M., P. H. Ammons, J. E. Mc Donald, R. W. Poston, and K. E. Kesner. 1999. Performance criteria for concrete repair materials; Phase II summary report. Technical Report REMR-CS-62. Vicksburg, MS: U.S. Army Engineer Waterways Experiment Station.

Witczak, M. W. 2005. Simple performance tests: Summary of recommended methods and database. NCHRP Report 547. Washington, DC: Transportation Research Board, National Research Council. 
Witczak, M. W. 2007. Specification criteria for simple performance tests for rutting; I: Dynamic modulus (E*); II: Flow number and flow time. NCHRP Report 580. Washington, DC: Transportation Research Board, National Research Council.

Witczak, M. W., K. Kaloush, T. Pellinen, M. El-Basyouny, and H. Von Quintus, H. 2002. Simple performance test for Superpave mix design. NCHRP Report 465.

Washington, DC: Transportation Research Board, National Research Council. 


\section{Appendix A: Test Results}

This appendix presents the sample data and results from the flow time, flow number, and durability tests.

Table A1. Flow time samples data.

\begin{tabular}{|c|c|c|c|}
\hline Sample ID & AV, $\%$ & $\begin{array}{l}\text { Height } \\
\text { in. }\end{array}$ & $\begin{array}{l}\text { Diameter } \\
\text { in. }\end{array}$ \\
\hline \multicolumn{4}{|c|}{ IRR } \\
\hline IRRFT1 & \multirow{4}{*}{11} & 5.912 & 3.431 \\
\hline IRRFT2 & & 5.890 & 3.433 \\
\hline IRRFT3 & & 5.910 & 3.437 \\
\hline IRRFT4 & & 5.916 & 3.378 \\
\hline \multicolumn{4}{|c|}{ EZ-Street } \\
\hline EZSFT1 & \multirow{4}{*}{3} & 5.927 & 3.440 \\
\hline EZSFT2 & & 5.852 & 3.435 \\
\hline EZSFT3 & & 5.849 & 3.430 \\
\hline EZSFT4 & & 5.892 & 3.433 \\
\hline \multicolumn{4}{|c|}{ EZ-Street Hybrid } \\
\hline EZSHFT1 & \multirow{4}{*}{10} & 5.886 & 3.419 \\
\hline EZSHFT2 & & 5.915 & 3.422 \\
\hline EZSHFT3 & & 5.903 & 3.420 \\
\hline EZSHFT4 & & 5.857 & 3.417 \\
\hline \multicolumn{4}{|c|}{ Wespro } \\
\hline WFT1 & \multirow{4}{*}{5} & 5.725 & 3.399 \\
\hline WFT2 & & 5.909 & 3.403 \\
\hline WFT3 & & 5.752 & 3.406 \\
\hline WFT4 & & 5.800 & 3.397 \\
\hline \multicolumn{4}{|c|}{ UPM 5.0} \\
\hline UPMFT1 & \multirow{4}{*}{9} & 5.753 & 3.419 \\
\hline UPMFT2 & & 5.769 & 3.419 \\
\hline UPMFT3 & & 5.779 & 3.421 \\
\hline UPMFT4 & & 5.770 & 3.419 \\
\hline
\end{tabular}


Table A2. Flow time test results.

\begin{tabular}{|c|c|c|c|c|c|c|c|c|}
\hline Sample ID & $\begin{array}{l}\text { Flow Time } \\
\text { sec }\end{array}$ & $\begin{array}{l}\text { Contact } \\
\text { Stress, psi }\end{array}$ & $\begin{array}{l}\text { Permanent } \\
\text { Microstrain }\end{array}$ & $\begin{array}{l}\text { Creep } \\
\text { Modulus } \\
\text { psi }\end{array}$ & $\begin{array}{l}\text { Compliance } \\
\text { (1/psi) }\end{array}$ & $\begin{array}{l}\text { Regression } \\
\text { End Time } \\
\text { sec }\end{array}$ & $\begin{array}{l}\text { Intercept } \\
\text { (D1) }\end{array}$ & Slope (M1) \\
\hline \multicolumn{9}{|c|}{ Instant Road Repair } \\
\hline IRRFT1 & 40 & 20 & 42142 & 2089 & 0.000478 & - & - & - \\
\hline IRRFT2 & 51 & 20 & 42041 & 2132 & 0.000470 & - & - & - \\
\hline IRRFT3 & 32 & 20 & 42511 & 2074 & 0.000483 & - & - & - \\
\hline IRRFT4 & 127 & 20 & 40440 & 2205 & 0.000452 & 100 & 0.01633 & 0.2664 \\
\hline AVG & 63 & 20 & 41784 & 2125 & 0.00047 & 100 & 0.02 & 0.27 \\
\hline STDEV & 44 & 0.09 & 918 & 59 & 0.00001 & - & - & - \\
\hline C.V. \% & $70 \%$ & $0.43 \%$ & $2.2 \%$ & $2.8 \%$ & $2.9 \%$ & - & - & - \\
\hline \multicolumn{9}{|c|}{ EZ-Street } \\
\hline EZSFT1 & 1872 & 21 & 23343 & 3771 & 0.00027 & 1000 & 0.01346 & 0.1395 \\
\hline EZSFT2 & 2079 & 22 & 22369 & 3916 & 0.00026 & 1000 & 0.01339 & 0.1354 \\
\hline EZSFT3 & 128 & 21 & 40424 & 2161 & 0.00046 & 100 & 0.01488 & 0.2137 \\
\hline EZSFT4 & 246 & 20 & 40126 & 2219 & 0.00045 & 100 & 0.01438 & 0.1945 \\
\hline AVG & 1081 & 21 & 31566 & 3017 & 0.00036 & 550 & 0.01403 & 0.1708 \\
\hline STDEV & 1037 & 0.58 & 10065 & 957 & 0.00011 & 520 & 0.00073 & 0.0393 \\
\hline C.V. \% & $96 \%$ & $2.8 \%$ & $32 \%$ & $32 \%$ & $32 \%$ & $94 \%$ & $5.2 \%$ & $23 \%$ \\
\hline \multicolumn{9}{|c|}{ EZ- Street Hybrid } \\
\hline EZSHFT1 & 621 & 21 & 40089 & 2190 & 0.00046 & 100 & 0.0148 & 0.1981 \\
\hline EZSHFT2 & 215 & 20 & 40353 & 2176 & 0.00046 & 100 & 0.0141 & 0.2279 \\
\hline EZSHFT3 & 606 & 20 & 40095 & 2205 & 0.00045 & 100 & 0.0147 & 0.1937 \\
\hline EZSHFT4 & 126 & 19 & 40558 & 2205 & 0.00045 & 100 & 0.0140 & 0.2945 \\
\hline AVG & 392 & 20 & 40274 & 2194 & 0.00046 & 100 & 0.0144 & 0.2286 \\
\hline STDEV & 258 & 0.69 & 226 & 14 & 0.000003 & 0.0 & 0.0004 & 0.05 \\
\hline C.V. \% & $66 \%$ & $3.4 \%$ & $0.56 \%$ & $0.63 \%$ & $0.63 \%$ & $0.0 \%$ & $2.9 \%$ & $20 \%$ \\
\hline \multicolumn{9}{|c|}{ Wespro } \\
\hline WFT1 & 64 & 19 & 40786 & 2190 & 0.00046 & - & - & - \\
\hline WFT2 & 13 & 19 & 45827 & 1958 & 0.00051 & - & - & - \\
\hline WFT3 & 159 & 19 & 40268 & 2234 & 0.00045 & 100 & 0.01945 & 0.2158 \\
\hline WFT4 & 53 & 19 & 41157 & 2176 & 0.00046 & - & - & - \\
\hline$A V G$ & 72 & 19 & 42010 & 2139 & 0.00047 & 100 & 0.02 & 0.22 \\
\hline STDEV & 62 & 0.04 & 2571 & 123 & 0.00003 & - & - & - \\
\hline C.V. \% & $86 \%$ & $0.21 \%$ & $6.1 \%$ & $5.8 \%$ & $6.0 \%$ & - & - & - \\
\hline \multicolumn{9}{|c|}{ UPM 5.0} \\
\hline UPMFT1 & 3 & 19 & 47448 & 1885 & 0.00053 & - & - & - \\
\hline UPMFT2 & 15 & 19 & 47833 & 1871 & 0.00054 & - & - & - \\
\hline UPMFT3 & 3 & 19 & 48498 & 1798 & 0.00056 & - & - & - \\
\hline UPMFT4 & 3 & 19 & 48696 & 1813 & 0.00055 & - & - & - \\
\hline AVG & 6 & 19 & 48119 & 1842 & 0.00054 & - & - & - \\
\hline STDEV & 6.00 & 0.01 & 580 & 43 & 0.00001 & - & - & - \\
\hline C.V. \% & $100 \%$ & $0.04 \%$ & $1.2 \%$ & $2.3 \%$ & $2.4 \%$ & - & - & - \\
\hline
\end{tabular}

Notes: (a) Temperature: $77^{\circ} \mathrm{F}$; (b) Confining Pressure, $\sigma_{3}: 10$ psi; (c) Deviator Stress, $\sigma_{\mathrm{d}}: 90$ psi. 
Table A3. Flow number sample data.

\begin{tabular}{|c|c|c|c|}
\hline Sample ID & AV, $\%$ & $\begin{array}{l}\text { Height } \\
\text { in. }\end{array}$ & $\begin{array}{l}\text { Diameter } \\
\text { in. }\end{array}$ \\
\hline \multicolumn{4}{|c|}{ IRR } \\
\hline IRRFN1 & \multirow{5}{*}{11} & 5.829 & 3.427 \\
\hline IRRFN2 & & 5.957 & 3.439 \\
\hline IRRFN3 & & 5.933 & 3.433 \\
\hline IRRFN4 & & 5.911 & 3.438 \\
\hline IRRFN5 & & 5.843 & 3.434 \\
\hline \multicolumn{4}{|c|}{ EZ-Street } \\
\hline EZSFN1 & \multirow{4}{*}{3} & 5.780 & 3.430 \\
\hline EZSFN2 & & 5.886 & 3.427 \\
\hline EZSFN3 & & 5.818 & 3.433 \\
\hline EZSFN4 & & 5.881 & 3.430 \\
\hline \multicolumn{4}{|c|}{ EZ-Street Hybrid } \\
\hline EZSHFN1 & \multirow{4}{*}{10} & 5.822 & 3.432 \\
\hline EZSHFN2 & & 5.859 & 3.431 \\
\hline EZSHFN3 & & 5.873 & 3.431 \\
\hline EZSHFN4 & & 5.894 & 3.428 \\
\hline \multicolumn{4}{|c|}{ Wespro } \\
\hline WFN1 & \multirow{4}{*}{5} & 5.827 & 3.422 \\
\hline WFN2 & & 5.817 & 3.422 \\
\hline WFN3 & & 5.748 & 3.425 \\
\hline WFN4 & & 5.830 & 3.421 \\
\hline
\end{tabular}


Table A4. Flow number test results.

\begin{tabular}{|c|c|c|c|c|c|c|c|c|}
\hline \multirow[b]{2}{*}{ Sample ID } & \multirow[b]{2}{*}{$\begin{array}{l}\text { Flow } \\
\text { Number }\end{array}$} & \multirow[b]{2}{*}{$\begin{array}{l}\text { Accum. } \\
\text { Microstrain }\end{array}$} & \multirow[b]{2}{*}{$\begin{array}{l}\text { Strain } \\
\text { Slope }\end{array}$} & \multirow[b]{2}{*}{$\begin{array}{l}\text { Resilient } \\
\text { Microstrain }\end{array}$} & \multirow{2}{*}{\begin{tabular}{|l|} 
Resilient \\
Modulus \\
psi
\end{tabular}} & \multirow{2}{*}{$\begin{array}{l}\text { Creep } \\
\text { Modulus } \\
\text { psi }\end{array}$} & \multicolumn{2}{|l|}{ Axial Strain } \\
\hline & & & & & & & Permanent & Resilient \\
\hline \multicolumn{9}{|c|}{ Instant Road repair } \\
\hline IRRFN1 & 145 & 27193 & 123 & 1680 & 52726 & 3257 & 0.163 & 2.98 \\
\hline IRRFN2 & 121 & 26974 & 156 & 1617 & 54806 & 3286 & 0.157 & 3.02 \\
\hline IRRFN3 & 106 & 26527 & 187 & 1791 & 49796 & 3362 & 0.174 & 2.98 \\
\hline IRRFN4 & 121 & 26883 & 158 & 1777 & 50725 & 3353 & 0.173 & 3.02 \\
\hline IRRFN5 & 118 & 26889 & 161 & 1753 & 50303 & 3280 & 0.171 & 2.96 \\
\hline AVG & 122 & 26893 & 157 & 1724 & 51671 & 3307 & 0.168 & 2.99 \\
\hline STDEV & 14 & 240 & 23 & 73 & 2075 & 47 & 0.01 & 0.03 \\
\hline C.V. $\%$ & $12 \%$ & $0.89 \%$ & $14 \%$ & $4.2 \%$ & $4.0 \%$ & $1.4 \%$ & $4.3 \%$ & $0.86 \%$ \\
\hline \multicolumn{9}{|c|}{ EZ-Street } \\
\hline EZSFN1 & 823 & 28022 & 16 & 1765 & 50219 & 3163 & 0.172 & 3.06 \\
\hline EZSFN2 & 241 & 26923 & 59 & 1859 & 46979 & 3245 & 0.181 & 3.01 \\
\hline EZSFN3 & 376 & 27768 & 38 & 1849 & 47721 & 3178 & 0.180 & 3.05 \\
\hline EZSFN4 & 235 & 27235 & 66 & 2046 & 42986 & 3229 & 0.199 & 3.08 \\
\hline AVG & 419 & 27487 & 45 & 1880 & 46976 & 3204 & 0.183 & 3.05 \\
\hline STDEV & 277 & 499 & 23 & 118 & 3000 & 39 & 0.012 & 0.028 \\
\hline C.V. $\%$ & $66 \%$ & $1.8 \%$ & $51 \%$ & $6.3 \%$ & $6.4 \%$ & $1.2 \%$ & $6.3 \%$ & $0.9 \%$ \\
\hline \multicolumn{9}{|c|}{ EZ-Street Hybrid } \\
\hline EZSHFN1 & 379 & 27741 & 35 & 1752 & 50419 & 3184 & 0.170 & 3.06 \\
\hline EZSHFN2 & 310 & 27715 & 43 & 1746 & 51010 & 3213 & 0.170 & 3.08 \\
\hline EZSHFN3 & 337 & 27858 & 42 & 1706 & 52209 & 3198 & 0.166 & 3.11 \\
\hline EZSHFN4 & 280 & 27591 & 51 & 1618 & 55284 & 3242 & 0.157 & 3.07 \\
\hline AVG & 327 & 27726 & 43 & 1705 & 52230 & 3209 & 0.166 & 3.08 \\
\hline STDEV & 42 & 110 & 6.4 & 62 & 2167 & 25 & 0.006 & 0.02 \\
\hline C.V. $\%$ & $13 \%$ & $0.4 \%$ & $15 \%$ & $3.6 \%$ & $4.1 \%$ & $0.8 \%$ & $3.6 \%$ & $0.6 \%$ \\
\hline \multicolumn{9}{|c|}{ Wespro } \\
\hline WPFN1 & 139 & 27166 & 81 & 2118 & 41951 & 3270 & 0.206 & 3.03 \\
\hline WPFN2 & 88 & 26580 & 198 & 2387 & 37308 & 3351 & 0.232 & 2.98 \\
\hline WPFN3 & 169 & 27368 & 55 & 2181 & 40964 & 3265 & 0.212 & 3.02 \\
\hline WPFN4 & 286 & 27757 & 31 & 1905 & 46657 & 3202 & 0.185 & 3.06 \\
\hline AVG & 171 & 27218 & 91 & 2148 & 41720 & 3272 & 0.209 & 3.02 \\
\hline STDEV & 84 & 490 & 74 & 199 & 3850 & 61 & 0.019 & 0.03 \\
\hline C.V. \% & $49 \%$ & $1.8 \%$ & $82 \%$ & $9.3 \%$ & $9.2 \%$ & $1.9 \%$ & $9.3 \%$ & $1.1 \%$ \\
\hline
\end{tabular}

Notes: (a) Temperature: $77^{\circ} \mathrm{F}$; (b) Confining Pressure, $\sigma_{3}: 10$ psi; (c) Deviator Stress, $\sigma_{\mathrm{d}}: 90$ psi. 
Table A5. Results from the durability test.

\begin{tabular}{|c|c|c|c|c|c|c|c|c|c|c|c|c|c|}
\hline $\begin{array}{l}\text { Sample } \\
\text { ID }\end{array}$ & Type & $\begin{array}{l}\% \text { Air } \\
\text { Voids }\end{array}$ & $\begin{array}{l}\text { Average } \\
\% \text { Air } \\
\text { Voids }\end{array}$ & $\begin{array}{l}\text { Load } \\
\text { lb }\end{array}$ & $\begin{array}{l}\text { Load } \\
\text { Average } \\
\text { lb }\end{array}$ & $\begin{array}{l}\text { Standard } \\
\text { Deviation }\end{array}$ & $\begin{array}{l}\mathrm{CV} \\
\%\end{array}$ & $\begin{array}{l}\text { \% } \\
\text { Sat. }\end{array}$ & $\begin{array}{l}\text { Dry } \\
\text { Strength } \\
\text { psi }\end{array}$ & $\begin{array}{l}\text { Dry } \\
\text { Strength } \\
\text { Average } \\
\text { psi }\end{array}$ & $\begin{array}{l}\text { Wet } \\
\text { Strength } \\
\text { psi }\end{array}$ & $\begin{array}{l}\text { Wet } \\
\text { Strength } \\
\text { Average } \\
\text { psi }\end{array}$ & TSR \\
\hline \multicolumn{14}{|c|}{ IRR } \\
\hline 1 & \multirow{3}{*}{$C$} & 5.6 & \multirow{3}{*}{5.6} & 187.5 & \multirow{3}{*}{184.2} & \multirow{3}{*}{8.0} & \multirow{3}{*}{$4 \%$} & 63.0 & & & 12.0 & \multirow{3}{*}{11.8} & \multirow{6}{*}{0.51} \\
\hline 2 & & 5.6 & & 175.0 & & & & 62.8 & & & 11.3 & & \\
\hline 3 & & 5.5 & & 190.0 & & & & 66.1 & & & 12.2 & & \\
\hline 4 & \multirow{3}{*}{ U } & 5.2 & \multirow{3}{*}{5.2} & 355.0 & \multirow{3}{*}{365.0} & \multirow{3}{*}{11.8} & \multirow{3}{*}{$3 \%$} & & 22.6 & \multirow{3}{*}{23.4} & & & \\
\hline 5 & & 5.3 & & 378.0 & & & & & 24.2 & & & & \\
\hline 6 & & 5.2 & & 362.0 & & & & & 23.3 & & & & \\
\hline \multicolumn{14}{|c|}{ EZ Street } \\
\hline 1 & \multirow{3}{*}{ C } & 5.8 & \multirow{3}{*}{5.4} & 90.0 & \multirow{3}{*}{150.8} & \multirow{3}{*}{53.1} & \multirow{3}{*}{$35 \%$} & 60.1 & & & 5.6 & \multirow{3}{*}{9.7} & \multirow{6}{*}{0.52} \\
\hline 4 & & 5.4 & & 187.5 & & & & 60.5 & & & 12.1 & & \\
\hline 5 & & 5.1 & & 175.0 & & & & 63.8 & & & 11.3 & & \\
\hline 2 & \multirow{3}{*}{ U } & 5.8 & \multirow{3}{*}{5.6} & 275.0 & \multirow{3}{*}{290.0} & \multirow{3}{*}{15.0} & \multirow{3}{*}{$5 \%$} & & 17.5 & & & & \\
\hline 3 & & 5.5 & & 305.0 & & & & & 19.7 & 18.6 & & & \\
\hline 6 & & 5.5 & & 290.0 & & & & & 18.6 & & & & \\
\hline & & & & & & EZ Stree & thybri & & & & & & \\
\hline 1 & & 7.5 & & 162.5 & & & & 79.9 & & & 9.5 & & \\
\hline 5 & C & 6.7 & 68 & 150.0 & 1513 & 105 & $7 \%$ & 80.0 & & & 9.6 & 95 & \\
\hline 6 & & 6.6 & & 155.0 & $10 \perp .3$ & 10.3 & $1 \%$ & 82.3 & & & 10.0 & & \\
\hline 8 & & 6.4 & & 137.5 & & & & 72.0 & & & 8.9 & & 061 \\
\hline 2 & & 6.2 & & 273.0 & & & & & 16.6 & & & & \\
\hline 3 & 11 & 5.8 & 63 & 275.0 & 2488 & 306 & $12 \%$ & & 17.1 & 155 & & & \\
\hline 4 & 0 & 6.9 & 0.3 & 235.0 & 248.0 & 30.0 & $12 \%$ & & 14.7 & 15.5 & & & \\
\hline 7 & & 6.5 & & 212.0 & & & & & 13.7 & & & & \\
\hline & & & & & & WESPR & Hybri & & & & & & \\
\hline $1^{a}$ & & 5.9 & & 0.0 & & & & 60.3 & & & 0.0 & & \\
\hline $3^{a}$ & C & 5.5 & 5.5 & 0.0 & 0.0 & - & - & 59.7 & & & 0.0 & 0.0 & \\
\hline $4^{a}$ & & 5.1 & & 0.0 & & & & 66.5 & & & 0.0 & & ח \\
\hline 2 & & 5.6 & & 190.0 & & & & & 12.2 & & & & 0.00 \\
\hline 5 & U & 5.8 & 5.8 & 182.0 & 172.3 & 24.0 & $14 \%$ & & 11.9 & 11.2 & & & \\
\hline 6 & & 5.9 & & 145.0 & & & & & 9.5 & & & & \\
\hline
\end{tabular}

Notes: $\mathrm{C}=$ Conditioned; $\mathrm{U}=$ Unconditioned.

a Samples broke apart after conditioning before the tensile strength test. Therefore, the wet strength could be measured. 


\section{Appendix B: Field Test Repair Cross Sections}

Figure B1 shows the points where measurements were taken. Figures B2- B9 show the cross sections that were measured before and after traffic.

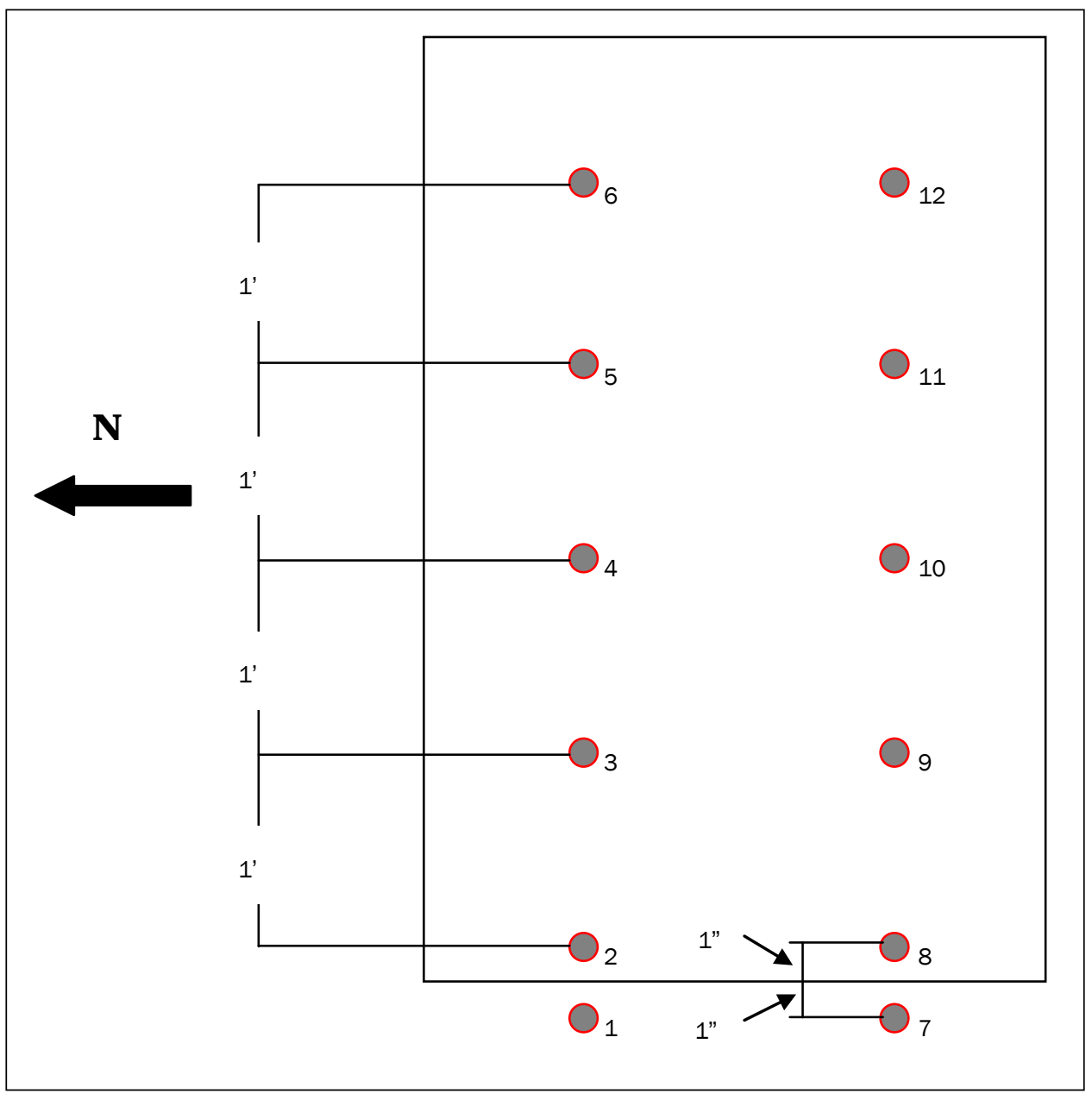

Figure B1. Distribution of the points for level measurements. 


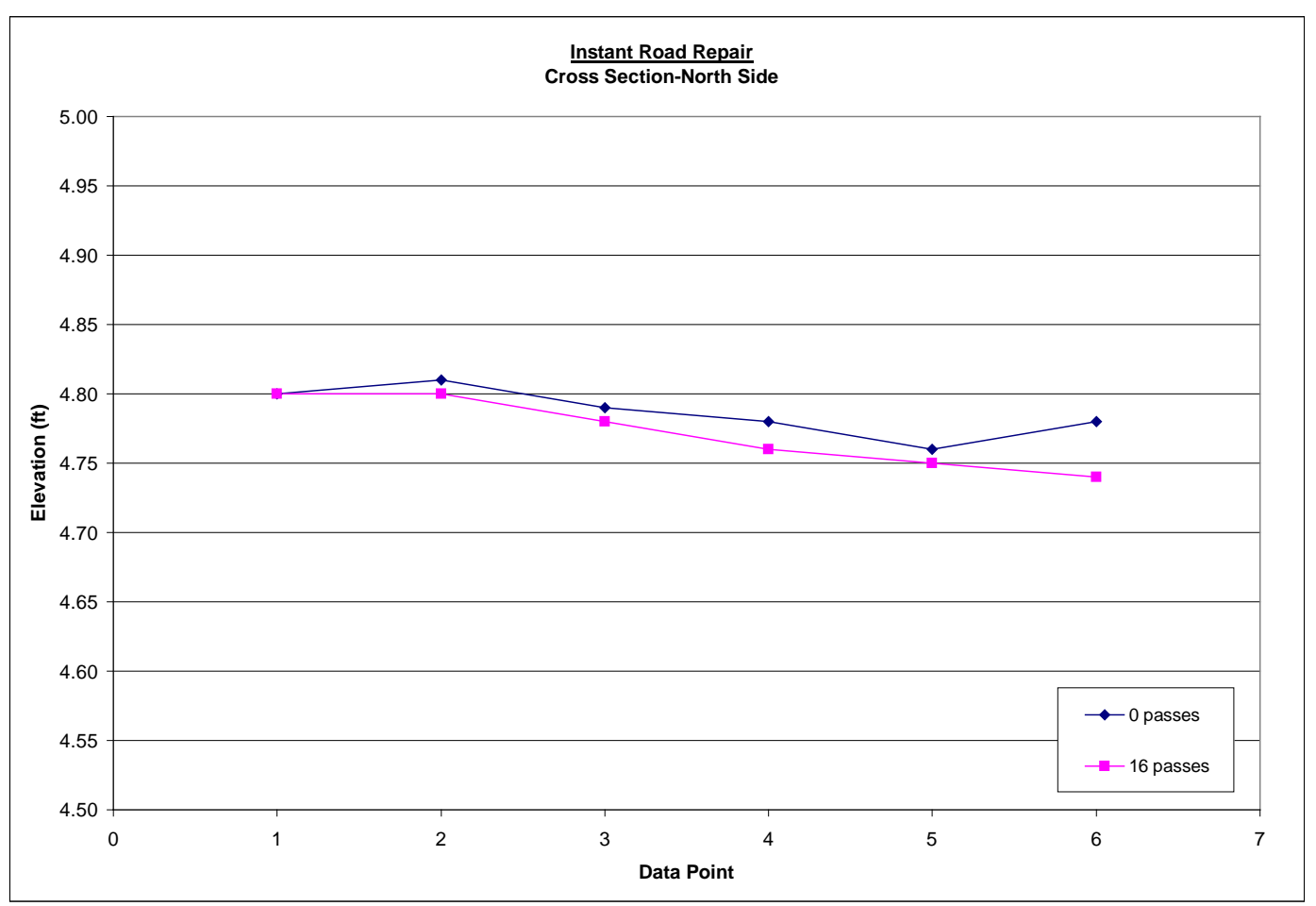

Figure B2. North cross section of the IRR repair area before and after traffic.

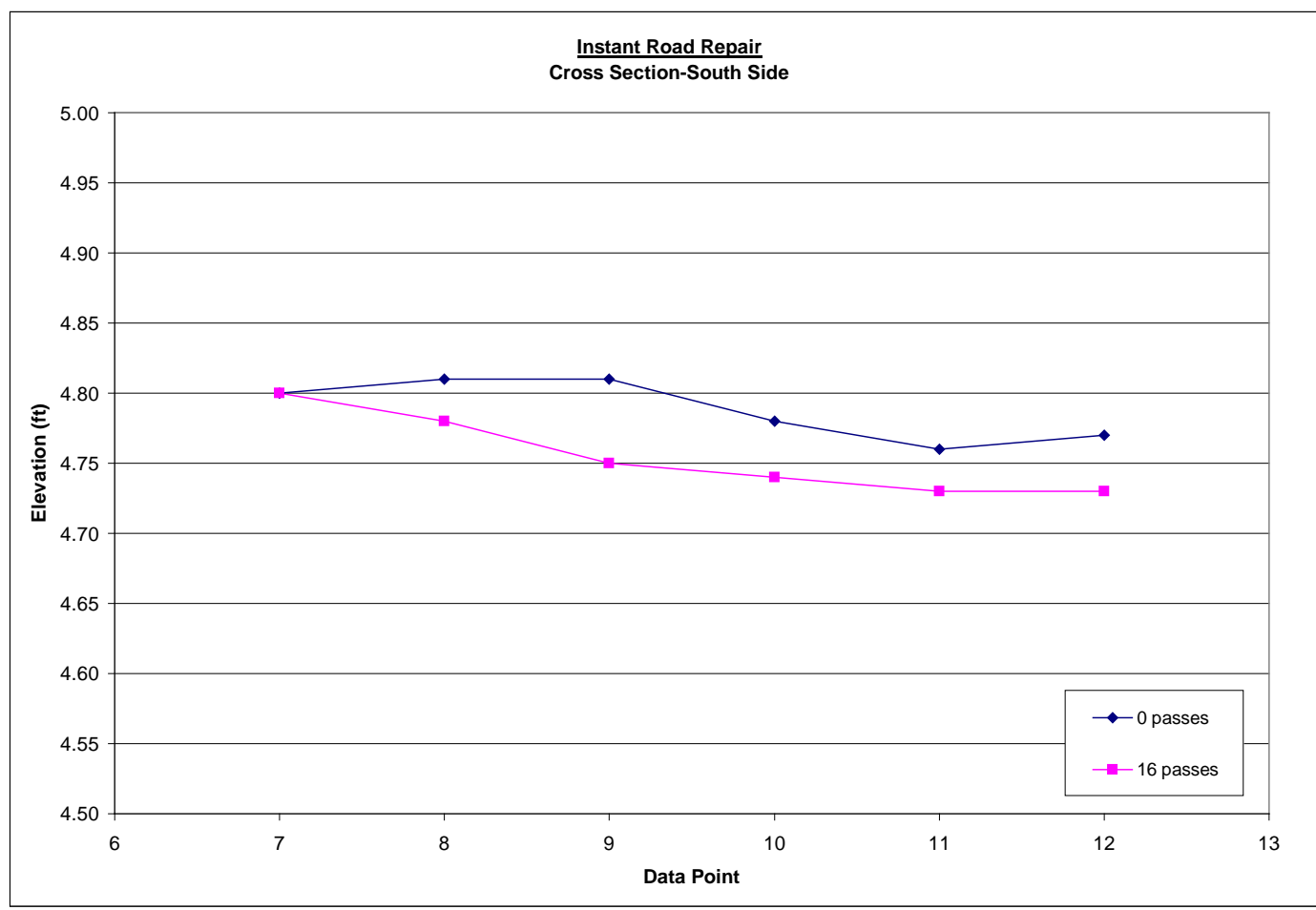

Figure B3. South cross section of the IRR repair area before and after traffic. 


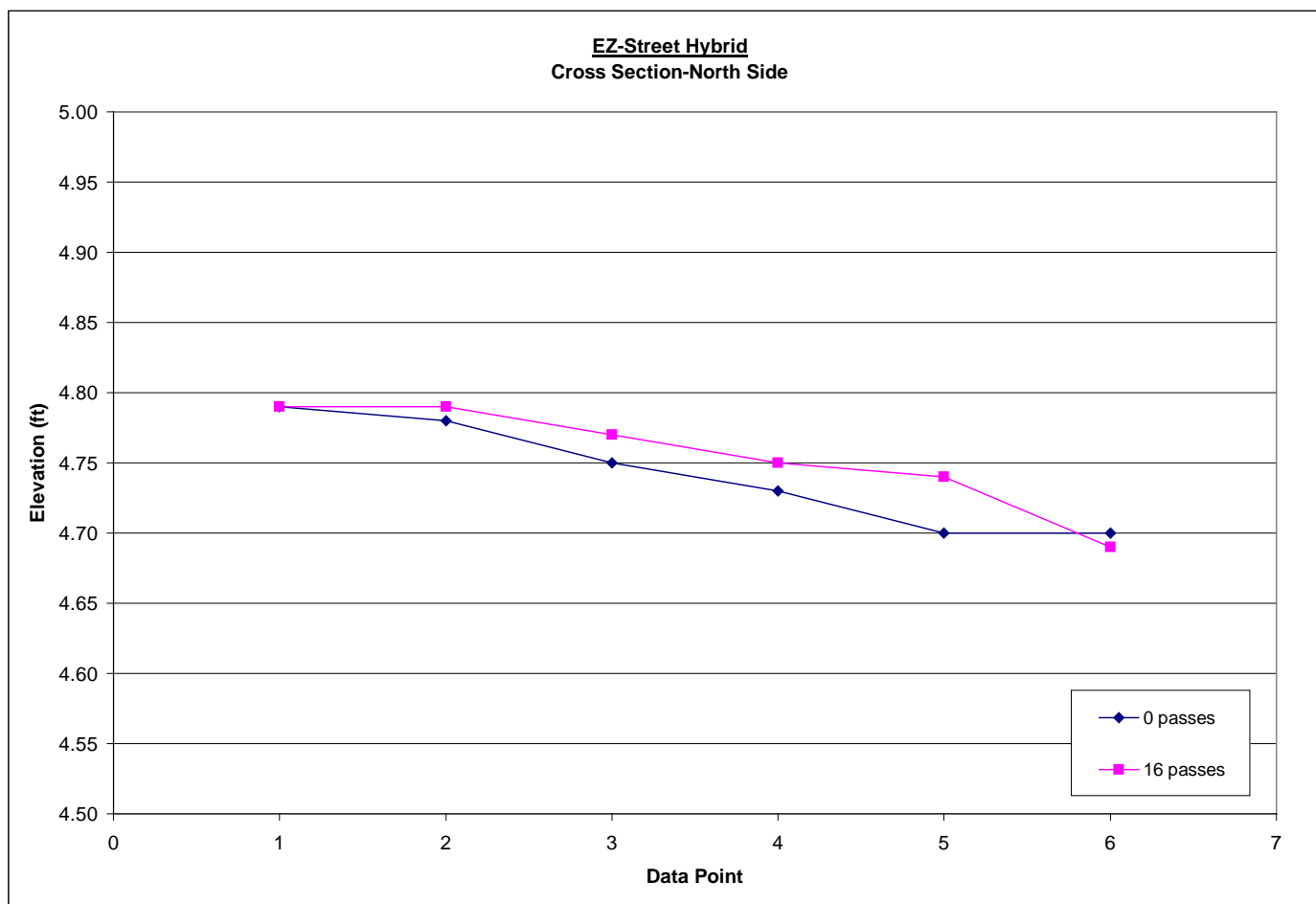

Figure B4. North cross section of the EZ-Street Hybrid repair area before and after traffic.

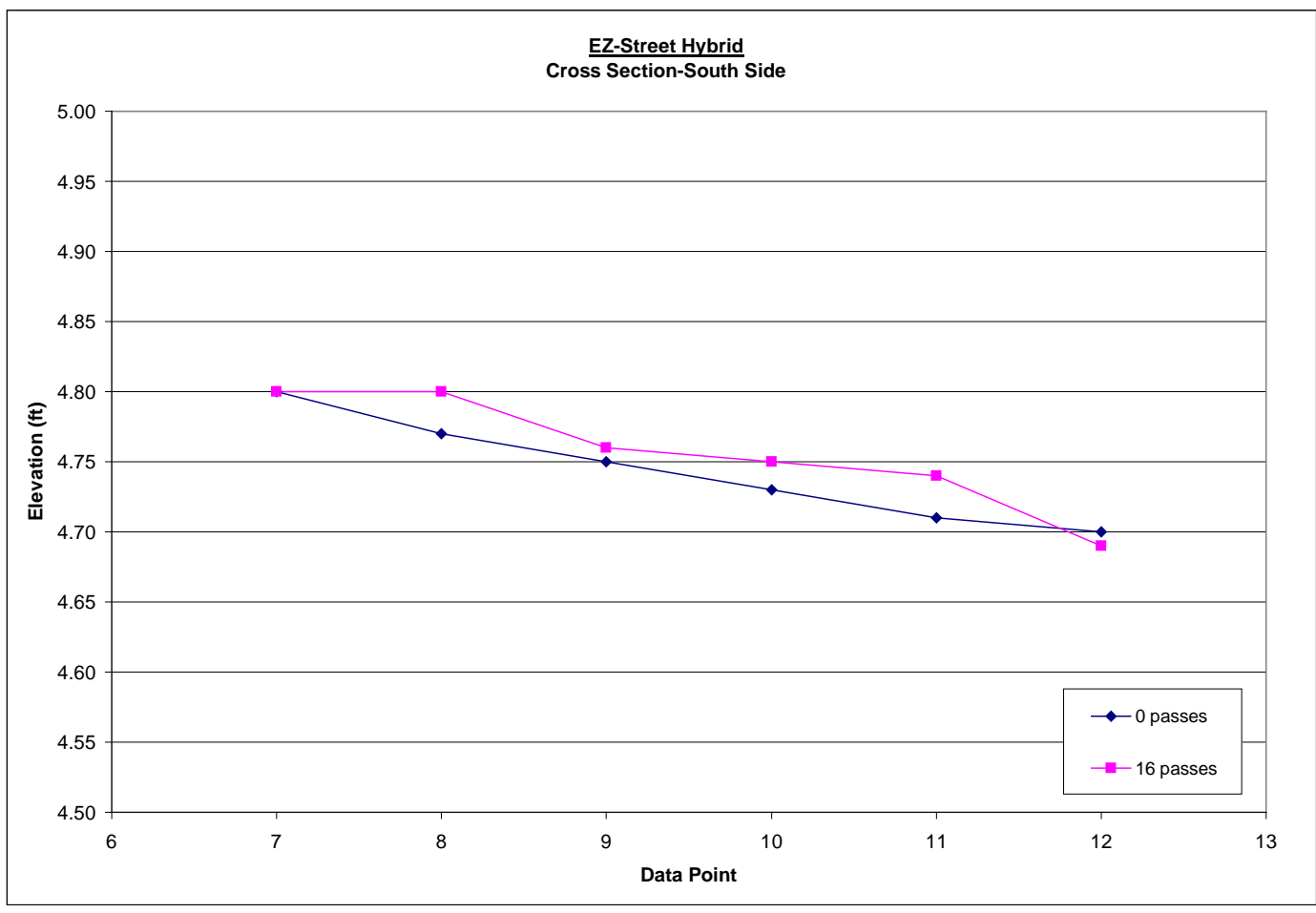

Figure B5. South cross section of the EZ-Street Hybrid repair area before and after traffic. 


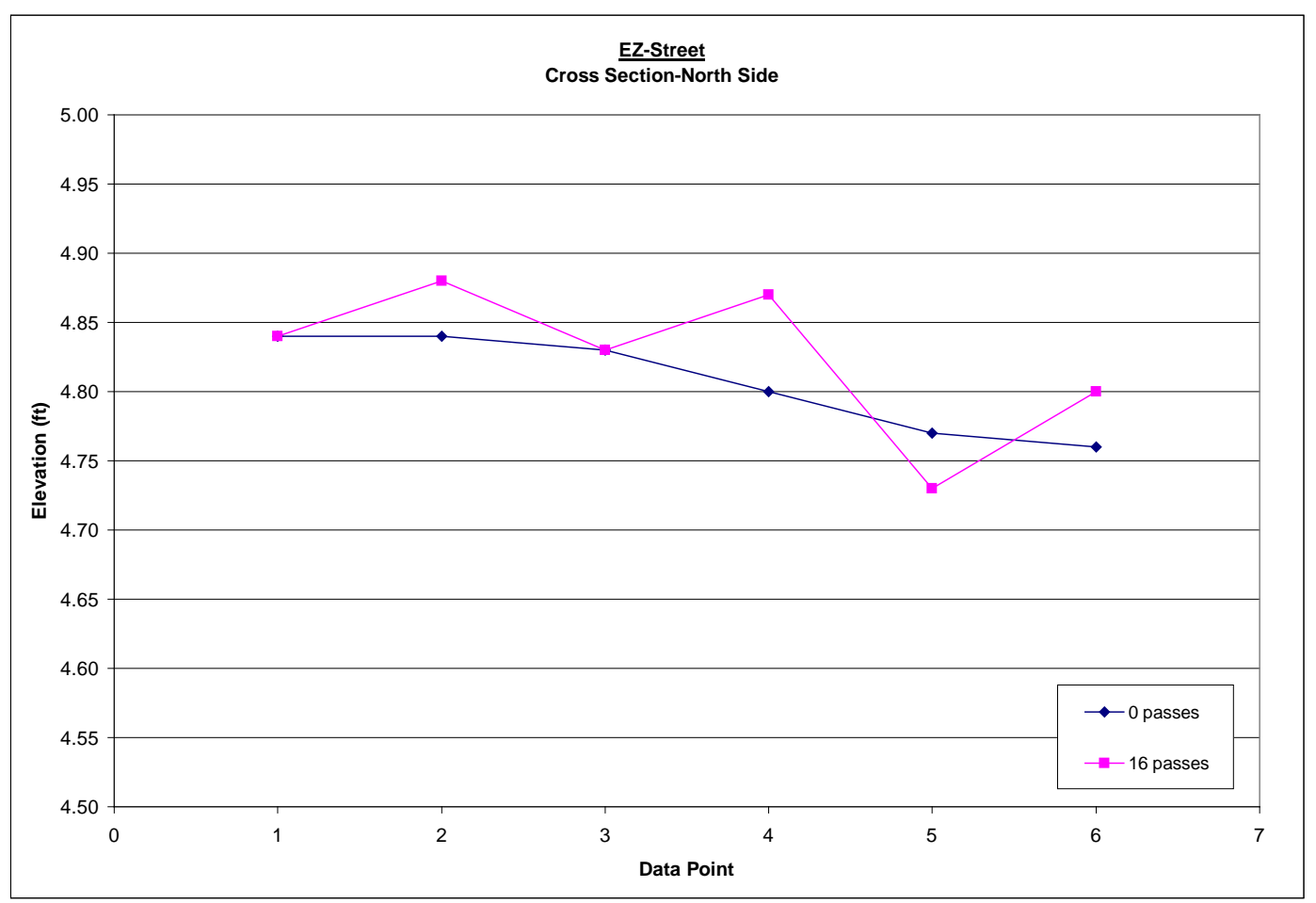

Figure B6. North cross section of the EZ-Street repair area before and after traffic.

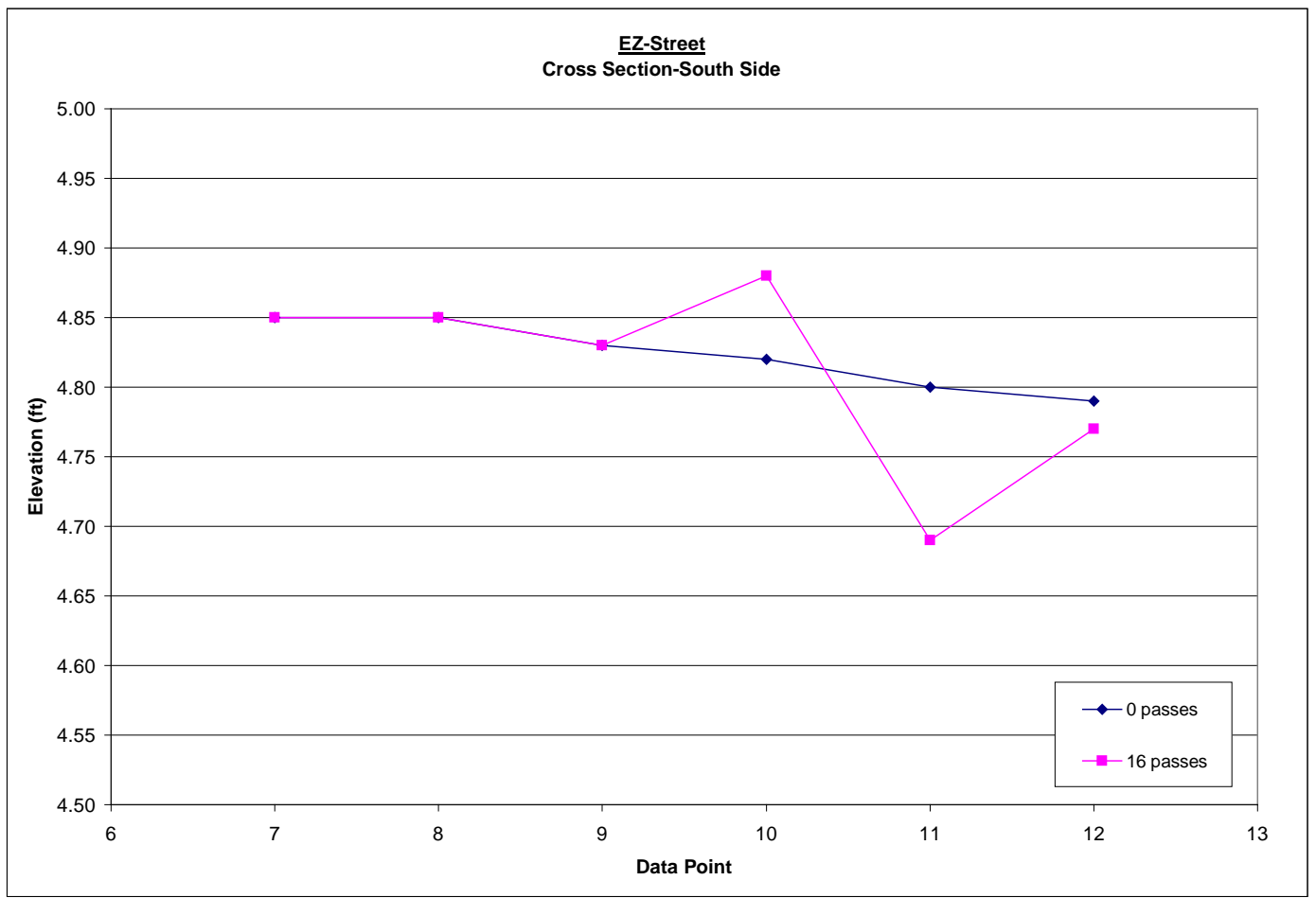

Figure B7. South cross section of the EZ-Street repair area before and after traffic. 


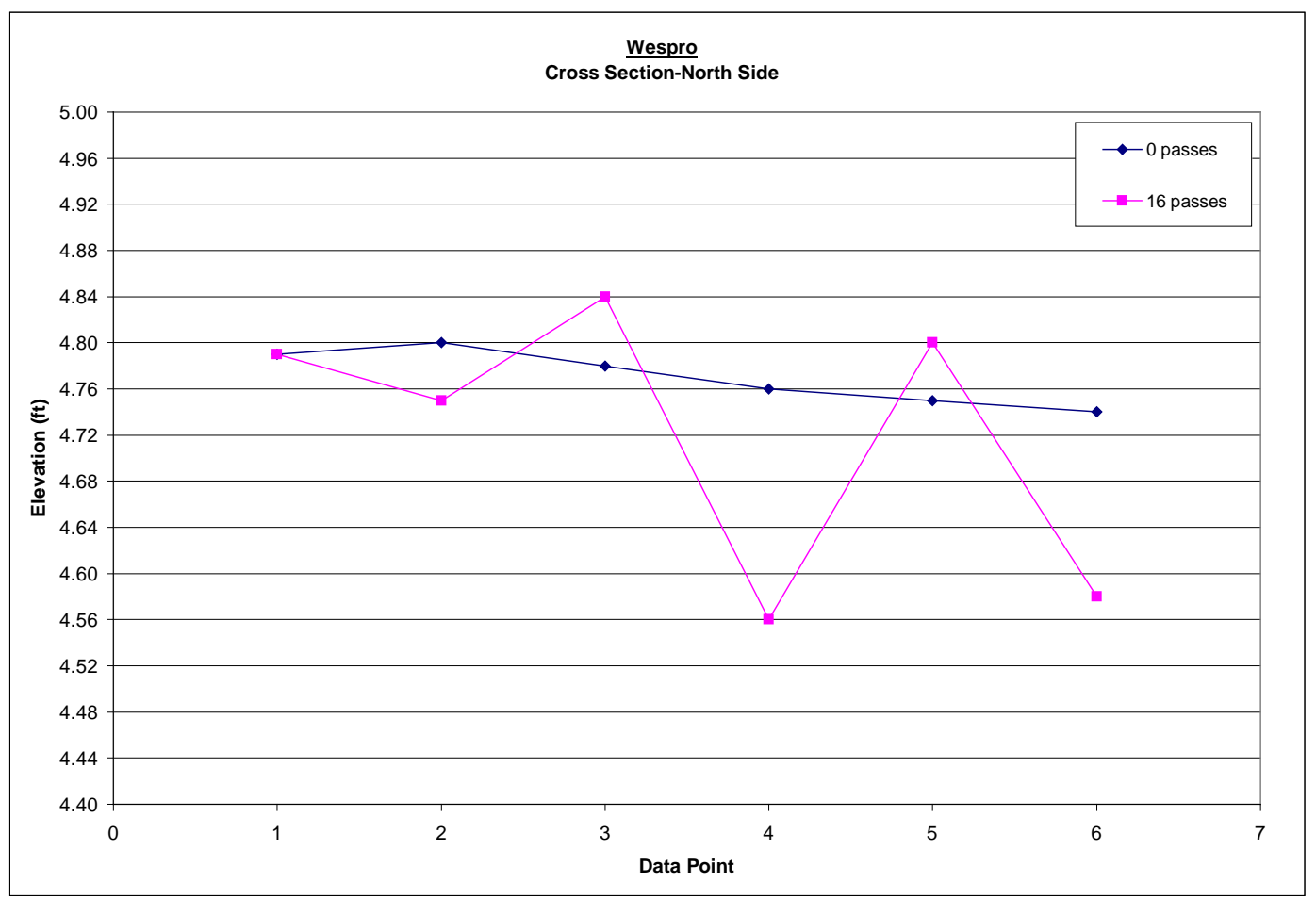

Figure B8. North cross section of the Wespro repair area before and after traffic.

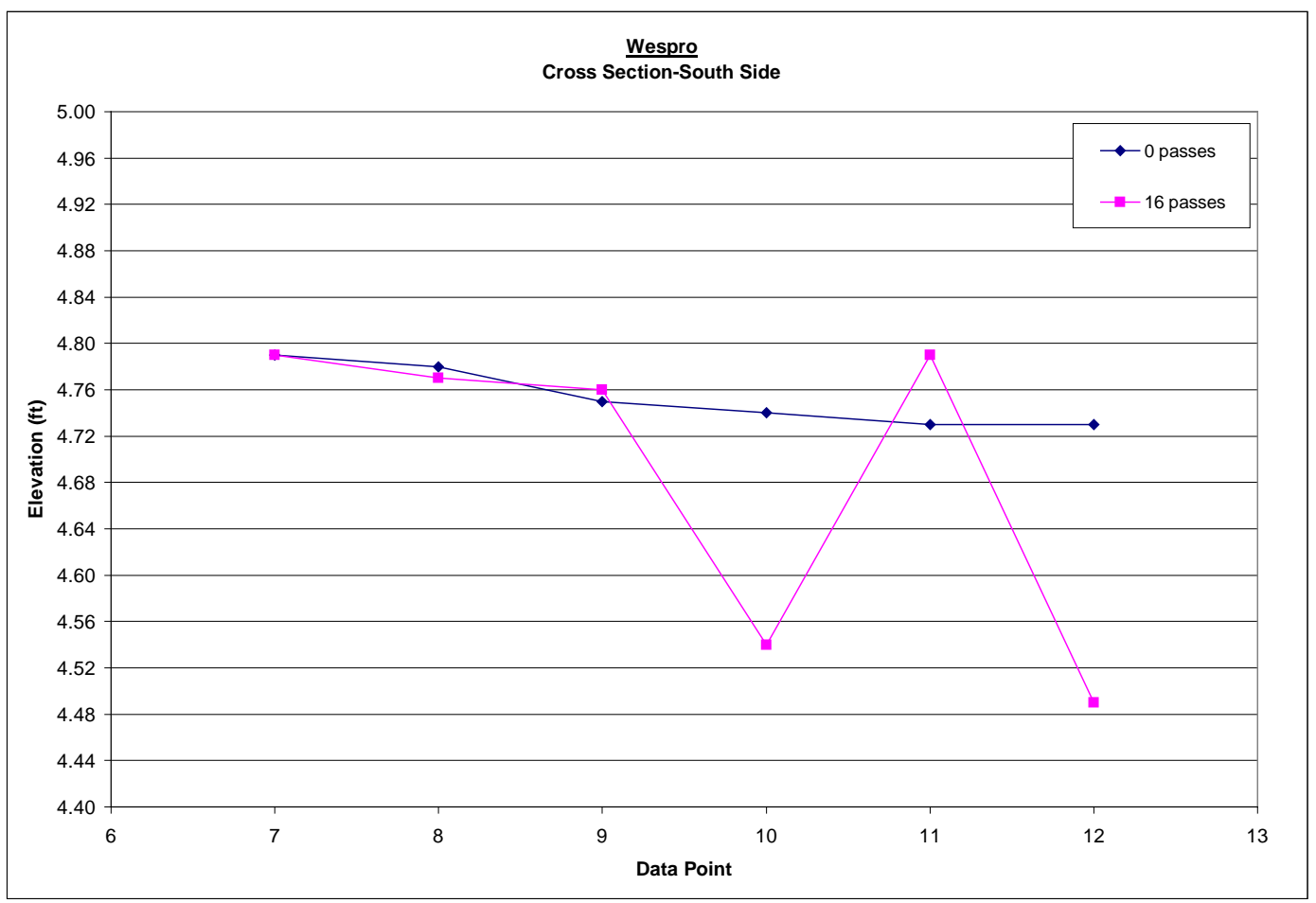

Figure B9. South cross section of the Wespro repair area before and after traffic. 


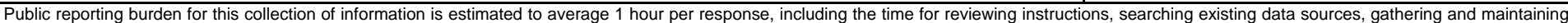

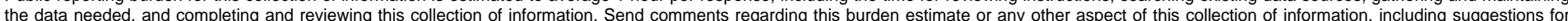

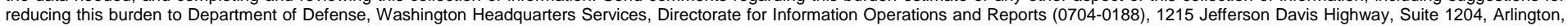

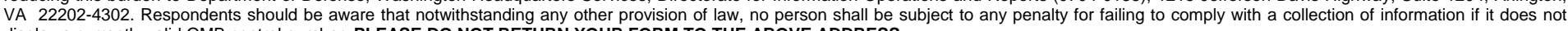
display a currently valid OMB control number. PLEASE DO NOT RETURN YOUR FORM TO THE ABOVE ADDRESS.
1. REPORT DATE (DD-MM-YYYY) 2. REPORT TYPE
June 2010
Final report

\section{TITLE AND SUBTITLE}

Certification Tests on Cold Patch Asphalt Repair Materials for Use in Airfield Pavements

5a. CONTRACT NUMBER

5b. GRANT NUMBER

5c. PROGRAM ELEMENT NUMBER

\section{AUTHOR(S)}

\section{5d. PROJECT NUMBER}

Mariely Mejías-Santiago, Francisco del Valle-Roldán, and Lucy P. Priddy

5e. TASK NUMBER

5f. WORK UNIT NUMBER

\section{PERFORMING ORGANIZATION NAME(S) AND ADDRESS(ES)}

8. PERFORMING ORGANIZATION REPORT NUMBER

U.S. Army Engineer Research and Development Center

Geotechnical and Structures Laboratory

ERDC/GSL TR-10-14

3909 Halls Ferry Road

Vicksburg, MS 39180-6199

\section{SPONSORING I MONITORING AGENCY NAME(S) AND ADDRESS(ES)}

10. SPONSOR/MONITOR'S ACRONYM(S)

Headquarters, U.S. Air Force Civil Engineer Support Agency

139 Barnes Avenue, Suite 1

Tyndall AFB, FL 32403-5319

11. SPONSOR/MONITOR'S REPORT NUMBER(S)

\section{DISTRIBUTION I AVAILABILITY STATEMENT}

Approved for public release; distribution is unlimited.

\section{SUPPLEMENTARY NOTES}

\section{ABSTRACT}

The U.S. Army Engineer Research and Development Center (ERDC) conducted laboratory and field tests on several commercial-offthe-shelf cold patch asphalt repair products to determine their suitability for airfield pavement repairs. Testing included a suite of material property tests that were compared with results from full-scale field tests. Laboratory tests included determination of maximum theoretical specific gravities, compaction density, durability, workability, static creep, and dynamic creep. The field evaluation consisted of four repairs that were trafficked $24 \mathrm{hr}$ after compaction under controlled traffic conditions to determine the ability of the repairs to support the gross load of an F-15E aircraft. Both the laboratory and full-scale traffic tests were conducted at the ERDC in Vicksburg, MS, from May to July 2009. Laboratory tests were evaluated to determine their suitability for a testing protocol to certify the use of cold patch materials for airfield asphalt pavement repairs.

\section{SUBJECT TERMS}

Asphalt repair Durability

Cold patch asphalt

16. SECURITY CLASSIFICATION OF:

\section{a. REPORT}

UNCLASSIFIED

b. ABSTRACT
UNCLASSIFIED

Flow number

c. THIS PAGE

UNCLASSIFIED

Flow time

Workability

17. LIMITATION OF ABSTRACT

\section{NUMBER} OF PAGES

68

\section{9a. NAME OF RESPONSIBLE} PERSON

19b. TELEPHONE NUMBER (include area code) 